\title{
STABILITY-BASED MOTION PLANNING FOR A MODULAR MORPHING WING
}

\author{
by \\ Michael Chi Fung Kwong, B. Eng \\ Aerospace Engineering \\ Ryerson University, 2011
}

A thesis presented to Ryerson University

\author{
In partial fulfillment of the \\ requirements for the degree of \\ Master of Applied Science \\ in the Program of \\ Aerospace Engineering
}

Toronto, Ontario, Canada

(C) Michael Chi Fung Kwong 2013 


\section{Author's Declaration}

I hereby declare that I am the sole author of this thesis. This is a true copy of the thesis, including any required final revisions, as accepted by my examiners.

I authorize Ryerson University to lend this thesis to other institutions or individuals for the purpose of scholarly research

I further authorize Ryerson University to reproduce this thesis by photocopying or by other means, in total or in part, at the request of other institutions or individuals for the purpose of scholarly research.

I understand that my thesis may be made electronically available to the public. 


\title{
Abstract
}

\author{
Stability-Based Motion Planning for a Modular Morphing Wing \\ Michael Chi Fung Kwong \\ A thesis for the degree of \\ Master of Applied Science, 2013 \\ Department of Aerospace Engineering \\ Ryerson University
}

\begin{abstract}
Aircraft wing geometry morphing is a technology that has seen recent interest due to demand for aircraft to improve aerodynamic performance for fuel saving. One proposed idea to alter wing geometry is by a modular morphing wing designed through a discretization method and constructed using variable geometry truss mechanisms (VGTM). For each morphing maneuver, there are sixteen possible actuation paths for each VGTM module, and thus offering a three module morphing wing to have a total of $16^{3}$ permutations of actuation paths for one morphing maneuver. Focused on longitudinal static stability, critical parameters and aircraft stability theory, this thesis proposes a method to find an optimal actuation path for a designated maneuver iteratively. A case study of a three module morphing wing demonstrated the actuation path selection process. Numerically, different actuation paths had different levels of longitudinal static stability; these paths were drawn in CATIA and were visually verified.
\end{abstract}




\section{Acknowledgments}

The completion of this thesis is the fruitful result of the continuous support that many individuals have so generously provided me. First and foremost, I would like to thank Dr. Jeff Xi for providing me with the opportunity to not only participate in the development of the morphing wing research project, but to be a part of his research team. Dr. Xi's passion lies not only with research, but he is a dedicated professor who cares very much for his students. That passion has led him to continually devote his time not only to the quality of his research, but to motivate and enhance the knowledge and research abilities of his students. Without his guidance, this thesis would not have been possible.

I would also like to thank Dr. Alighanbari for providing me with the technical understanding that I require for the completion of this thesis. Dr. Alighanbari has boundless patience for his students because of the countless number of hours that he has spent to ensure that I understand the technical material well. His role as cosupervisor has also allowed me to freely experiment with technical ideas; because I always have the assurance that he would be able to guide me to our objective.

Afterwards, I would like to thank my fellow graduate students who endured the same hardships as I did. The times we have spent together in company and the sharing of stories and experiences which only research students will understand those were the best times during graduate school. I have met a few of these 
graduate students during my undergraduate years, and the most grateful thing I have heard them say was during the undergraduate commencement ceremony, where they said, "I'll see you again in a few months." I am very fortunate to have been their friend and teammate through my university years. They were friends who I could count on, and without these guys, my academic career would surely have been significantly different.

Finally, the last, but my most sincere thanks, I would like to thank my mother and my father for their ever unwavering support. My mother who would always provide me with the physical and mental tools I need to tackle any obstacle. While my father, a tireless family man who would like nothing more than our family could enjoy a comfortable lifestyle. Without their immeasurable energy and effort, my accomplishment would never have been possible. 


\section{Table of Contents}

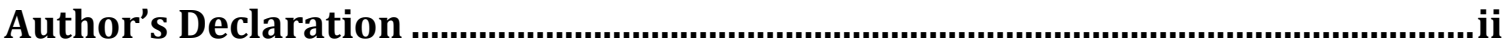

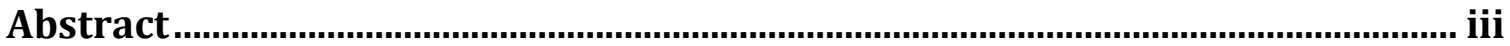

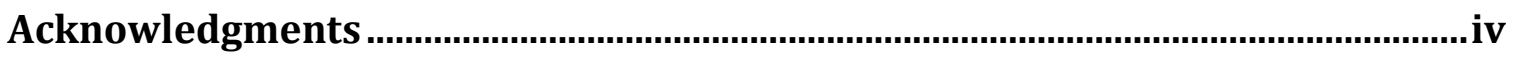

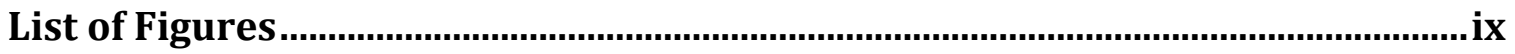

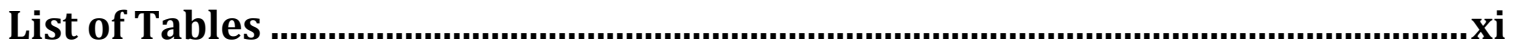

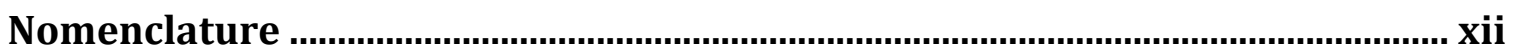

1. Introduction

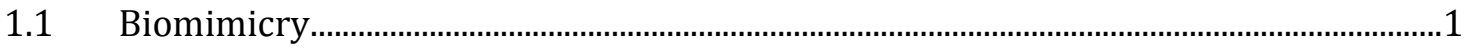

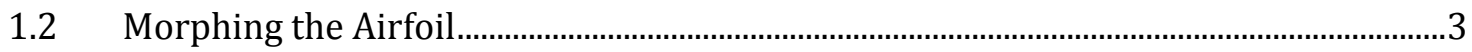

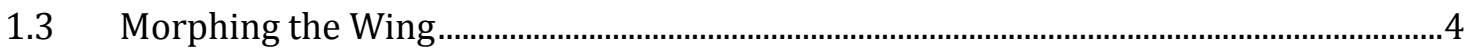

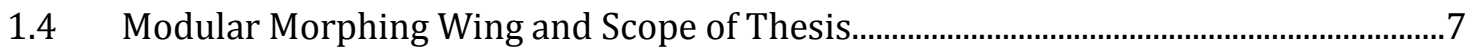

2. Literature Review

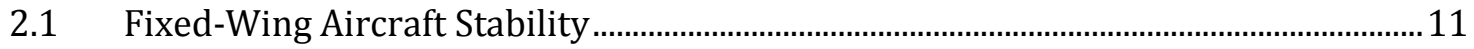

2.2 Challenges and Further Considerations of Morphing Wings .........................................13

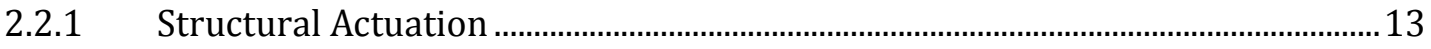

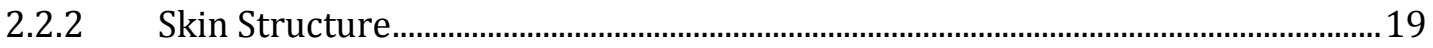

2.2 Physical Engineering Challenges and Stability Performance.......................................23 


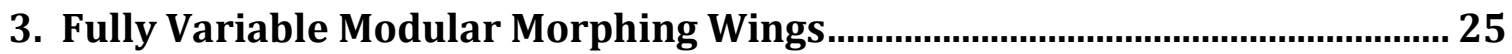

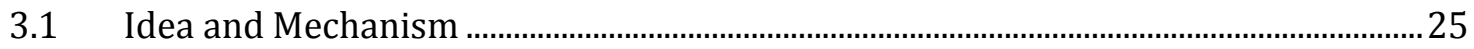

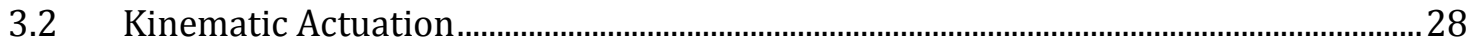

3.2.1 Position Analysis ..............................................................................................................2

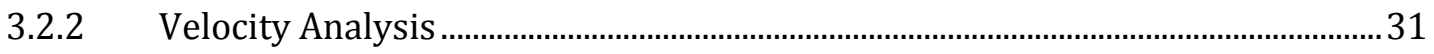

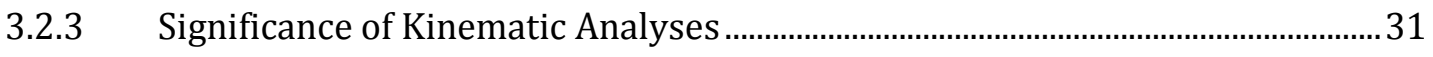

4. Longitudinal Stability Analysis ……........................................................ 36

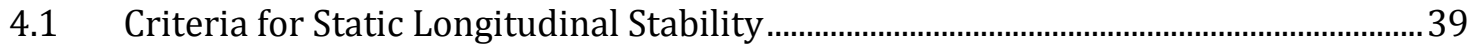

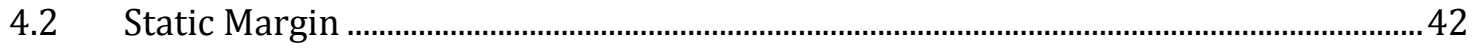

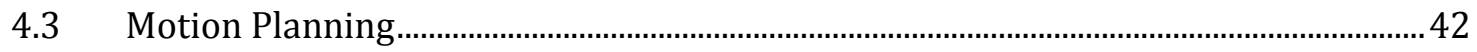

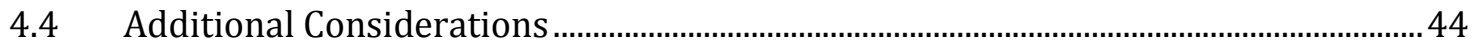

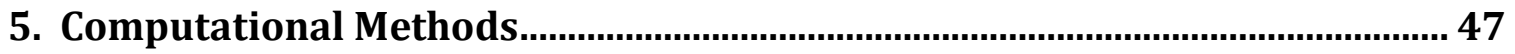

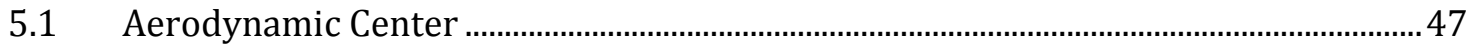

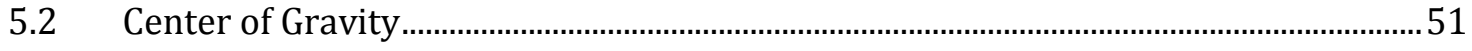

6. Theory Application: A Case Study …….................................................... 55

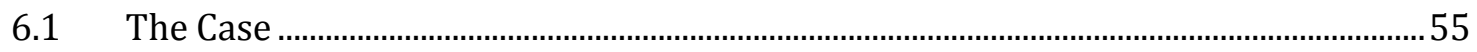

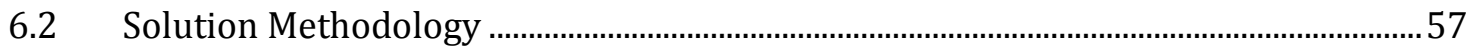

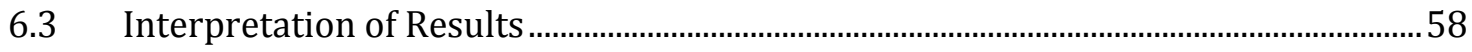

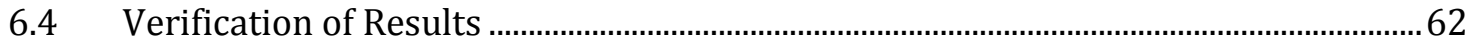

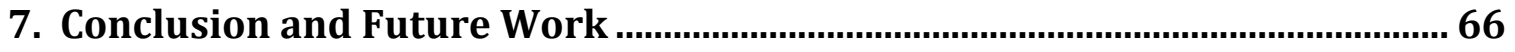

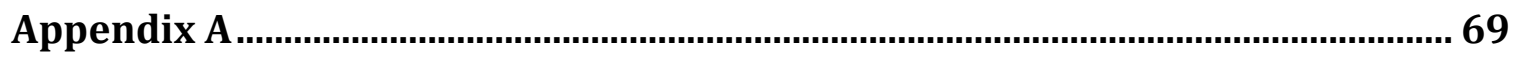


Module Pose Vectors for Case Study

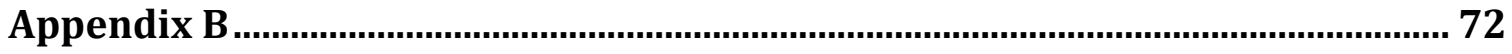

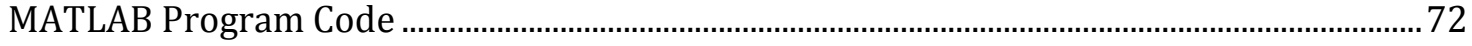

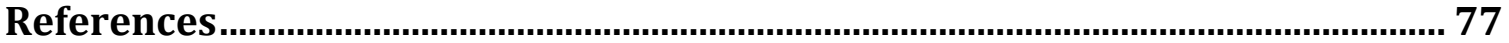




\section{List of Figures}

FIGURE 1: SPIDER PLOT COMPARISON OF FIXED-WING AND MORPHING WING IN DIFFERENT FLIGHT

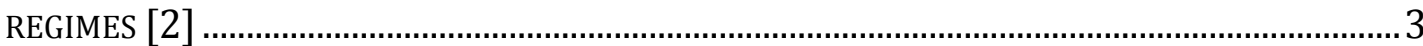

FIGURE 2: SPIDER PLOT OF A FIREBEE COMPARING VARIOUS FLIGHT PERFORMANCE PARAMETERS WITH THE FIREBEE HAVING A FIXED-WING, MORPHING AIRFOIL, AND MORPHING WING

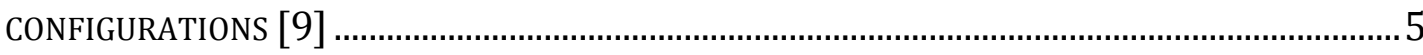

FIGURE 3: COEFFICIENTS OF LIFT AND DRAG VERSUS ASPECT RATIO [11] ........................................ 6

FIGURE 4: ONE PROPOSED DESIGN OF THE VGTM MODULE WITH SIX DEGREES OF FREEDOM [13]..8

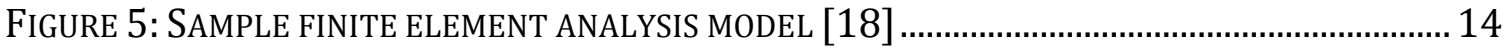

FIGURE 6: TOPOLOGY ANALYSIS SOLUTIONS WHERE (A) LOITER, (B) HIGH-LIFT, (C) CLIMB

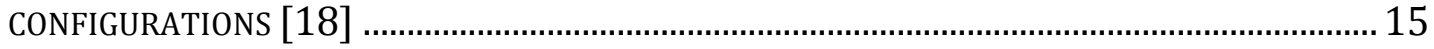

FigURE 7: CELLULAR TRUSS STRUCTURE OF A HYPERELLIPTIC CAMBERED SPAN [19]..................... 16

FIGURE 8: MORPHING WING STRUCTURE - SCISSOR MECHANISM [21] …....................................... 17

FiguRE 9: CHORD-WISE BENDING THROUGH HEATING OF SMA WIRES. (A) UNMORPHED AND (B)

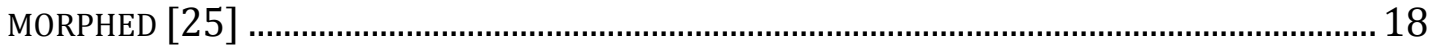

FIGURE 10: SCHEMATIC FOR IDEAL FMC FIBRE ORIENTATION FOR SPAN MORPH AND

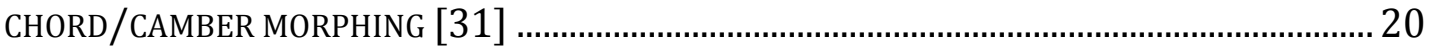

FIGURE 11: FINITE ELEMENT MESH OF THE WING OF THE MICRO AIRCRAFT [34] ........................... 21

FIGURE 12: DISPLACEMENT (IN INCHES) OF THE WING OPTIMIZED FOR ROLL RATE (TOP), FOR L/D

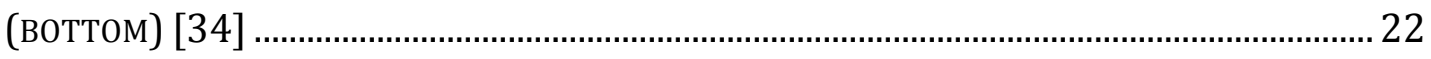

FiguRE 13: VGTMS LINED UP TO FORM A WING. SHOWN HERE ARE FIVE MODULES [41] ............. 25 
FIGURE 14: VGTMS AFTER A MORPHING MANEUVER [41] _..................................................... 26

FIGURE 15: THE FOUR ISOSTATIC TOPOLOGIES USED FOR ACTUATION [13] .................................. 26

FIGURE 16: THREE MODULE SYSTEM SIMPLIFIED TO ONE PRISMATIC JOINT AND ONE SPHERICAL

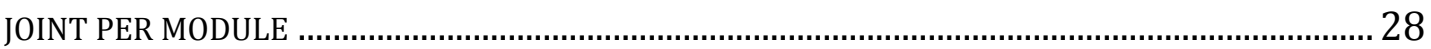

FIGURE 17: TRIMETRIC VIEW OF THE SIMPLIFIED VGTMS, RESEMBLING AN AIRCRAFT WING........ 29

FIGURE 18: MODULE WORKSPACE FOR ONE MODULE (FIRST PLATFORM MOBILITY)......................... 32

FIGURE 19: MODULE WORKSPACE FOR TWO MODULES (SECOND PLATFORM MOBILITY).................. 33

FIGURE 20: MODULE WORKSPACE FOR THREE MODULES (TIP PLATFORM MOBILITY)........................ 33

FIGURE 21: MODULE WORKSPACE VOLUME COMPARISON OF TWO MODULES.................................... 34

FIGURE 22: MODULE WORKSPACE VOLUME COMPARISON OF THREE MODULES ................................ 34

FIGURE 23: DRAWING TO ILLUSTRATE THE TENDENCY OF STABILITY [44]_.................................... 37

FIGURE 24: AIRCRAFT PRINCIPAL AXES AND THEIR DIMENSIONS OF ROTATION................................ 37

FIGURE 25: FREE BODY DIAGRAM OF WING CONTRIBUTION TO AIRCRAFT PITCHING ......................... 39

FIGURE 26: VISUAL REPRESENTATION OF CG AND MEAN AERODYNAMIC CHORD DISTANCE IN THE

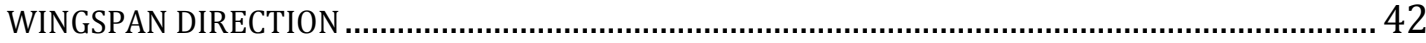

FIGURE 27: REPRESENTATION OF AERODYNAMIC CENTERS TO A REFERENCE WING APEX LINE AND THE MEAN AERODYNAMIC CENTER CHORD ....................................................................... 50

FIGURE 28: GEOMETRIC MEASUREMENTS OF ONE MODULE ......................................................... 52

FIGURE 29: TOP VIEW FOR THE DIMENSIONS OF THE THREE MODULE WING IN INITIAL POSITION

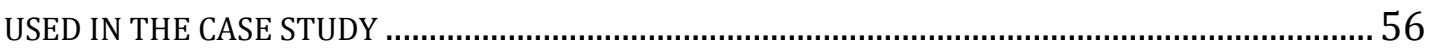

FIGURE 30: A COMPARISON OF STATIC MARGIN AND RESPECTIVE MORPHING PATHS ........................60

FIGURE 31: AIRCRAFT AXES AND ROTATION; TO DEMONSTRATE POSE VECTOR DIMENSIONS........... 69 


\section{List of Tables}

TABLE 1: BRIEF EXPLANATION OF EFFECTS OF EACH WING MORPHING DIMENSION ........................... 6

TABLE 2: 16 ACTUATION SEQUENCES FOR OPTIMAL MOTION CONTROL [13] .................................. 27

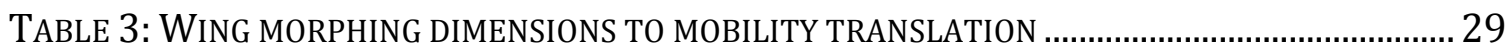

TABLE 4: POSE PERFORMANCE PARAMETERS OF THE THREE LEAST MOVEMENT MODULE PATHS

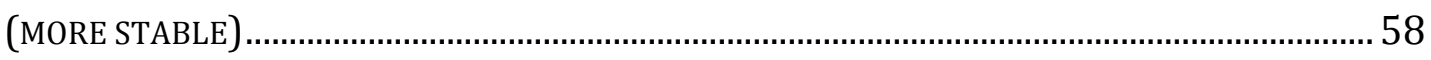

TABLE 5: POSE PERFORMANCE PARAMETERS OF THE THREE MOST MOVEMENT MODULE PATHS

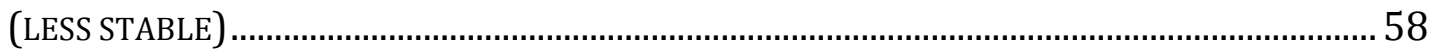

TABLE 6: TABLE OF MODULE PATH RESULTS AND STATIC MARGIN COMPARISONS ............................ 59

TABLE 7: VISUAL MORPHING PATH FOR LEAST STATIC MARGIN CHANGE (MORE STABLE PATH) ..... 63

TABLE 8: VISUAL MORPHING PATH FOR MOST STATIC MARGIN CHANGE (LESS STABLE PATH) ........ 64

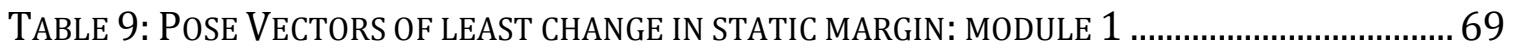

TABLE 10: PoSE VECTORS OF LEAST CHANGE IN STATIC MARGIN: MODULE 2 .................................. 70

TABLE 11: PoSE VECTORS OF LEAST CHANGE IN STATIC MARGIN: MODULE 3................................. 70

TABLE 12: PoSE VECTORS OF MOST CHANGE IN STATIC MARGIN: MODULE 1.................................... 70

TABLE 13: PoSE VECTORS OF MOST CHANGE IN STATIC MARGIN: MODULE 2 .................................. 70

TABLE 14: PoSE VECTORS OF MOST CHANGE IN STATIC MARGIN: MOdULE 3................................... 71 


\section{Nomenclature}

$\overline{\mathrm{c}}$

$\mathrm{C}_{\mathrm{L}}$

$\mathrm{C}_{\mathrm{LO}}$

$\mathrm{C}_{\mathrm{m}}$

b

b

h

$\mathrm{m}_{i}$

$\mathrm{x}$

$\overline{\mathrm{x}}$

y

$\overline{\mathrm{y}}$

Z

$s_{i} Z_{i}$

$\mathrm{X}_{\mathrm{ac}}$
Mean chord length

Coefficient of lift

Coefficient of lift at zero angle of attack

Coefficient of moment

Prismatic joint coordinates

Wingspan length

Initial wing module height position

Wing module number

Longitudinal axis

$\mathrm{x}$ - coordinate of mean aerodynamic chord

Vertical axis

$\mathrm{y}$-coordinate of mean aerodynamic chord

Lateral axis

Wing span length

Displacement from leading edge to aerodynamic center 


\begin{tabular}{|c|c|}
\hline$x_{\mathrm{cg}}$ & Displacement from leading edge to center of gravity \\
\hline$\alpha_{\mathrm{w}}$ & Angle of attack of wing \\
\hline$\alpha_{\mathrm{t}}$ & Angle of attack of tail \\
\hline$\varepsilon$ & Downwash angle \\
\hline$\eta$ & Tail efficiency \\
\hline$\theta_{x}$ & Wing dihedral angle \\
\hline$\theta_{y}$ & Wing sweep angle \\
\hline$\theta_{z}$ & Wing twist angle \\
\hline$\lambda$ & Taper ratio \\
\hline$\rho$ & Material density \\
\hline$\sigma$ & Standard deviation \\
\hline$\omega$ & Angular velocity \\
\hline $\mathrm{AA}$ & Aerodynamic axis \\
\hline $\mathrm{AC}(\mathrm{ac})$ & Aerodynamic center \\
\hline CG (cg) & Center of gravity \\
\hline $\mathrm{K}_{\mathrm{n}}$ & Static margin \\
\hline 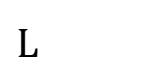 & Lift force \\
\hline
\end{tabular}




$\begin{array}{ll}\text { L/D } & \text { Lift-Drag ratio } \\ \text { MA } & \text { Mass of wing module } \\ \text { MAC } & \text { Mass axis } \\ \mathbf{P} & \text { Mean aerodynamic chord } \\ \mathbf{R} & \text { Rotation matrix } \\ \mathrm{S} & \text { Surface area } \\ \mathrm{V}_{\mathrm{H}} & \text { Tail volume ratio } \\ \mathbf{V}_{0} & \text { Velocity of original tip velocity of serial robot } \\ \mathbf{V}_{\text {tip }} & \text { Velocity of tip of serial robot } \\ \mathrm{W} & \text { Weight }\end{array}$




\section{Chapter 1}

\section{Introduction}

Since the introduction of commercial flight, there has been a strong demand for increasing the performance level of airliners to generate more profit. There are several methods to doing so, one being to increase payload, two being to increase cost of each airline ticket, and three is to reduce operating costs. As fuel represents a significant portion of the operating costs, commercial airline companies emphasize the need for aircraft manufacturers to produce aircraft with reduced fuel requirements. To reduce fuel consumption, much research is geared towards the use of lighter materials, or improving efficiency of the engines, or enhancing aerodynamic performance of the aircraft. Recently, enhancing the performance of the aircraft by morphing the exterior to mimic bird-like behaviours is being researched.

\subsection{Biomimicry}

The idea of wing morphing originated from biomimicry of birds once technology became feasible of achieving this feat [1]. Prior to the idea of wing morphing, all aircraft developments in the past were concerned only with the 
optimization of one flight mission. Of course, the optimization on an aircraft would be highly dependent on the time spent by the aircraft in each of the mission segments. Long-ranged aircraft would be designed such that optimizations of the cruise portion would have higher precedence, where short-ranged aircraft would have precedence in the climb and descent portion. Ultimately, the disadvantage to this optimization approach would be that for every type of flight mission, only one aircraft would be optimally designed for it. This may be acceptable in a civilian application as most flight missions are fairly similar, but this is not so for military applications. Depending on the flight mission, different performance parameters are required. For example, a reconnaissance aircraft would need high range and endurance whereas a fighter aircraft would need a large flight envelope to perform various maneuvers. In addition, these design optimizations are based on ideal environmental parameters which cannot always be satisfied. The result is that most modern day aircraft perform less optimally than their intended theorized designs. Less optimal performance is compensated by increased fuel consumptions and in turn, increased cost.

In the figure below, a comparison between the effectiveness of fixed wing and morphing wing aircraft for different aircraft regimes is shown. In nearly every parameter of flight, the performance values of the ideal morphing wing are equally or better than the ideal fixed wing aircraft. And thus, the idea to resolve the addressed problem is to have an aircraft that can perform optimally under a larger scope. 


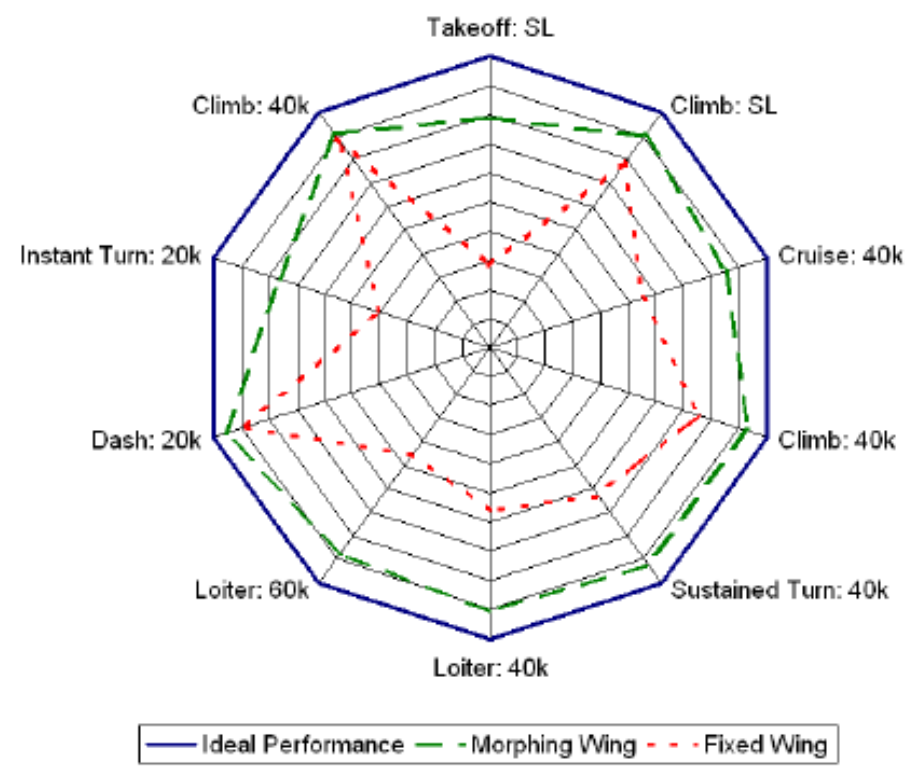

Figure 1: Spider plot comparison of fixed-wing and morphing wing in different flight regimes [2]

Morphing aircraft wings have the potential to change geometry according to the flight mission as well as the ability to adapt to in-flight environmental conditions. The ability to alter wing geometry can heavily influence the aerodynamics of the aircraft; thus, performance can be increased greatly in several flight regimes $[2][3][4]$.

\subsection{Morphing the Airfoil}

There are two main paths of wing morphing, one on an airfoil level, and one on a full-scale wing morphing level. For the airfoil morphing level, there is research that attempts to change parameters such as camber, thickness, chord, or a combination of them. The goal of airfoil morphing is to reduce drag by manipulating the viscous effects of the boundary layer over the airfoil. Various teams have 
attempted to control the boundary layer behaviour to reduce drag. One research team controlled the upper surface of the airfoil to reduce drag of boundary layer separation [5] while another team applied piezoelectric actuators to control the thickness of the airfoil to reduce drag [6].

Airfoil morphing could have a meaningful impact on flight performance parameters such as flight velocity. For velocities nearing a shock wave, Bauer et al. (1997) could achieve span differential camber and featured a contour bump in the shock area which had effects in shock reduction [7]. Secanell et al. (2006) investigated morphing airfoils and discovered that the main difference between optimal airfoils is their camber [8]. They found that with minimal actuation and maximum performance impact, the camber only need to vary by $7.9 \%$ of the chord for the typical civilian flight regime of takeoff, cruise, and decent. However, morphing the airfoil will only allow the reduction of drag and the applications of such are fairly limited in a larger scope.

\subsection{Morphing the Wing}

From a utility standpoint, morphing the entire geometry of the wing will likely yield a more fruitful result. Joshi et al. (2004) showed that morphing the geometry of the wing can result in greater performance improvements [9]. 


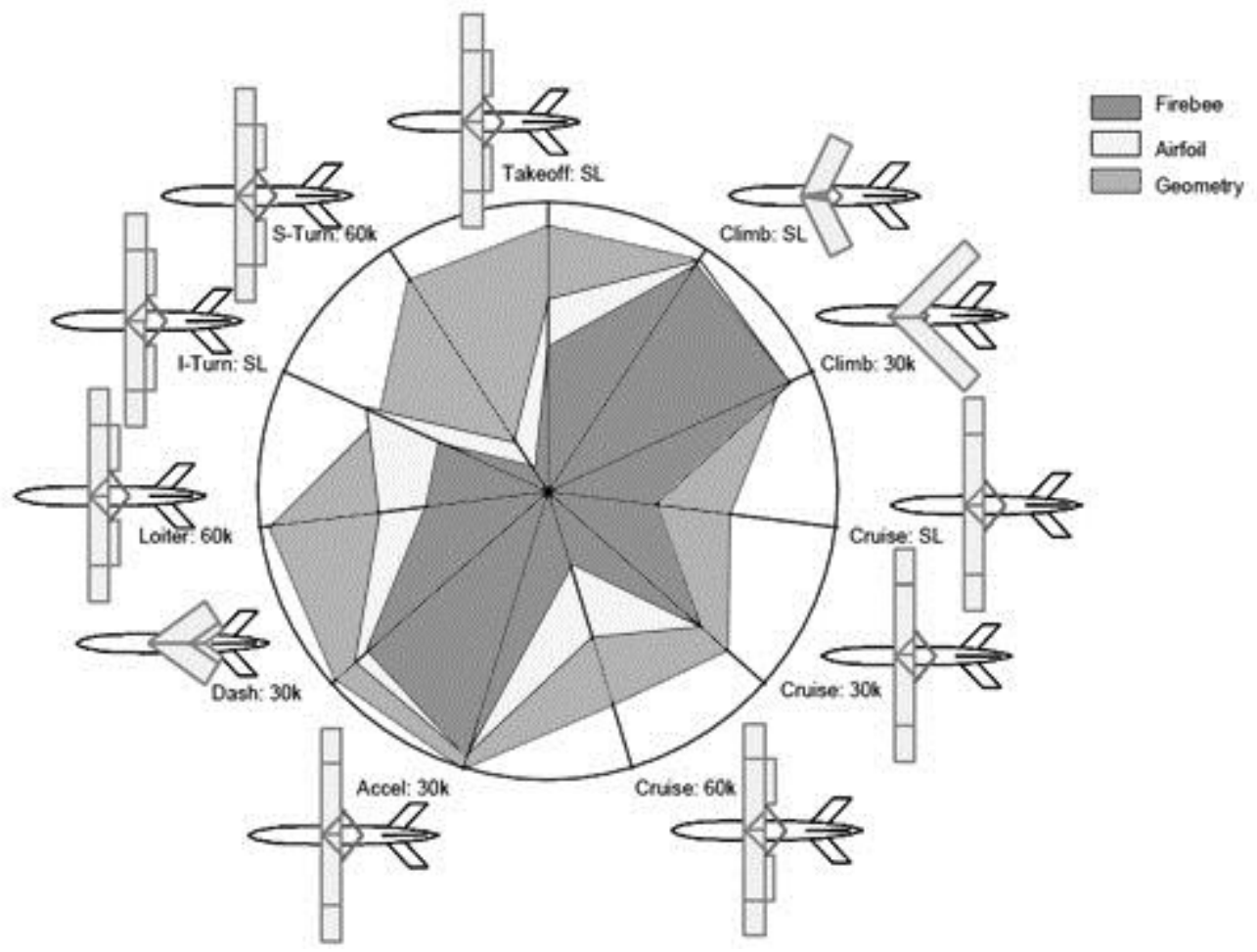

Figure 2: Spider plot of a Firebee comparing various flight performance parameters with the Firebee having a fixed-wing, morphing airfoil, and morphing wing configurations [9]

Figure 2 above, it can be seen that morphing the geometry of the wing gives a much greater improvement over morphing the airfoil. There are four dimensions of wing morphing: sweep, dihedral, span, and twist. Changing one or any combination of these dimensions of the wing will also change other important parameters such as wing loading, aspect ratio, and others [10]. Thus, if we take platform to be of an airfoil shape, and translate these platforms into different configurations, it can enhance aerodynamic performance. Intuitively, every dimension change will yield advantages and disadvantages, and it is imperative that the advantages and disadvantages are optimized for certain flight regimes. Below is a table that briefly summarizes the morphing dimensions of the wing and their characteristics. 
Table 1: Brief explanation of effects of each wing morphing dimension

\begin{tabular}{|c|c|c|c|}
\hline $\begin{array}{l}\text { Wing Morph } \\
\text { Dimension }\end{array}$ & Effects & Advantages & Disadvantages \\
\hline Sweep & $\begin{array}{l}\text { Drag decrease for higher } \\
\text { Mach numbers; lower } \\
\text { structural stresses }\end{array}$ & $\begin{array}{c}\text { Performing dash } \\
\text { maneuvers, gives aircraft } \\
\text { higher speed cruise }\end{array}$ & Lowers lift coefficient \\
\hline Span & $\begin{array}{l}\text { Changes area and wingspan; } \\
\text { or aspect ratio, wing loading }\end{array}$ & $\begin{array}{l}\text { Larger aspect ratio increase } \\
\text { range and endurance; } \\
\text { Lower increases } \\
\text { manoeuvrability }\end{array}$ & $\begin{array}{l}\text { Large span increases } \\
\text { wing root stresses } \\
\text { (deformations) }\end{array}$ \\
\hline Twist & $\begin{array}{c}\text { Changes lift and drag } \\
\text { moments }\end{array}$ & May control roll stability & $\begin{array}{l}\text { Lower wing torsional } \\
\text { stiffness, too much twist } \\
\text { may affect aeroelasticity }\end{array}$ \\
\hline Dihedral & $\begin{array}{l}\text { Control lateral stability, } \\
\text { especially in turning situations }\end{array}$ & $\begin{array}{l}\text { Increase roll stability, } \\
\text { reduce sideslip }\end{array}$ & $\begin{array}{l}\text { Increased stability } \\
\text { reduces manoeuvrability }\end{array}$ \\
\hline
\end{tabular}

Another positive result for morphing wings as opposed to morphing airfoils can be seen in the research paper of Heryawan et al. (2005) They found via their own investigation that through a wind tunnel test at a Reynolds number of 300,000, the total lift increases more than three times during wingspan expansion from aspect ratio 4.7 to 8.5 [11]. The graphs that illustrate this are shown below.
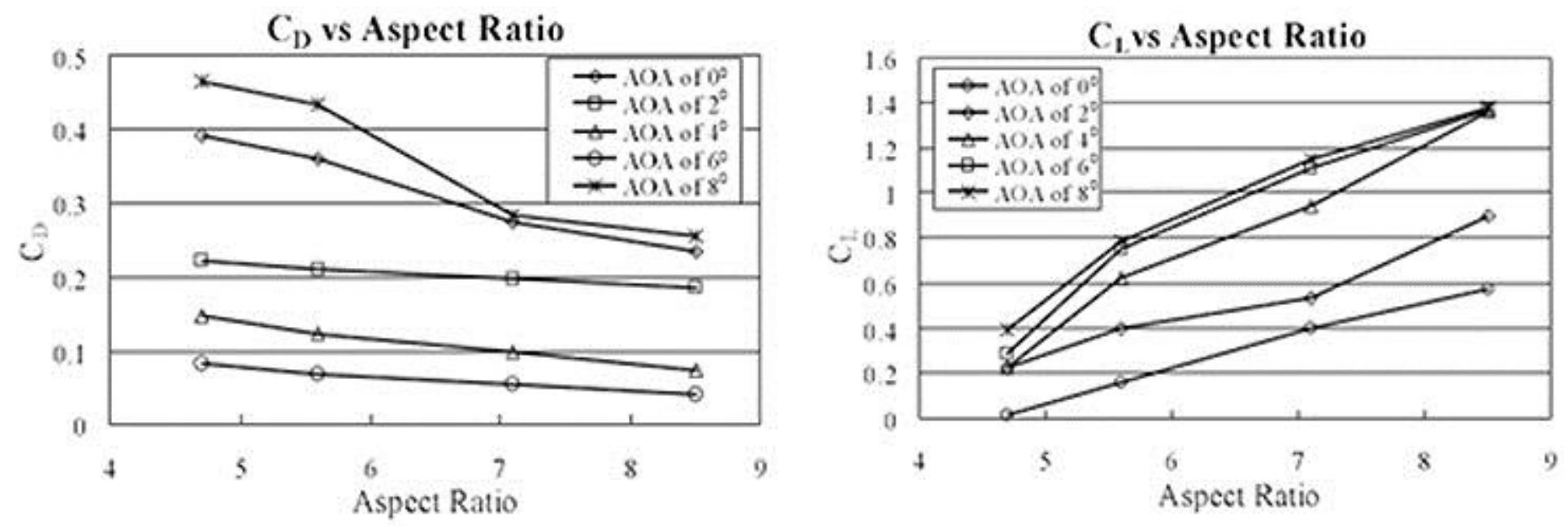

Figure 3: Coefficients of lift and drag versus aspect ratio [11] 


\subsection{Modular Morphing Wing and Scope of Thesis}

The proposed idea of using VGTMs to construct a modular morphing wing and to alter wing geometry is to achieve greater performance from an aircraft. Current aircraft have rigid frames and are designed specifically for singular types of flight missions. For passenger and commercial aircraft, a critical attribute of an aircraft is its ability to reduce cost by consuming less fuel, which leads research in the direction of saving weight through the use of lighter materials such as composites and magnesium alloys [12]. Instead of addressing the savings of weight, morphing wings aim to drastically change the aerodynamics of the aircraft by altering the wing geometry tailored for specific aircraft missions and maneuvers such that the ideal aerodynamic performance can be obtained. With wing morphing, every bit of change in wing geometry could dramatically affect aerodynamic performance. As a result, detailed analyses must be performed to determine the correct movements of the modules. Correct movements could be defined in several ways depending on the desired effect; one could seek the minimal amount of power required from the actuators where another could seek for the greatest stiffness of the wing during the morph.

A VGTM is composed of four actuators and four hydraulic locks illustrated in the figure below. The proposed design offers six degrees of freedom and has been designed with the intent of maximizing movement to enhance aerodynamic performance while considering some structural rigidity. For the morphing of one module, one could design thousands of patterns of actuator movement to produce the morphing path. However, Moosavian et al. suggested limiting the movement 
types to sixteen different paths [13]. Thus, if a morphing wing consists of three adjacent modules, there can be 4096 different paths of movement for one maneuver. The designed module by Moosavian et al. is shown in the below figure.

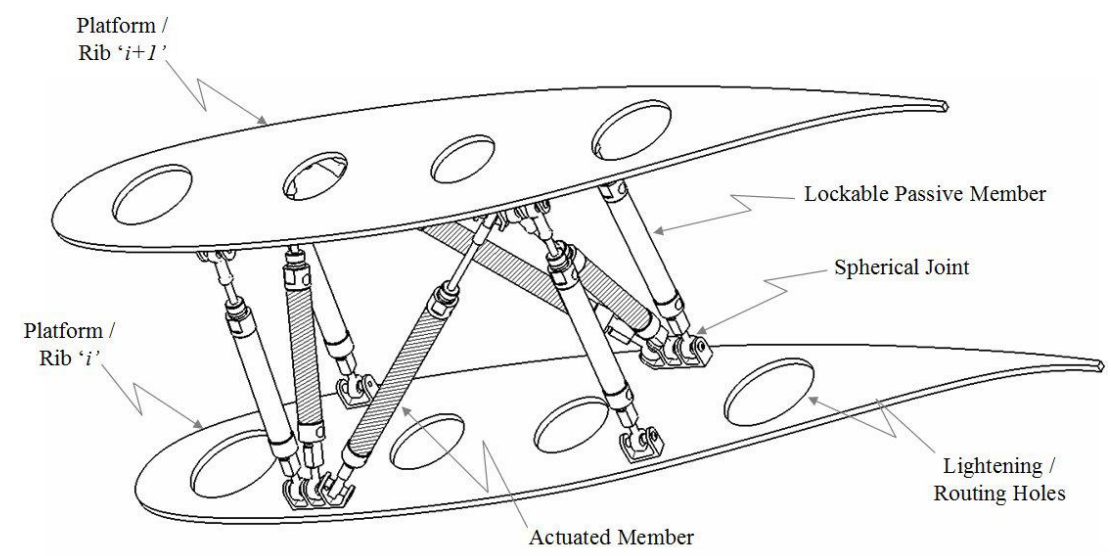

Figure 4: One proposed design of the VGTM module with six degrees of freedom [13]

For this thesis, we are seeking the best actuation path from the perspective of longitudinal stability. To do this, stability concepts are explained and a case study is also performed based on the ideas discussed. The scope of this thesis can be broken down into several chapters:

- Chapter one is the introduction to the thesis, and they provide the reader with the overview of this thesis. It illustrates why morphing wings are incredibly efficient compared to other innovations in aerodynamics such as morphing airfoils. The goal of the thesis is explained coupled with background information on the project allows readers to foresee the content in the remainder of the thesis. 
- Chapter two is a literature review of previous work performed on morphing wings. There are also descriptions of engineering challenges that must be considered into a prototype design of the morphing wing. The literature review also relates current engineering challenges of morphing wing design and their relevance to the performance of aircraft stability.

- Chapter three is a concise summary on the VGTM idea for a morphing wing. In addition to outlining the idea of modularity, there will be a section on the kinematic analyses of the VGTM modules.

- Chapter four begins with the foundation and definitions of stability and further expands into theory, which is then applied specifically for the modularity of the morphing wing. A plan to determine the most preferred actuation path is also explained. Further, there are other considerations about the morphing wing that are deemed to be outside the scope of this thesis, explanations of these assumptions are found near the end of the chapter.

- Chapter five is where the computational methods to obtain critical stability parameters are developed and applied. The explanations are condensed to the determination of the aerodynamic center of the wing and the center of gravity. 
- Chapter six is a case study where methods that were discussed are to be applied. For the case, a three module VGTM morphing wing is deemed as the sample. In addition to theory and methods, a Matlab code was developed to apply the procedures and a most preferred actuation path is determined. From the results of the case study, the final parameters of the morphing wing were able to be modeled in CATIA. This set of CATIA drawings allow for visual verification of the theory.

- Chapter seven is the conclusion of the thesis. It summarizes the theory discussed, and discusses the results of the case study. It also discusses potential future research areas which expand from the theory in this thesis. 


\section{Chapter 2}

\section{Literature Review}

As research in this field has yet been deeply explored, most research topics in this field of aerospace engineering revolve around the design and positivity of the morphing wing concept. Several researchers have approached the problem by morphing the wing in one dimension, including: variable span wings [4], variable twist wings [14], variable sweep wings [15], and variable dihedral wings [16]. Some researchers such as Neal et al. [17] have been able to morph various dimensions of the wing, albeit not simultaneously as a combination. Since so far, combinational morphing on aircraft wings of different dimensions is not achievable, there is little merit in performing aircraft performance analyses on them.

\subsection{Fixed-Wing Aircraft Stability}

In modern aerospace engineering, fixed-wing aircraft stability has been covered extensively. Stability of aircraft in every degree of freedom as well as for specific flight missions and flight envelopes has been studied for many decades as well. 
Current aircraft stability research topics revolve more around specific solutions to specific problems. Such research topics include effects of icing on aircraft stability and control [36][37], blended wing body designs [38], or for other specific aircraft [39]. For more generic topics on aircraft stability, aircraft control will also be discussed. These topics are generally found within textbooks such as from Anderson [40], Nelson [44], and Etkin/Reid [45].

There are not many publications which discuss morphing wings. Some of those include description of challenges [27] or for specific parts which may contribute to the design of a morphing wing, such as a flexible skin for shear forces [46]. As a result, of the few papers discussing morphing wings, there are only a selective handful of publications that deal with the development of a feasible mechanism and actuation sequence. Most of these publications also focus on one dimensional wing morph. Thus, there is almost no literature on the aircraft stability performance based on a morphing wing.

Therefore, there is great merit to be pioneering basic aircraft stability performance analyses on morphing wings. With the variable modular morphing wing described in Chapter 3, this thesis aims to perform longitudinal static stability analyses on the modular morphing wing. 


\subsection{Challenges and Further Considerations of Morphing Wings}

After understanding analyses of the effectiveness and benefits of morphing wings, what follows are the desire and research to construct a feasible prototype. This section is dedicated to the explanation of many challenges that must be considered for the construction of the morphing wing.

\subsubsection{Structural Actuation}

To actuate the morphing wing, an intricate system must be designed. Not only does the mechanism have to withstand the repetitive fatigue of morphing the wing through orientations, but it also has to provide the structural support and rigidity to ensure safety of the aircraft. Further, the structure of the wing must work co-operatively with the aerodynamics; notably the skin of the wing. Asides from aerodynamics, the weight of the actuation system must also be as light as possible in order to not hinder the performance of the aircraft. If the actuating mechanisms weigh too much, it will negate the advantages produced by the morphing wing and no advantage will be generated. Furthermore, the actuating mechanism is preferred to use as little energy as possible. As the aircraft will not stay stationary, there is a limited amount of power that can be stored and generated on board.

Lastly, the actuation of the structure must cooperate with the performance of aircraft stability as well. Given a morphing wing in an initial configuration, if physical model limitations are removed, there are an infinite number of morphing paths that the morphing wing can undergo to reach another configuration. However, there must be a structural system installed, and this system will have physical 
limitations. These limitations should aim to promote stability or maneuverability, depending on the objective of the aircraft.

As such, the actuators should also be designed to optimize for the stability of the aircraft. All of these factors contribute to a very difficult challenge to design properly. Listed below are some of the ideas explored by researchers as of late, and all the research is mainly geared towards only a functional mechanism.

\section{Finite Element Analyses}

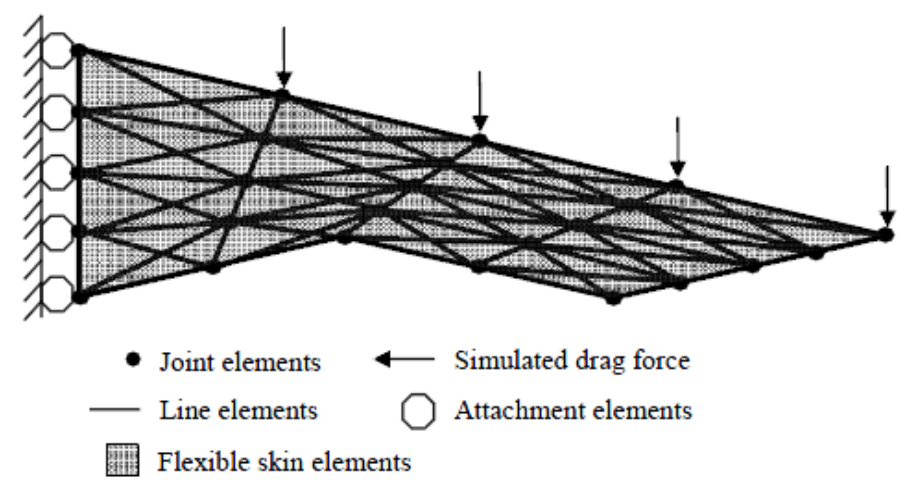

Figure 5: Sample finite element analysis model [18]

Shown in Figure 5, Inoyama et al. (2007) studied the use of finite elements to understand the various forces that the morphing wing needs to withstand. For this model, they assumed it to be in-plane, performing a topology synthesis, which yielded the following interesting results [18].

From the results shown in Figure 6 below, it can be seen that for loitering Figure 6 (a), there needs to be a high strength section at the rear part of the wing root. A mid-strength section is shown in the frame area in high-lift configuration Figure 6 (b). Through this design of truss and frames, climb configuration Figure 6 (c) shows that even a tapered wing can be made possible when necessary. 


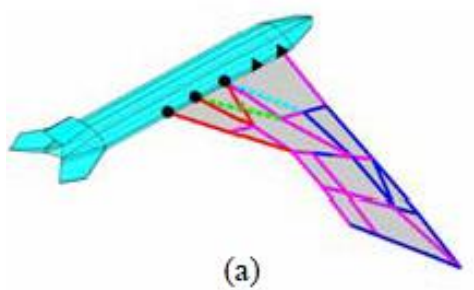

(a)

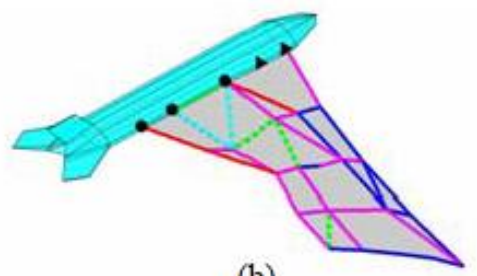

(b)

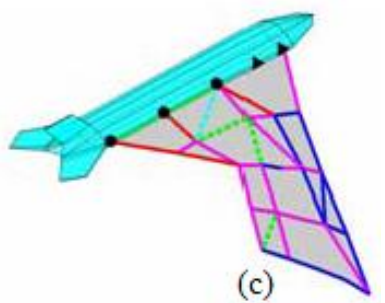

(c)

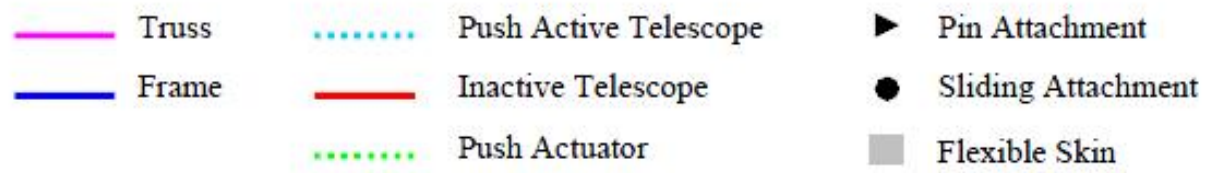

Figure 6: Topology analysis solutions where (a) loiter, (b) high-lift, (c) climb configurations [18]

The actuation method proposed above is fairly complex. As depicted in the figure, there are numerous truss, frame, and telescoping actuators. With this many members within the system, there will be very strict limitations imposed on the degrees of freedom of the system on the morphing path. Therefore, by intuition, it would be difficult for this system to simulate the ideal morphing path from one configuration to another.

\section{$\underline{\text { Truss and Tendons }}$}

Generic truss structures are researched due to their effective strength-toweight ratio. This combination makes it ideal for aerospace applications where weight savings matter incredibly. Truss structures are also simple to build and are very rigid. 


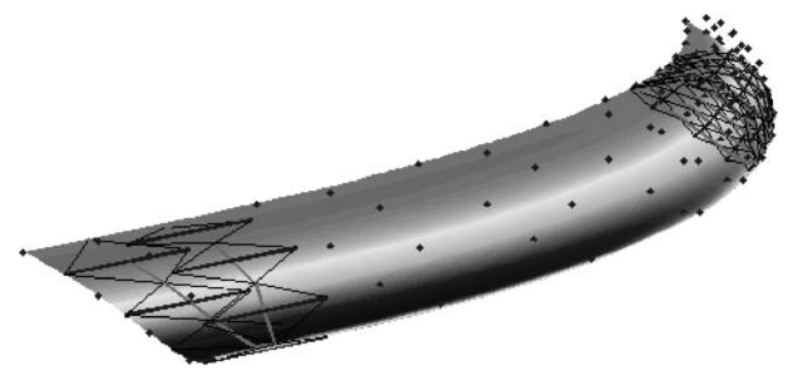

Figure 7: Cellular truss structure of a hyperelliptic cambered span [19]

In Figure 7 above, it is a cellular truss internal structure of a hyperelliptic wing. This method of actuation structure is sturdy in the sense that they can withstand a great deal of tension and compression [19]. In combination with this cellular structure, a few cables will be applied. To actuate the structure, tension will be applied to corresponding cables which will cause the structure to morph. The limitations to this design are the inability to morph the wing in more than one dimension. The application of tendons to actuate different portions of the wing is lightweight and simple to apply; however, from Figure 7 above, it can be shown that there may be difficulty in actuating in dimensions other than wing twist. The use of cables may put repetitive stresses onto the cables or truss structures. If pin-joint mechanisms are considered, issues such as friction, pin slops and joint bending could occur. Bharti et al. (2007) discovered that, and their subscale design could still achieve a 55\% span change using a DC motor actuated spooling screw [20]. It may be more worth the examining the cellular structure in conjunction with the use of linear actuators. To emphasize, this truss and tendon actuation method may only apply to one dimensional morphing, notably only for wing twist. 


\section{Linear Actuators}

Linear actuators have been one of the most basic and go-to methods of actuation choice. The primary reason for this is the relative availability, cost, and simplicity of the mechanism.

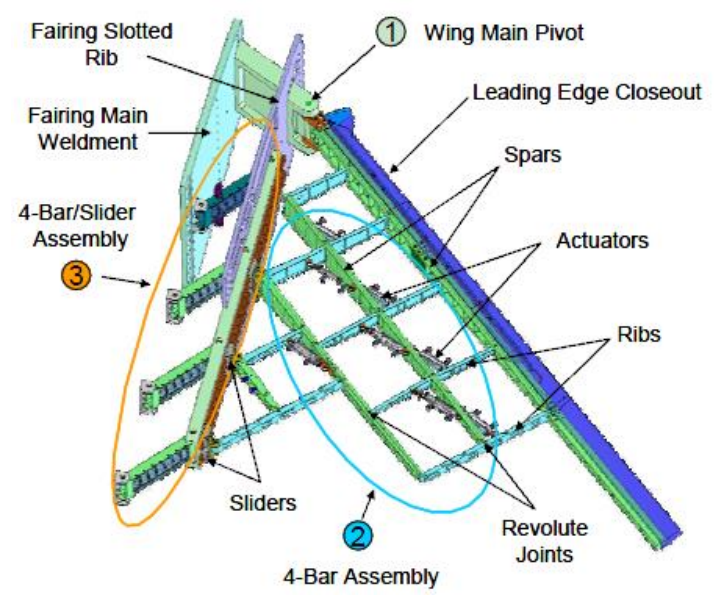

Figure 8: Morphing wing structure - scissor mechanism [21]

Due to weight restraints, it is more likely that mechanical and pneumatic actuators will be preferred over hydraulic actuators. Andersen et al. (2007) designed a feasible morphing wing structure with the aid of linear actuators. In Figure 8 , the task of the actuators is to extend the wing outwards or to pull it inwards [21]. Optimization of the locations of the actuators can increase system efficiency while providing flexibility and resistance to external loads [22]. The advantage to the scissor mechanism is that the transitions from one orientation to another will be a fairly smooth motion to disturb aerodynamics as little as possible, but the disadvantage is that the range of morphing is fairly limited. However, if the actuators were dedicated to span-wise morphing, the wing's lift to drag ratios can 
increase by up to $25 \%$ [23]. Within a robust structure, linear actuators are one of the best actuation methods available.

\section{Shape Memory Alloys (SMA)/Shape Memory Polymers (SMP)}

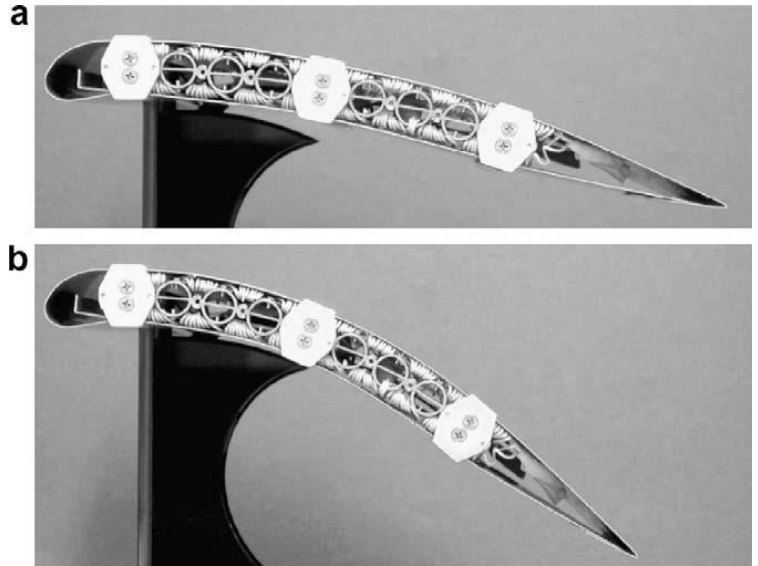

Figure 9: Chord-wise bending through heating of SMA wires. (a) unmorphed and (b) morphed [25]
One of the most exciting and cutting-edge technologies to be applied to morphing wings is the use of shape memory materials. Shape memory alloys offer super elastic and shape memory properties along with a capacity to transmit large loads. This combination of properties makes them

Jacob et al. (2005) used SMA wires on the bottom surface of the wing. This allowed downward bending of the trailing edge once the SMA actuator heated up, resulting in control over wing twisting [25]. The rib of the wing is shown in Figure 9 above, where there are three actuation hinges. The hinges offer elastic properties to provide structural rigidity during and after the morphing procedure. Upon actuation, the wires will contract, allowing the bottom-side to rotate relative to the hinges, and moves the plates downward, forming the twist [26]. One downside to this method of actuation is that it can only change the geometry that does not affect the overall area. It cannot affect the size of the geometry, but it can only change the orientation of the shape, and as such, cannot perform span-wise actuation. However, 
it can likely affect the wing twist, sweep, and dihedral, as those morphing dimensions do not require a morph of planform area [27].

Shape memory polymers have already seen use in the industry despite it being a relatively new technology. In 2006, The Boeing Company has adapted the use of shape memory polymers on the serrated aerodynamic devices located on the trailing edge of the engine nacelles, also known as chrevons [28]. By doing so, they have introduced morphing aerostructures which meld seamlessly onto existing aircraft in order to solve an engineering challenge.

At this time, the only publications which discuss the performance analysis of an external morphing part of an aircraft revolve around Boeing's variable geometry chevrons [29][30]. Due to the use of that technology, it also proves that there is a demand for technological improvements within the field of aerospace, and that the industry leaders are willing to apply new technologies. However, in order to safely apply these technologies with confidence, performance studies of these parts require extensive study. As such, due to such few numbers of publications in technology of morphing aircraft parts, there is great merit to produce publications which analyze the performance of these parts to pioneer improvement in a new technology.

\subsubsection{Skin Structure}

The skin of the morphing wing must satisfy a large number of criteria to be successful. One of the materials examined by Murray et al. (2007) known as flexible matrix composites (FMC) has been one of the earlier attempts at constructing this 
skin system. They used the FMC for one-dimensional wing morphing applications such as span, camber, and chord changes. Due to the nature of composites, the stiffness modulus of the fibres is much higher than that of the matrix. Thus, if the matrix dominated direction is aligned with the actuation direction, there needs to be little power in actuation, where the out-of-plane actuation direction will be provided with stiff structural support [31]. As shown in the figure below, it is more ideal to align the matrix dominated direction with the actuation direction.

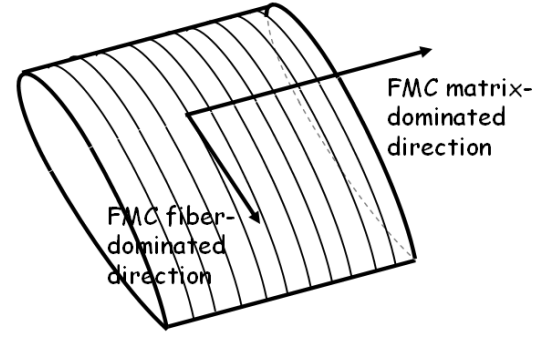

Span-Morphing

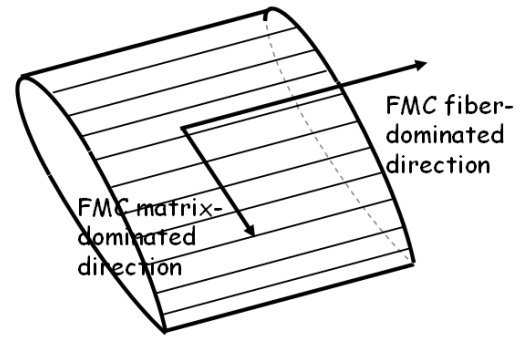

Chord- or Camber-Morphing

Figure 10: Schematic for ideal FMC fibre orientation for span morph and chord/camber morphing [31]

The skin of the morphing wing must have a high flexural stiffness. One reason is to prevent skin sections between supports to undergo local deformations in bending due to aerodynamic pressure. If this occurs, the skin could warp undesirably, and may even inhibit further morphing of the wing. Secondly, it is to prevent buckling in the skin sections between supports [32].

Other materials considered include rubber materials and smart materials such as shape memory polymers. Metals and high stiffness or low strain polymer membranes are not suitable candidates for skins due to the need for flexibility and tolerances for high strains [33]. 
On a micro scale, membranes elements for a latex skin were used along with carbon fibre laminates to create the morphing wing. The morphing portion of the wing will be consisted of just one membrane with an actuation wire to modify wing twist during flight [34]. After applying a finite element mesh, the wing of the micro aircraft appears as in the below figure.

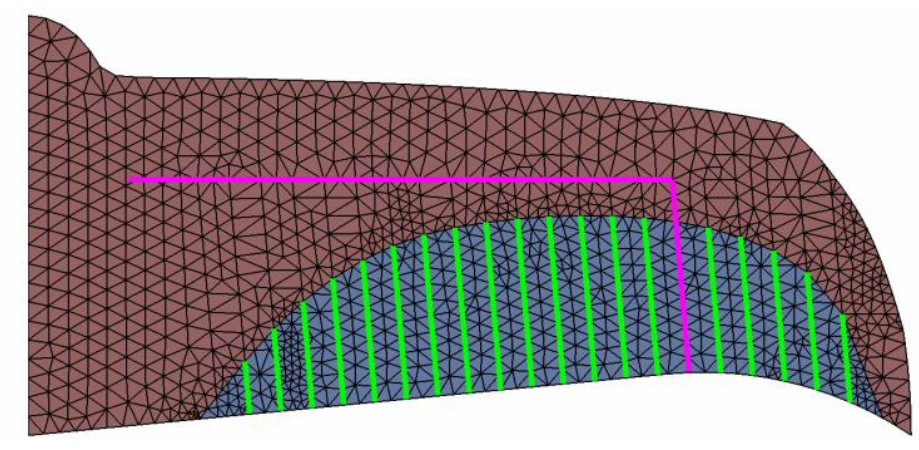

Figure 11: Finite element mesh of the wing of the micro aircraft [34]

The objective of this micro air vehicle is to demonstrate the effect of wing twist morphing as a form of control surface. The actuation method is very simple, as only a rod controlling the membrane to push upwards or downwards. The results show that morphing the wing of the aircraft for twist does simulate an aileron. Albeit not as effective, but the theory and practical building techniques are present.

Below in Figure 12 are a series of finite element results that demonstrate how effective the wing twist morphing was on flying performance after wing morphing. The top figure is optimized for best roll rate and the bottom figure is optimized for a high lift-over-drag (L/D) ratio. 


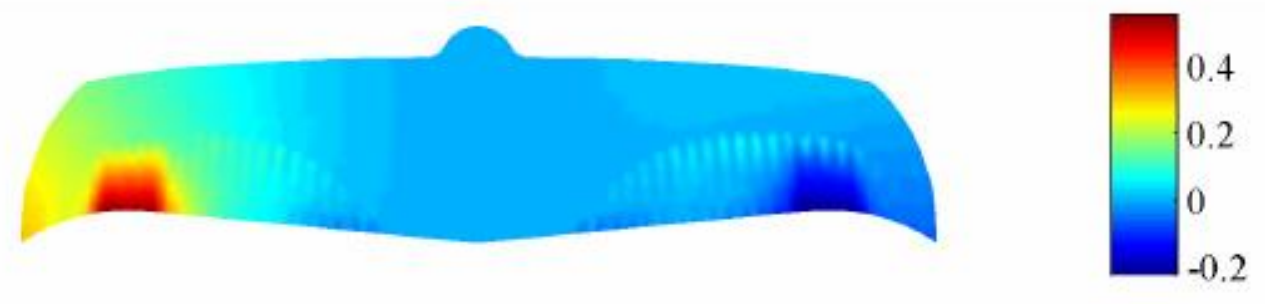

roll rate $=20.2 \%$ $\mathrm{LD}=15.7$

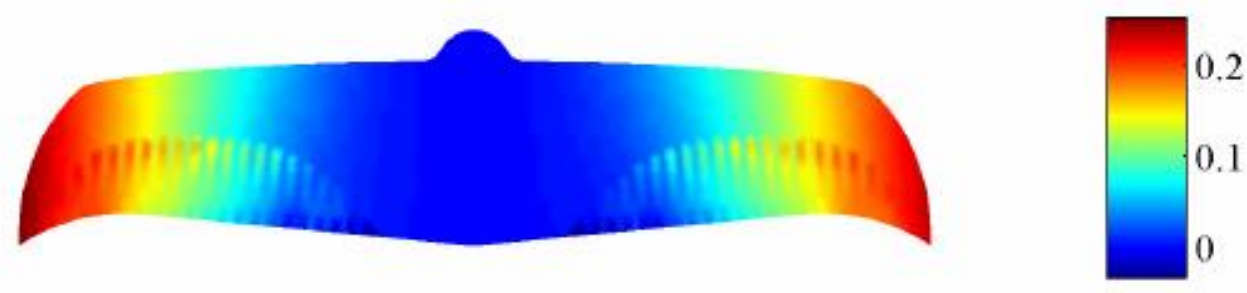

Figure 12: Displacement (in inches) of the wing optimized for roll rate (top), for L/D (bottom) [34]

Through testing on a micro scale, it demonstrates the possibility of performance enhancements of the addition of morphing wings compared to current fixed-wing aircraft. Further practical testing is required, along with numerous hours of wind-tunnel testing to ensure that morphing wings are fully understood in performance.

A relevant paper which combines the contribution to the development of the skin structure for the purpose of a morphing wing is best demonstrated by Bubert, in a thesis presented to the University of Maryland [35]. Bubert was able to design a functional structure for the skin through two technologies, optimized for span morphing, as well as perform performance testing on both skins through applying uniaxial force. This thesis demonstrates the effort to propose, design, fabricate and test an integral piece towards functional morphing technologies.

The construction of the skin is extremely important to aircraft stability. This is because the skin is the part of the morphing wing which will be in direct contact 
with the aerodynamic forces. As a result, any non-uniformity in the skin would hinder aerodynamic performance. Should this occur, it is possible that aircraft stability could be affected, notably if the aerodynamic forces are distributed unequally on the two wings. In addition, most aircraft performance theories are based on an assumption that the aircraft wing has an ideal external surface.

\subsection{Physical Engineering Challenges and Stability Performance}

The reviewed literature details various structural challenges and considerations of the design of a morphing wing. Structural considerations of an aircraft wing have strong ties with the stability performance of the aircraft. Therefore, all of the above topics can relate structural involvement with aircraft stability.

The topics of structural actuation, aeroelasticity, and skin structure will all contribute to the alteration of the external geometry of the wing. Structural actuation is the primary system to actuate the wing from one configuration to another, and the algorithm for shape morphing will highly influence in-flight performance. Depending on the material, manufacturing, and theory of the skin structure, the surface of the skin will affect performance in several ways. Some

arguments include an increase in surface friction, higher localized stress concentrations in some areas, and other viscous effects. 
As mentioned in Chapter 2.1 there is very limited of literature on morphing wing aircraft stability performance. This thesis attempts to serve as a base for the study by taking into account reasonable assumptions and applying static stability theory. In the near future, it is expected that there will be more contribution which discuss theories, evaluation, and performance of morphing parts for aerospace applications. 


\section{Chapter 3}

\section{Fully Variable Modular Morphing Wings}

\subsection{Idea and Mechanism}

Very recently, methods of design and control of fully variable morphing wings have been undergoing development. As shown in Figure 13 and 14, the idea is to discretize the wing into modules and actuating each of these modules to produce a final wing geometry [41][42]. Given a desired flight maneuver or regime, an optimization for the wing geometry can be performed. Once that geometry has been determined, an estimate of the number of discretized modules and their spacing in the morphing wing to produce that geometry can be produced. This discretization is mainly based on the curvature and twist distribution of the solution geometry.

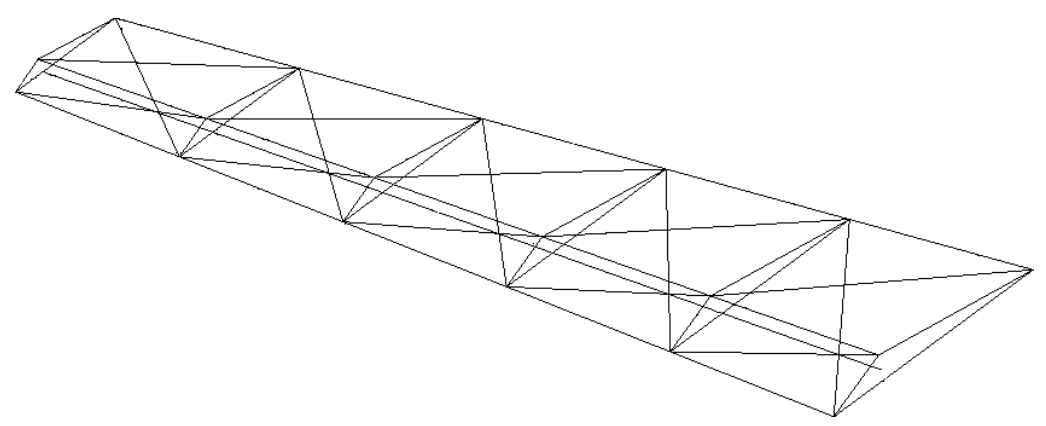

Figure 13: VGTMs lined up to form a wing. Shown here are five modules [41] 


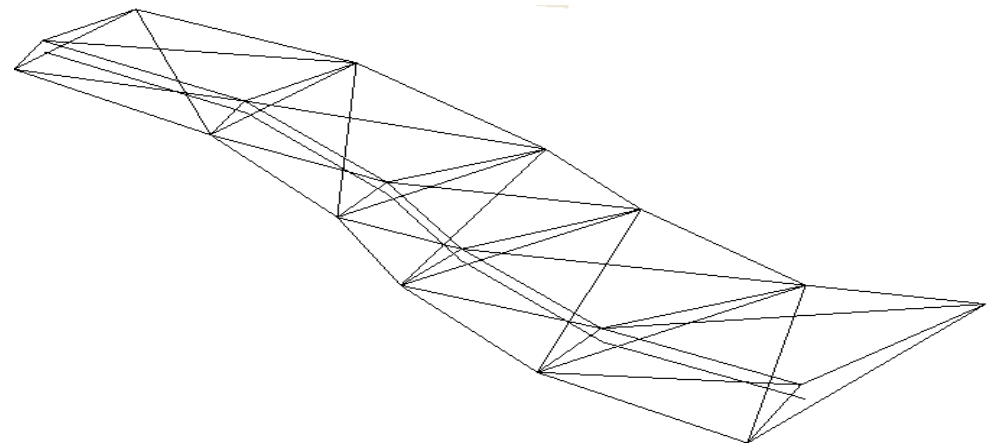

Figure 14: VGTMs after a morphing maneuver [41]

Built on the principle of under-actuation mechanism, a new design and motion control have been researched. Moosavian et al. [13] have produced a morphing module and developed a morphing algorithm for a single module. For each actuation path, there are four poses: initial configuration, first interim pose, second interim pose, and final configuration. To calculate actuation paths, there are four isostatic topologies: A, B, C, and D as shown in Figure 15, each constrained in different ways to limit movement. Through permutation of these limiting motions, a total of 16 actuation paths are produced, as summarized in Table 2.

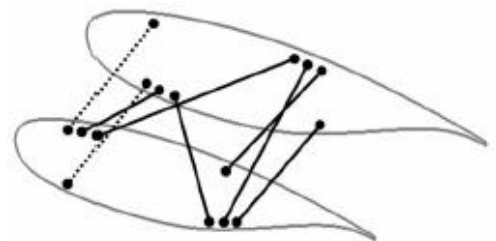

Isostatic Topology ' $\boldsymbol{A}$ '

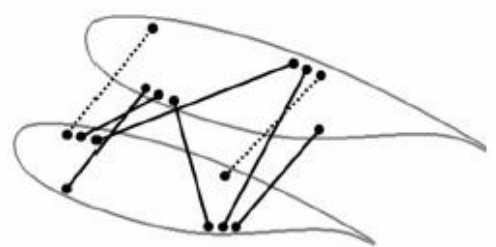

Isostatic Topology ' $C$ '

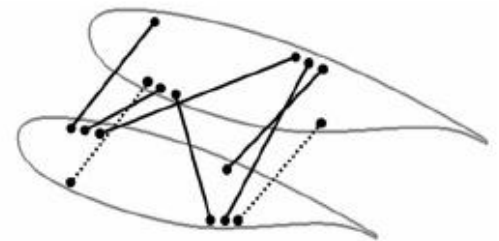

Isostatic Topology ' $\boldsymbol{B}$ '

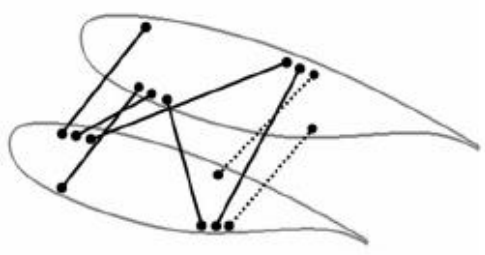

Isostatic Topology ' $D$ '

Figure 15: The four isostatic topologies used for actuation [13] 
In [13], a method was proposed to determine a final actuation path based on minimum energy. In this thesis, we propose a new method to select a final actuation path based on maximum stability margin.

Table 2: 16 Actuation sequences for optimal motion control [13]

\begin{tabular}{cccc} 
Path & Stage 1 & Stage 2 & Stage 3 \\
\hline \hline 1 & A & B & D \\
2 & A & D & B \\
3 & A & D & C \\
4 & A & C & D \\
5 & B & A & C \\
6 & B & C & A \\
7 & B & C & D \\
8 & B & D & C \\
9 & C & A & B \\
10 & C & B & A \\
11 & C & B & D \\
12 & C & D & B \\
13 & D & B & A \\
14 & D & A & B \\
15 & D & A & C \\
16 & D & C & A \\
\hline \hline
\end{tabular}

For each morphing maneuver, each module in the morphing wing may undergo one of the 16 actuation paths. Therefore, if there are three modules, there can be a potential for 4096 different actuation paths. Depending on the optimization objectives, the ideal actuation path may be different. Some optimization objectives include the minimal use of actuation energy or maximal structural stiffness. Here, the objective is the maximization of aircraft longitudinal stability. 


\subsection{Kinematic Actuation}

Given the system is composed of one base platform, and three additional movable platforms, between each platform will be a spherical joint attached to a prismatic actuator. Each module is comprised of the spherical joint and the prismatic actuator, and thus, the system at hand will consist of three modules. For each module, there will be four degrees-of-freedom, giving the system a total of twelve degrees-of-freedom.

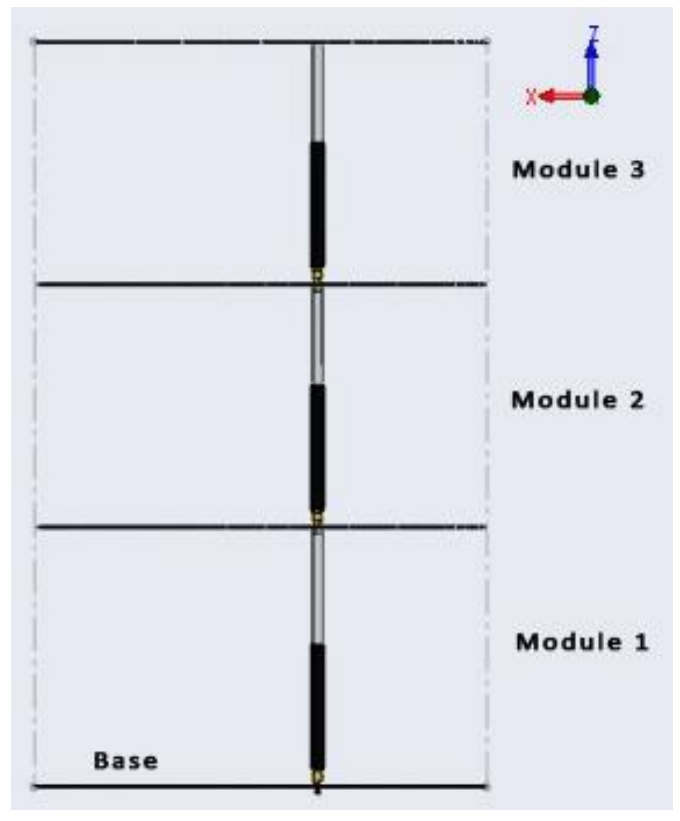

Figure 16: Three module system simplified to one prismatic joint and one spherical joint per module For convention, the $\mathrm{z}$-axis will be defined in Figure 16 to be the vector perpendicular to the base, while $\mathrm{x}$ and $\mathrm{y}$-axes will be parallel to the base where the $y$-axes is out of the page, also parallel to the base. The pose of the system in Figure 16 will be the initial configuration. The default length of each actuator (black) is of fixed length while it can be assumed the actuator arm can extend an additional length (gray). For the spherical joints, they have a maximum rotation limit in the $\mathrm{x}$ and y direction. Rotation along the z-axis can be considered negligible as it would provide no physical movement other than to allow for planar rotation of the platforms. If we rotate Figure 16, we can obtain a view that resembles more like an aircraft wing, shown in Figure 17 below. 
Taking the furthest platform in Figure 17 to be the base platform and considering it to be the wing root, the conclusions in Table 3 can be drawn.

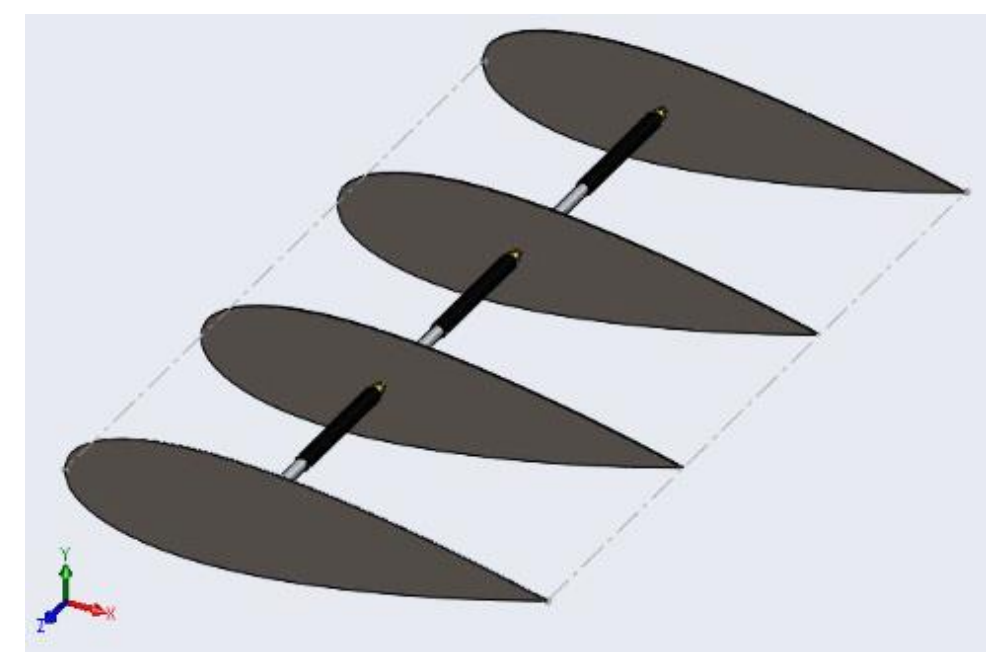

Figure 17: Trimetric view of the simplified VGTMs, resembling an aircraft wing

Table 3: Wing morphing dimensions to mobility translation

\begin{tabular}{c|lc|}
$\begin{array}{c}\text { Wing Morphing } \\
\text { Dimension }\end{array}$ & Mobility Translation & Nomenclature \\
\hline Sweep & Rotation around y-axis & $\theta_{y}$ \\
Span & Extension along z-axis & $s_{i} z_{i}$ \\
Twist & Rotation around z-axis & $\theta_{z}$ \\
Dihedral & Rotation around x-axis & $\theta_{x}$ \\
\cline { 2 - 3 } & &
\end{tabular}

\subsubsection{Position Analysis}

To begin, the limitation of the prismatic actuators is its minimum length while retracted and a maximum length which is equal to its actuator stroke length. The spherical joints also have their limits of rotations in certain directions. For these theoretical analyses, the importance is in recognizing the existence of limitations; the quantitative values of limitations are less significant. For one 
module, the rotation of the first platform is dependent on the rotation of the one spherical joint, and can be obtained with [43],

$$
\begin{aligned}
\mathbf{R}\left(\theta_{\mathrm{x}}\right) & =\left[\begin{array}{ccc}
1 & 0 & 0 \\
0 & \cos \theta_{\mathrm{x}} & -\sin \theta_{\mathrm{x}} \\
0 & \sin \theta_{\mathrm{x}} & \cos \theta_{\mathrm{x}}
\end{array}\right] \\
\mathbf{R}\left(\theta_{\mathrm{y}}\right) & =\left[\begin{array}{ccc}
\cos \theta_{\mathrm{y}} & 0 & \sin \theta_{\mathrm{y}} \\
0 & 1 & 0 \\
-\sin \theta_{\mathrm{y}} & 0 & \cos \theta_{\mathrm{y}}
\end{array}\right] \\
\mathbf{R}\left(\theta_{\mathrm{z}}\right) & =\left[\begin{array}{ccc}
\cos \theta_{\mathrm{z}} & -\sin \theta_{\mathrm{z}} & 0 \\
\sin \theta_{\mathrm{z}} & \cos \theta_{\mathrm{z}} & 0 \\
0 & 0 & 1
\end{array}\right] \\
\mathbf{R} & =\mathbf{R}\left(\theta_{\mathrm{x}}\right) \mathbf{R}\left(\theta_{\mathrm{y}}\right) \mathbf{R}\left(\theta_{\mathrm{z}}\right)
\end{aligned}
$$

The first platform position can therefore be obtained by multiplying the joint rotation matrix with the one prismatic joint. For this serial robot, the prismatic joint can only extend in the z-axis, resulting in

$$
\mathbf{P}=\mathbf{h}+\mathbf{R b}^{\prime}
$$

For the equation above, $\mathbf{P}$ is the position of the first platform, $\mathbf{R}$ as the rotation matrix and $\mathbf{b}^{\prime}$ to be the transpose of the prismatic joint. Here, $\mathbf{h}$ is the default starting position, but since we can assume the robot base point is located at the origin, this term is dropped. For additional modules, each position is calculated with a rotation matrix and multiplied by the length of the link. Thus, for this three module morphing wing, the equation to obtain the final tip position will be given as [43], 


$$
\mathbf{P}_{\text {tip }}=\mathbf{R}_{\mathbf{0 1}} \mathbf{b}_{1}^{\prime}+\mathbf{R}_{\mathbf{0 1}} \mathbf{R}_{\mathbf{1 2}} \mathbf{b}_{\mathbf{2}}^{\prime}+\mathbf{R}_{\mathbf{0 1}} \mathbf{R}_{\mathbf{1 2}} \mathbf{R}_{\mathbf{2 3}} \mathbf{b}_{\mathbf{3}}{ }^{\prime}
$$

\subsubsection{Velocity Analysis}

Using basic kinematics, the velocity can be obtained by taking the first derivative of the position function with respect to time. Using the equations in Chapter 3.2.1, taking the first derivative and simplifying, it can be said that the velocity of this serial robot can be obtained by [43],

$$
\mathbf{V}_{\text {tip }}=\mathbf{V}_{0}+\left(\boldsymbol{\omega}_{1} \times \mathbf{b}_{1}\right)+\left(\boldsymbol{\omega}_{2} \times \mathbf{b}_{2}\right)+\left(\boldsymbol{\omega}_{3} \times \mathbf{b}_{3}\right)
$$

Where,

$$
\begin{gathered}
\boldsymbol{\omega}_{3}=\left(\mathbf{R}_{\mathbf{0 1}} \dot{\mathbf{b}}_{\mathbf{1}}^{\prime}\right)+\left(\mathbf{R}_{\mathbf{0 1}} \mathbf{R}_{\mathbf{1 2}} \dot{\mathbf{b}}_{\mathbf{2}}^{\prime}\right)+\left(\mathbf{R}_{\mathbf{0 1}} \mathbf{R}_{\mathbf{1 2}} \mathbf{R}_{\mathbf{2}} \dot{\mathbf{b}}_{\mathbf{3}}^{\prime}\right) \\
\boldsymbol{\omega}_{2}=\left(\mathbf{R}_{\mathbf{0 1}} \dot{\mathbf{b}}_{\mathbf{1}}^{\prime}\right)+\left(\mathbf{R}_{\mathbf{0 1}} \mathbf{R}_{\mathbf{1 2}} \dot{\mathbf{b}}_{\mathbf{2}}^{\prime}\right) \\
\boldsymbol{\omega}_{1}=\left(\mathbf{R}_{\mathbf{0 1}} \dot{\mathbf{b}}_{\mathbf{1}}^{\prime}\right)
\end{gathered}
$$

\subsubsection{Significance of Kinematic Analyses}

Through the use of the position analyses, one is able to control the robot and move it into a desired position. With the velocity analysis included, the robot is able to move into a desired position through a desired actuation path. Along with these characteristics, it is helpful to generate a robot workspace. The robot workspace is compiled volume of space in which the robot is allowed movement. It can be computed point by point and displayed as a rough graph or generated very accurately by plotting functions. Here, the methods above are utilized and points 
are plotted while MATLAB functions are used to connect the points together to generate a full volume 3-D graph.

The following are three figures that show the workspace of one, two, and three modules assumed as a serial robot in this report. The workspace is generated by using nested loop functions with restrictions to first save all the potential points that the platforms can reach. Afterwards, the points are plotted and a function called convex hull is used to connect these points to form a rough surface. As such, these workspaces are a rough estimation and not fully developed. However, these workspaces give a general idea of what the module mobility limits are.

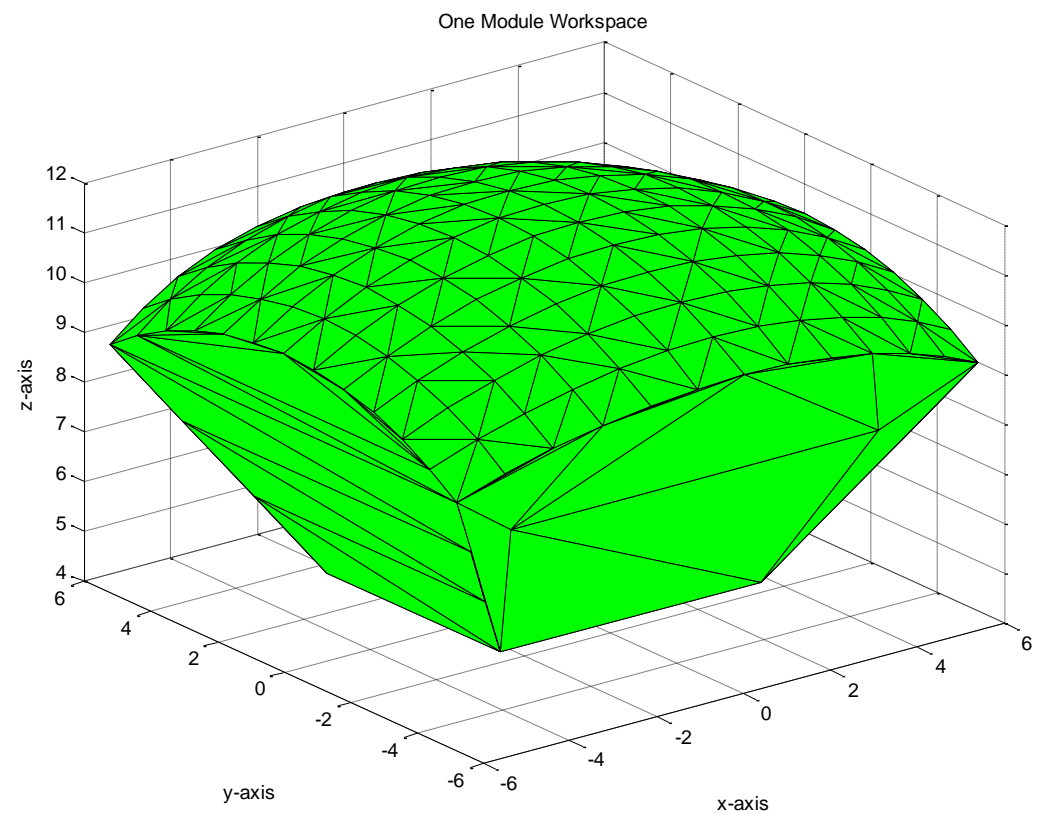

Figure 18: Module workspace for one module (first platform mobility) 


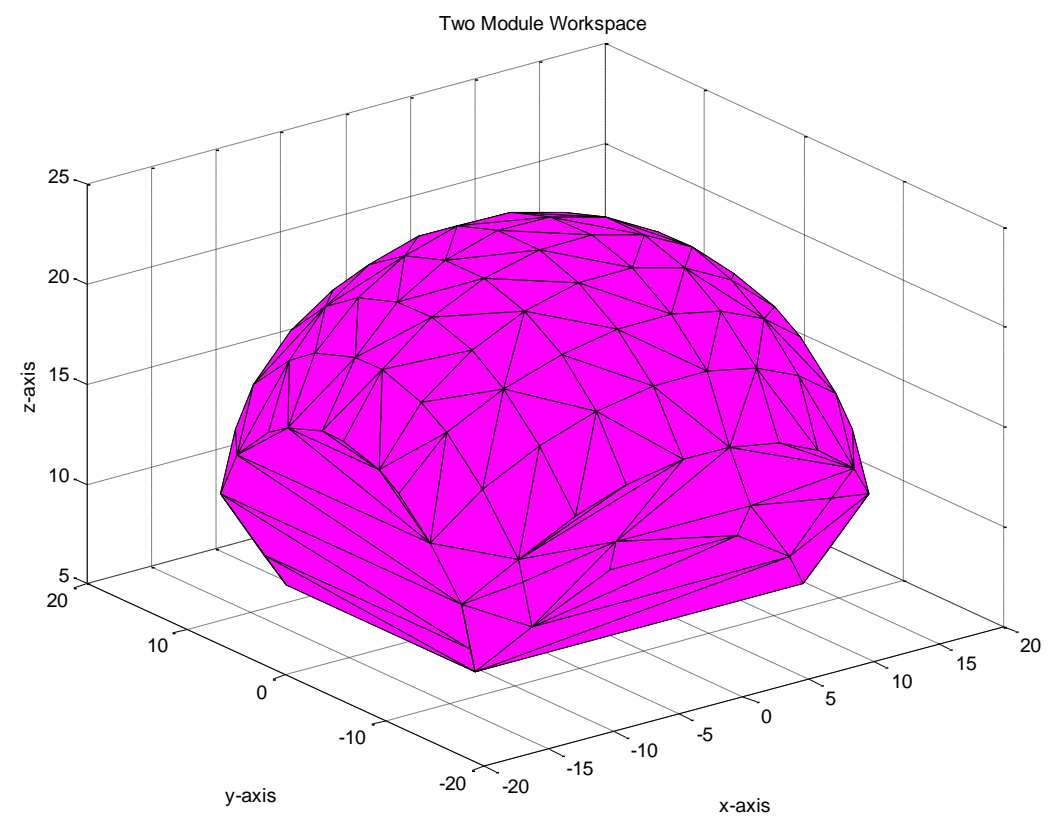

Figure 19: Module workspace for two modules (second platform mobility)

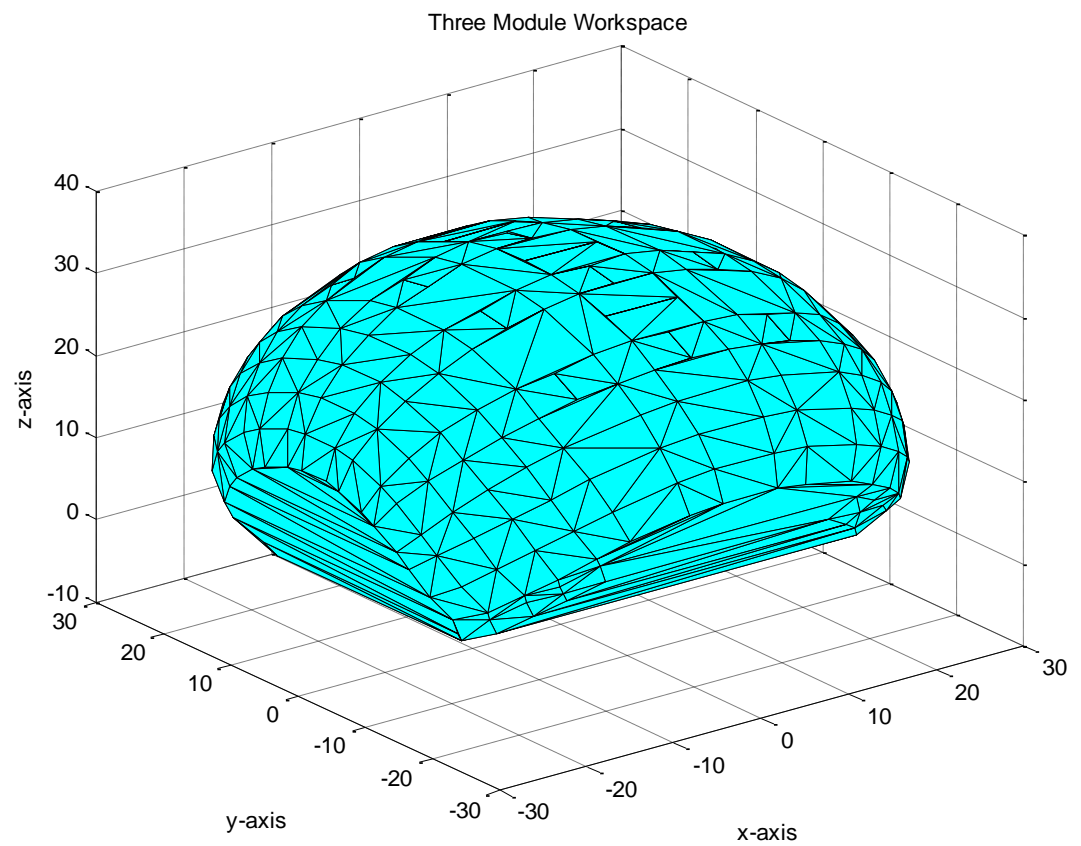

Figure 20: Module workspace for three modules (tip platform mobility) 
It can be seen that the workspace enlarges with each module in terms of distance and total rotation angle, which is what we would expect. If we were to make the figures transparent in order to compare the additional volume of the workspace, we would find the following,

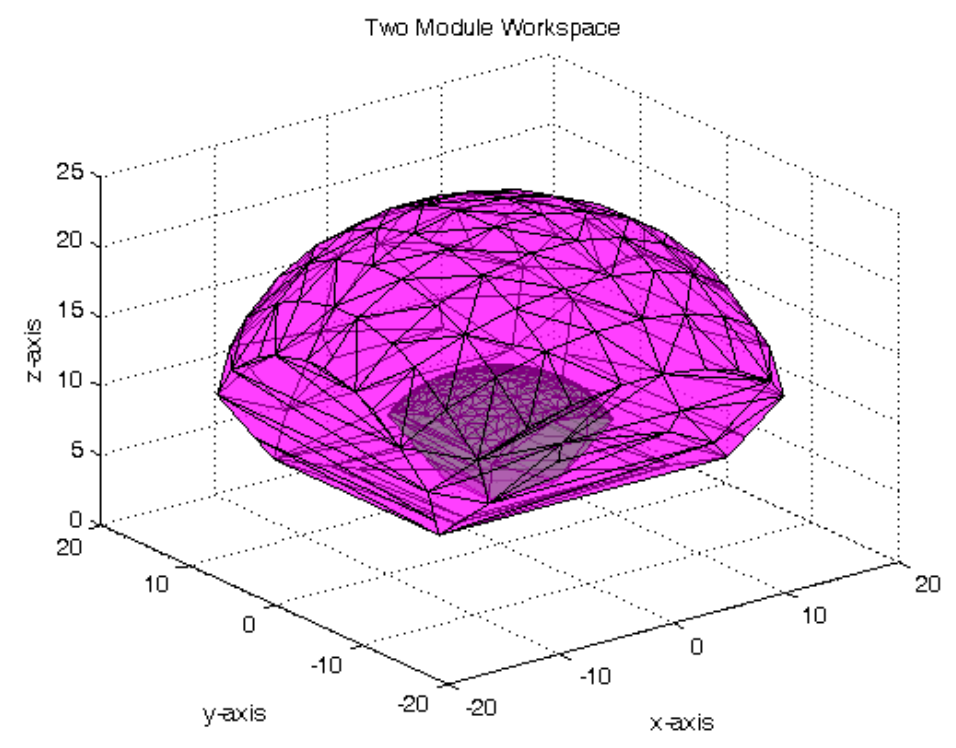

Figure 21: Module workspace volume comparison of two modules

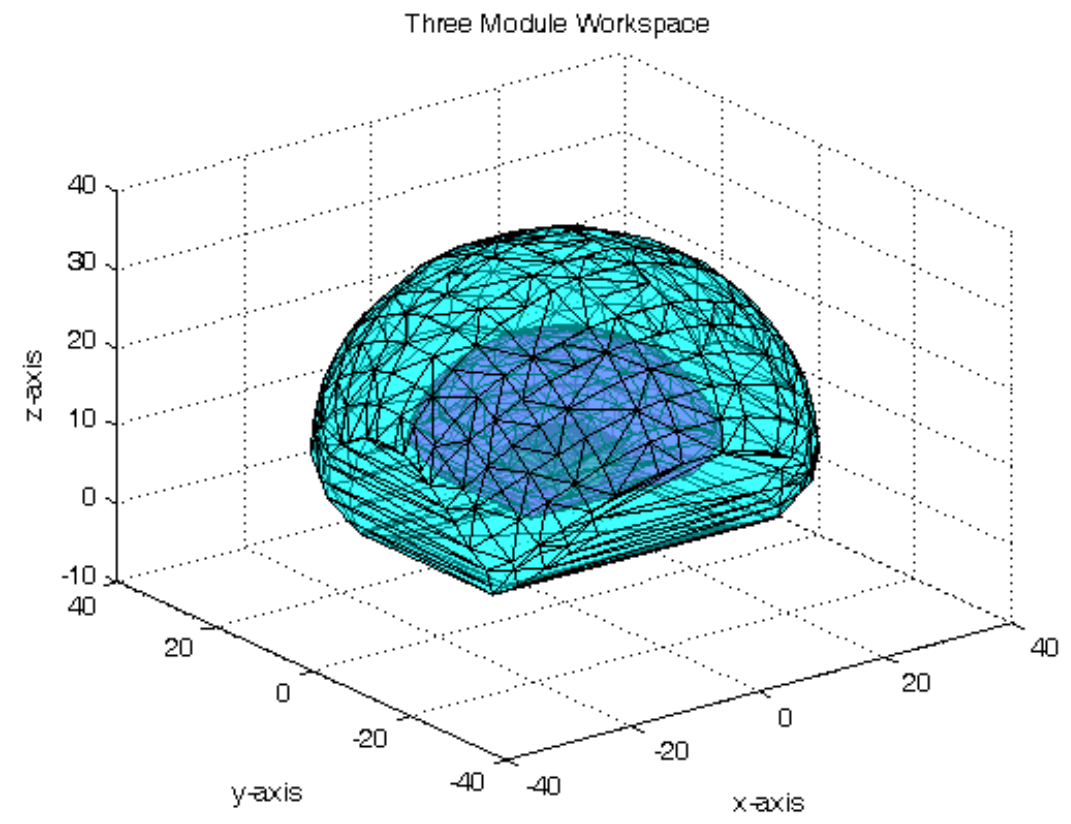

Figure 22: Module workspace volume comparison of three modules 
The intersections of the grid are the plotted points obtained from MATLAB via the position calculations used in Chapter 3.2.1. The triangular patterns are generated by the convex hull command. Figure 21 and 22 offer a comparison of the additional volume in the robot workspace when an additional module is added. For every module, the workspace increases substantially, and greater range and flexibility of motion can be achieved.

The objective to determining the robot workspace is to understand the limits of the robot and its working area. With this information, the limit of the range of motion of the three module morphing wing can be factored in for topics such as aircraft performance and control. In terms of aircraft performance, this workspace defines a finite amount of movement for the three module wing and which may limit certain aerodynamic considerations. For controls, this workspace defines the boundaries of which the three module wing cannot exceed. 


\section{Chapter 4}

\section{Longitudinal Stability Analysis}

Stability is the tendency of the aircraft to return to its equilibrium position after it has been disturbed [44]. The disturbance can be caused by actions within the aircraft or by atmospheric disturbances. Actions within the aircraft could be actions of the pilot or shifting of masses such as passengers or cargo while atmospheric disturbances include wind gusts and turbulence. In order for the aircraft to fly successfully, it must be capable of performing equilibrium flight and perform adaptive maneuvers.

Static stability is non-time dependent, and it is best described as the tendency of the aircraft to smoothly return to its equilibrium position after a disturbance; i.e. with no oscillation around the stability point. As static stability is not time dependent, upon examining a set of parameters for that instance in time will allow for the determination of the tendency. The following illustration demonstrates this idea. If the ball was disturbed, according to the external factors, the snapshot of the ball's disturbed state can allow a deduction of whether the system is stable. 

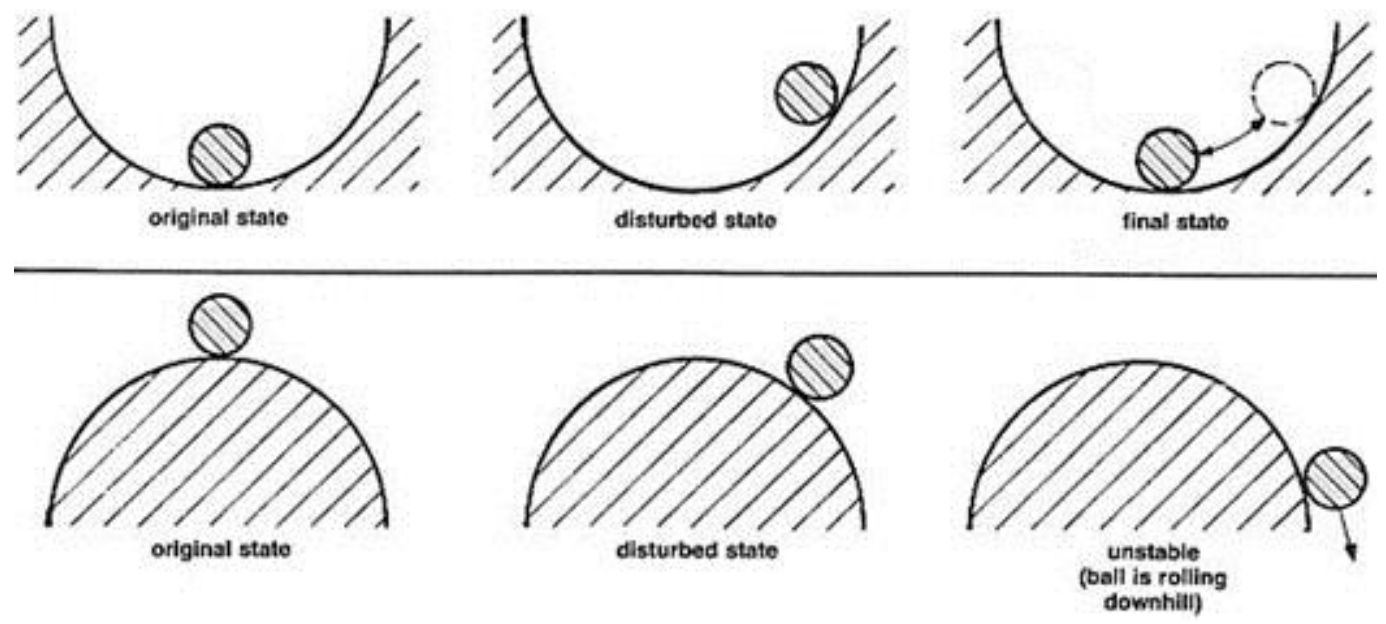

Figure 23: Drawing to illustrate the tendency of stability [44]

The top set of images illustrate that the system is stable, that after a disturbance, the system will return to its initial configuration. The bottom set of images illustrates the opposite; that the system will not return to its initial position and is thus unstable. This is the context of stability and it does apply for the case of an aircraft. For an aircraft in flight, there are three dimensions of rotation: roll, pitch and yaw. Roll is the rotation around the longitudinal axis, which runs from the tail to the nose of the aircraft.

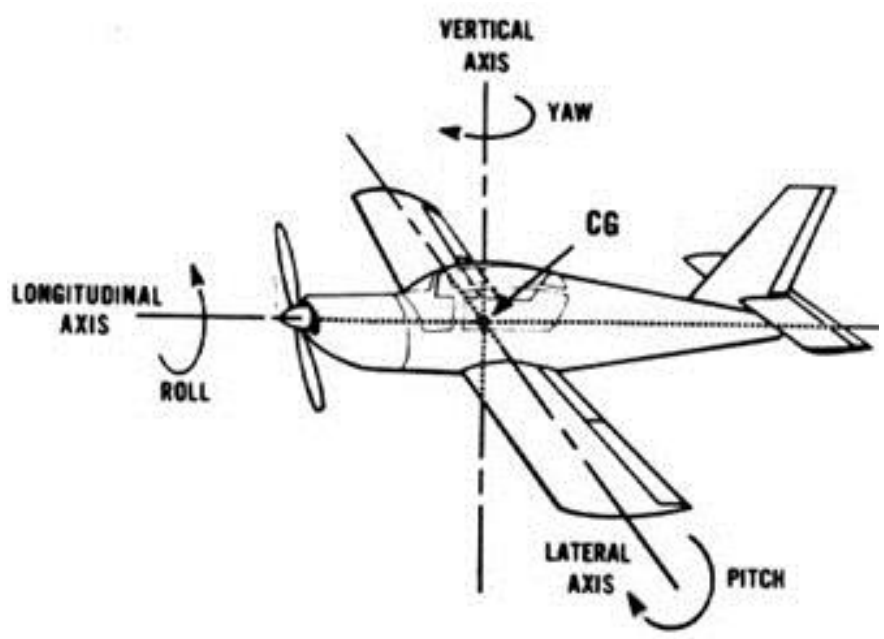

Figure 24: Aircraft principal axes and their dimensions of rotation 
Figure 24 illustrates the principal axes and the dimensions of rotation for an aircraft. Pitch is the rotation around the lateral axis, which runs from one wingtip to the other; while yaw is the rotation around the vertical axis, which runs from the top to the bottom of the aircraft. To achieve the goal of equilibrium flight, control surfaces are used to alter aerodynamics around the aircraft to maintain flight to mitigate disturbances or to perform maneuvers. The control of all three dimensions is very important; however, the present study is focused on the pitching stability, or, the stability in the longitudinal direction.

During flight, various forces act on the aircraft and displace the aircraft from its original position. If the aircraft is stable, it will have a tendency to return to its original position; otherwise, the aircraft is unstable. For instance, if one looks solely at longitudinal static stability, when a downward gust is applied onto the aircraft and decreases its angle of attack, the aircraft needs to develop a nose-up pitching moment to counteract the gust and rotate back to its trim position. Similarly, a nose-down pitching moment is necessary to counteract upward gust forces. Thus, for an aircraft to have static stability, the pitching moment curve must have a negative slope. Also, to maintain the aircraft at trim position, the aircraft needs to pitch upwards with a positive angle of attack [10]. Given this, we have the conditions of $\frac{\partial \mathrm{C}_{\mathrm{m}}}{\partial \alpha}<0$ and $\frac{\partial \mathrm{C}_{\mathrm{m}}}{\partial \mathrm{C}_{\mathrm{L}}}<0$, where $\mathrm{C}_{\mathrm{m}}$ and $\mathrm{C}_{\mathrm{L}}$ are coefficients of pitching moment and lift, $\alpha$ is angle of attack. Looking only at the wing, the diagram for static stability analysis is shown in Figure 25. From theory, through the assumption of a small angle of attack and considering that vertical contributions are negligible; the 
formula that results to the wing satisfying the condition for static stability is as follows,

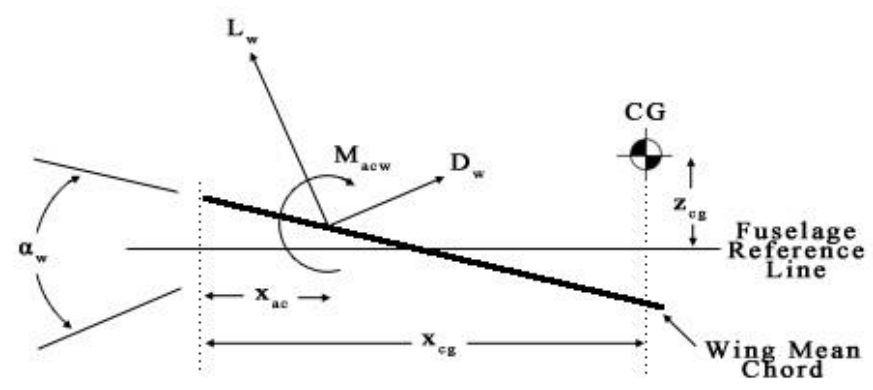

Figure 25: Free body diagram of wing contribution to aircraft pitching

$$
\mathrm{C}_{\mathrm{m}_{\mathrm{w}}}=\mathrm{C}_{\mathrm{m}_{\mathrm{ac}}}+\left(\mathrm{C}_{\mathrm{L}_{\mathrm{w}}}+\frac{\partial \mathrm{C}_{\mathrm{L}}}{\partial \alpha_{\mathrm{w}}} \alpha_{\mathrm{w}}\right)\left(\frac{\mathrm{x}_{\mathrm{cg}}}{\overline{\mathrm{c}}}-\frac{\mathrm{x}_{\mathrm{ac}}}{\overline{\mathrm{c}}}\right)
$$

Where the subscripts ac refer to the aerodynamic center, cg is the center of gravity, and $w$ is the wing. As for coefficients, $\mathrm{C}_{\mathrm{m}}$ is the coefficient of moment, $\mathrm{C}_{\mathrm{Lo}}$ is the coefficient of lift at zero angle of attack, $\bar{c}$ is the mean chord, $\alpha$ is the angle of attack, $\mathrm{x}_{\mathrm{cg}}$ is distance between leading edge and center of gravity, and $\mathrm{x}_{\mathrm{ac}}$ is distance between leading edge and aerodynamic center.

\subsection{Criteria for Static Longitudinal Stability}

For a conventional aircraft with a horizontal stabilizer, the governing expression for its longitudinal static stability is given as,

$$
\frac{\partial \mathrm{C}_{\mathrm{m}}}{\partial \alpha}<0
$$

Equation (4.2) states that the change in coefficient of pitching moment for each change in angle of attack must be negative. This is to ensure that the aircraft 
will rotate back to equilibrium position after any small disturbance. In the context of longitudinal static stability, the instance that the angle of attack is changed due to a disturbance, the aircraft requires its coefficient of pitching moment to return the aircraft back to equilibrium position. In order to achieve this criterion, we can look at the full equation [10],

$$
\frac{\partial \mathrm{C}_{\mathrm{m}}}{\partial \alpha}=\frac{\partial \mathrm{C}_{\mathrm{L}}}{\partial \alpha_{\mathrm{w}}}\left(\frac{\mathrm{x}_{\mathrm{cg}}}{\overline{\mathrm{c}}}-\frac{\mathrm{x}_{\mathrm{ac}}}{\overline{\mathrm{c}}}\right)+\frac{\partial \mathrm{C}_{\mathrm{m}}}{\partial \alpha_{\mathrm{f}}}-\eta \mathrm{V}_{\mathrm{H}} \frac{\partial \mathrm{C}_{\mathrm{L}}}{\partial \alpha_{\mathrm{t}}}\left(1-\frac{\partial \varepsilon}{\partial \alpha}\right)
$$

Where the subscripts $f$ is the fuselage and $t$ is the tail. Other coefficients include: $\eta$ is the tail efficiency, $\mathrm{V}_{\mathrm{H}}$ being the horizontal tail volume ratio, $\alpha$ is angle of attack and $\varepsilon$ is the downwash angle. From Equation (4.3), there are three terms on the right side to manipulate to obtain our desired criterion. The first term is related to the main wing, the second term is related to the coefficient of moment and the angle of attack of the fuselage while the last term is regarding the horizontal stabilizer. Thus, one can see that to obtain the criterion, the two most evident methods are to increase the distance between the center of gravity and aerodynamic center with the aerodynamic center behind the center of gravity and to increase performance of the horizontal stabilizer. For this thesis, we are most interested on effects of stability in relation to the modular wing itself, thus, treating the fuselage and horizontal stabilizer contributions as constants, equation can be slightly rewritten to be,

$$
\frac{\partial \mathrm{C}_{\mathrm{L}}}{\partial \alpha_{\mathrm{w}}}\left(\frac{\mathrm{x}_{\mathrm{cg}}}{\overline{\mathrm{c}}}-\frac{\mathrm{x}_{\mathrm{ac}}}{\overline{\mathrm{c}}}\right)+\frac{\partial \mathrm{C}_{\mathrm{m}}}{\partial \alpha_{\mathrm{f}}}-\eta \mathrm{V}_{\mathrm{H}} \frac{\partial \mathrm{C}_{\mathrm{L}}}{\partial \alpha_{\mathrm{t}}}\left(1-\frac{\partial \varepsilon}{\partial \alpha}\right)<0
$$


The last piece of information required is the location of the neutral point. The neutral point is defined as the "aerodynamic center of the entire aircraft". To obtain this position, we can set $\frac{\partial \mathrm{C}_{\mathrm{m}}}{\partial \alpha}$ to zero and reducing,

$$
\frac{\partial \mathrm{C}_{\mathrm{m}}}{\partial \alpha}=\frac{\partial \mathrm{C}_{\mathrm{L}}}{\partial \alpha}\left(\mathrm{x}_{\mathrm{cg}}-\mathrm{x}_{\mathrm{np}}\right)
$$

From this equation, a new parameter can be derived, known as the static margin,

$$
\mathrm{K}_{\mathrm{n}}=\mathrm{x}_{\mathrm{np}}-\mathrm{x}_{\mathrm{cg}}
$$

The static margin allows us to predict whether a wing morph will make the aircraft more or less stable. However, depending on the flight mission and the objective of the aircraft, stability may not be a goal. Assuming the aircraft is in equilibrium prior to a wing morph procedure, if the static margin increases during and after the wing morphing, the aircraft is more statically stable than prior to wing morphing. Performance-wise, instead of focusing on whether the aircraft is stable or unstable, it is more beneficial to seek the least change in the static margin due to morphing.

It can be assumed that the neutral point is equal to the aerodynamic center of the center chord. Given the above theory, the analysis for static stability will be based on the change in static margin during and after a wing morph maneuver. 


\subsection{Static Margin}

In order to obtain the change in the static margin, we need to find the change in the location of the center of gravity and the aerodynamic center of the aircraft. To do this, we need to further assume that the wings are tapered, and that external parameters such as planform area and length of each module are known. From Figure 26, the location of center of gravity is drawn whereas the aerodynamic center is not drawn due to its dependency on the airfoil shape. However, both of these points lie on the same chord, known as the mean aerodynamic chord. If the wing was to be simply represented as a rectangular wing with a constant chord, the mean aerodynamic chord would be that average chord. Therefore, the mean aerodynamic chord is important in its length as well as its location.

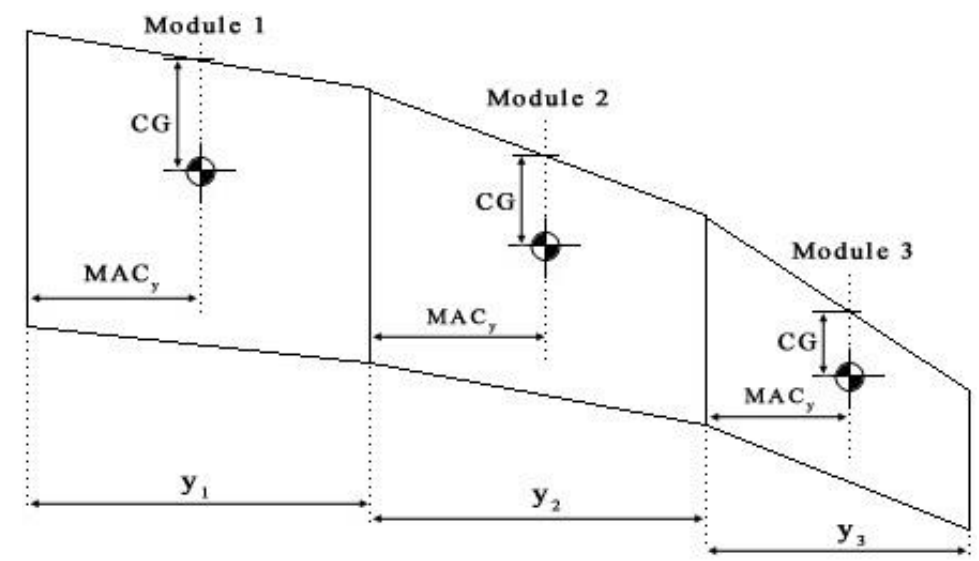

Figure 26: Visual representation of CG and mean aerodynamic chord distance in the wingspan direction

\subsection{Motion Planning}

With a three module morphing wing, there will be a total of $16^{3}$, or 4096 , number of possible actuation paths. In order to determine the best possible 
actuation path from longitudinal stability point of view, the series of criteria will be applied on to every actuation path. The desire is to obtain the change in static margin for every configuration and to compare them. Building on the theory of static margin for longitudinal stability, the difference and change in static margin will be the basis of the selection criteria.

From the initial configuration to the final configuration, recall that there are two interim poses in between, making every actuation process a sequence of three smaller movements. For the initial position, the static margin is calculated. Then for the first interim pose, the static margin is also calculated, and the difference is obtained. Until the morphing wing reaches the final configuration, the static margin is calculated at every interim pose and the difference in static margin is calculated. Afterwards, these differences are averaged out to determine an average change in the static margin for the one actuation path. Due to the large number of actuation paths, there will be several configurations that yield the same locations of aerodynamic centers and center of gravities. This means that the average static margin will be very similar or even identical among several actuation paths. To further refine the results, we introduce standard deviation such that to determine which actuation paths have the least amount of displacement change.

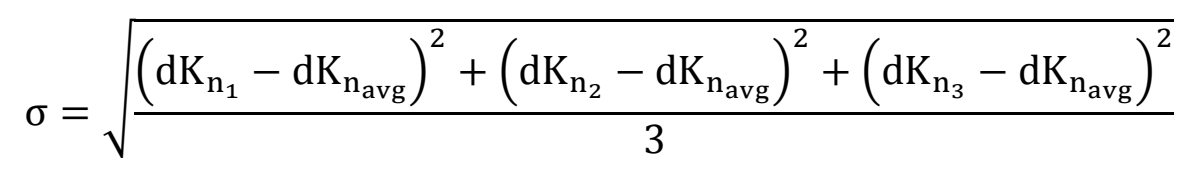

Here, for the standard deviation, $\mathrm{dK}_{\mathrm{n}_{1}}$ is the difference in static margin between the first interim pose and the initial configuration. Similarly, $\mathrm{dK}_{\mathrm{n}_{2}}$ is the 
difference in static margin between the second and first interim poses and $d_{\mathrm{n}_{\text {avg }}}$ is the average difference in static margins for the all three stages of movement.

Usually, a lower difference between the static margins for each wing morph, the greater the stability for the maneuver. However, this is dependent on other external factors such as: tail forces, desired performance, and build of the aircraft.

\subsection{Additional Considerations}

In addition to the theory described above, due to the nature of the morphing wing, there are several factors that have been considered. Whether or not the topics are discussed and analyzed depend on the depth of the topic and scope of its considerations.

The change in lift force is one major consideration in aircraft stability. For each morphing maneuver, the aerodynamic characteristics around the wing will change and compensating calculations will have to be applied for accurate results. Depending on complexity and accuracy of results, one could apply thorough analyses such as the lift distribution for each element of each module. In the scope of this thesis, basic approximate compensation techniques will be used.

For instance, the general idea of span elongation will increase the surface area of the wing and increase overall lift as a result. The obvious consideration for span would be the increase in skin friction. However, since this thesis does not take 
into account the properties of the skin, these considerations are outside the scope of this thesis.

Regarding the change of dihedral or cant, this thesis assumes that the lift force is undisturbed. However, in reality, the change in dihedral would affect the stability of the aircraft in several ways. One effect is that the lift force is reduced. When dihedral is introduced, the lift force is directed slightly towards the fuselage of the aircraft (or away from the fuselage in negative dihedral), meaning the supposed lift force used in longitudinal stability calculations should be multiplied by the cosine of the dihedral angle. Furthermore, the introduction of dihedral also introduces distance in the z-direction between the $\mathrm{x}$-directional wing axis and tail axis. The significance is that the drag forces of the wing and tail will now generate a moment around the center of gravity of the aircraft and thus affecting longitudinal stability. The above effects are not considered in this study.

Positive wing sweep moves the aerodynamic center and the center of gravity further aft of the aircraft. The dramatic shift of these locations and their effects are considered within the calculations in this thesis. Yet, a less intuitive effect of wing sweep is its effect on lift distribution of the wing. The lift distribution is affected because sweep affects the velocity seen at the wing tips. This results in an increased lift generation at the wingtips and reduced lift generation near the wing root. [47]

When the wing twist maneuver is performed, it changes the angle of attack at the module that wing twist is applied. As the coefficient of lift is an airfoil characteristic and changes with the angle of attack, an airfoil must first be chosen. 
Also, depending on the magnitude of twist, it is possible that this maneuver shifts the aerodynamic center or center of gravity slightly fore or aft along the aircraft. For this thesis, neither of the above is considered because the airfoil is arbitrary with an aerodynamic center at quarter-chord point and thus no dependable analyses can be performed.

Further, the exact weight distribution in each module was not taken into account. Taking into account weight fluctuations of the actuator while it is retracted and extended, brackets, nuts and bolts would be too onerous and would not produce a large contribution to the result of the analyses. 


\section{Chapter 5}

\section{Computational Methods}

The methods used in this thesis to obtain the aerodynamic center and center of gravity are based on the theory of the discretized modular wing as shown below.

\subsection{Aerodynamic Center}

For a regular half-wing with a constant airfoil shape along with knowledge of the airfoil characteristics, the equation to obtain the aerodynamic center in the longitudinal ( $x$-direction) is given by [45]

$$
\overline{\mathrm{x}}=\frac{2}{\mathrm{C}_{\mathrm{L}} \mathrm{S}} \int_{0}^{\frac{\mathrm{b}}{2}} \frac{\partial \mathrm{C}_{\mathrm{L}}}{\partial \alpha}(\mathrm{y}) \cdot \mathrm{c}(\mathrm{y}) \cdot \mathrm{x}(\mathrm{y}) \cdot \mathrm{dy}
$$

Thus, if each module of the morphing wing uses the same airfoil shape, for a three module wing we can change the above integral into three piecewise integrals. 


$$
\begin{array}{r}
\overline{\mathrm{x}}=\frac{2}{\mathrm{C}_{\mathrm{L}} \mathrm{S}}\left(\int_{0}^{\mathrm{m}_{1}} \frac{\partial \mathrm{C}_{\mathrm{L}}}{\partial \alpha}(\mathrm{y}) \cdot \mathrm{c}(\mathrm{y}) \cdot \mathrm{x}(\mathrm{y}) \cdot \mathrm{dy}_{\mathrm{m}_{1}}\right. \\
+\int_{\mathrm{m}_{1}}^{\mathrm{m}_{2}} \frac{\partial \mathrm{C}_{\mathrm{L}}}{\partial \alpha}(\mathrm{y}) \cdot \mathrm{c}(\mathrm{y}) \cdot \mathrm{x}(\mathrm{y}) \cdot \mathrm{dy}_{\mathrm{m}_{2}} \\
\left.+\int_{\mathrm{m}_{2}}^{\mathrm{m}_{3}} \frac{\partial \mathrm{C}_{\mathrm{L}}}{\partial \alpha}(\mathrm{y}) \cdot \mathrm{c}(\mathrm{y}) \cdot \mathrm{x}(\mathrm{y}) \cdot \mathrm{dy}_{\mathrm{m}_{3}}\right)
\end{array}
$$

Where $\frac{\partial \mathrm{C}_{\mathrm{L}}}{\partial \alpha}$ is the lift curve slope for the local module, $c(y)$ is the chord length at each location $\mathrm{y}$, and $\mathrm{x}(\mathrm{y})$ is the distance between the aerodynamic center of local chord $\mathrm{y}$ and the wing apex. Here, the wing apex is the leading edge of the wing root. $\mathrm{S}$ is the planform area of the entire half-wing, and $C_{L}$ is the coefficient of lift for the whole half-wing. To obtain the overall $\mathrm{C}_{\mathrm{L}}$, using basic principles and manipulating, we obtain

$$
\mathrm{C}_{\mathrm{L}}=\frac{\mathrm{C}_{\mathrm{L}_{1}} \mathrm{~S}_{1}+\mathrm{C}_{\mathrm{L}_{2}} \mathrm{~S}_{2}+\mathrm{C}_{\mathrm{L}_{3}} \mathrm{~S}_{3}}{\mathrm{~S}_{1}+\mathrm{S}_{2}+\mathrm{S}_{3}}
$$

However, this equation requires the knowledge of airfoil characteristics, $\frac{\partial \mathrm{C}_{\mathrm{L}}}{\partial \alpha}$, which is determined based on the performance of the selected airfoil. Depending on the airfoil (such as symmetrical airfoil, supercritical airfoil, and so forth), the value of $\frac{\partial \mathrm{C}_{\mathrm{L}}}{\partial \alpha}$ will be different. Recall that it can be assumed that the aerodynamic center lies on the same plane as the mean aerodynamic chord and that the aerodynamic center is approximately $25 \%$ chord length behind the leading edge. Given this, we can solve for the mean aerodynamic chord and then apply basic trigonometry to obtain the mean aerodynamic center. By definition, the mean aerodynamic chord for a half-wing is given by, 


$$
\bar{c}=\frac{2}{S} \int_{0}^{\frac{b}{2}} c^{2} d y
$$

However, through the use of the $\bar{c}$ equation above, we can simply use the average distance from a reference point, the wing apex, to the local aerodynamic center at every chord element. This will simplify the way to solve for the mean aerodynamic chord. Since each module resembles a tapered wing, to use the equation above, the chord length at each y-coordinate is solved by,

$$
c_{m}(y)=\frac{2 \cdot S_{m}}{\left(1+\lambda_{m}\right) b_{m}}\left(1-\frac{\left(1-\lambda_{m}\right) y}{b_{m}}\right)
$$

Where $\lambda_{m}$ is taper ratio of the module, $S_{m}$ is the surface area of the module and $b_{m}$ is the span of the module. After solving for the mean aerodynamic chord of each module, one must be sure that the $x$-directional distance is made with a common reference point. A helpful reference point is the wing apex. With given sweep angles, the distance between the wing apex and the leading edge of the mean aerodynamic chord can be found, and the $x$ location of the mean aerodynamic center of the module will also be found.

If we want to determine the $x$ location of the aerodynamic center through the use of the aerodynamic chord, in order to find the mean aerodynamic chord for each module, we also treat each module as a wing. To determine the mean aerodynamic chord for a tapered wing as a geometry, for module 1 ,

$$
\mathrm{MAC}_{1}=\frac{2}{3} \mathrm{C}_{\mathrm{r}_{1}}\left(\frac{1+\lambda_{1}+\lambda_{1}^{2}}{1+\lambda_{1}}\right)
$$


Next, we determine the location of the mean aerodynamic chord in the $y$ direction for each module. For module 1, the formula is as,

$$
\bar{y}_{1}=y_{1} \cdot\left(\frac{1+2 \lambda_{1}}{3\left(1+\lambda_{1}\right)}\right)
$$

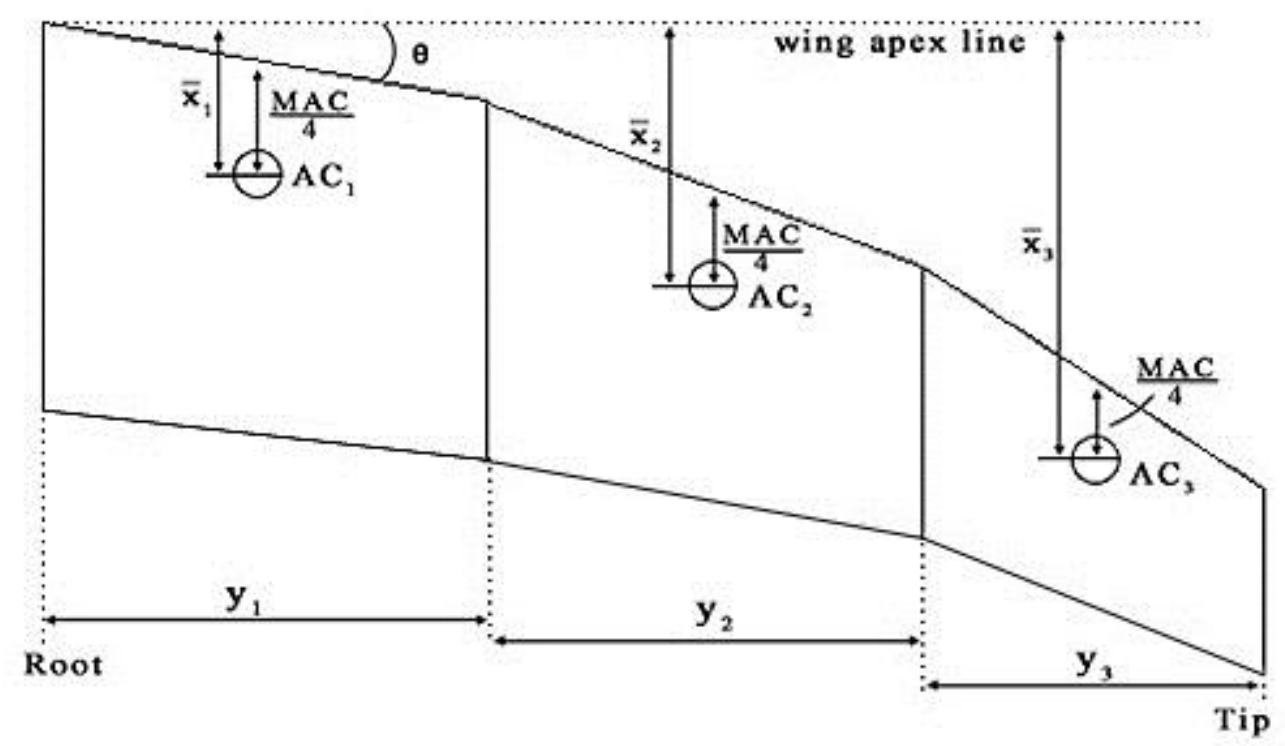

Figure 27: Representation of aerodynamic centers to a reference wing apex line and the mean aerodynamic center chord

Since we are dealing with the aerodynamic center for the entire wing, a common $x$ location must be set as a reference point. Again, we set the wing apex. The $x$-direction distance of each aerodynamic center in modules is measured to be the wing apex, as shown in Figure 27. Assuming that the aerodynamic center lies at quarter chord of the airfoil, again for the first module,

$$
\overline{\mathrm{x}}_{1}=\frac{\mathrm{MAC}_{1}}{4}+\overline{\mathrm{y}}_{1} \tan \theta
$$


Where $\theta$ is the sweep angle of the module. After the $x$-direction of the aerodynamic center is solved for each module, we can apply weighted average to determine the overall location of the mean aerodynamic center. Each module will produce a moment equal to its lift multiplied by the $x$-directional distance from its aerodynamic center to the wing apex. Assuming that the airfoil shape remains constant and that all the modules are in a uniform configuration, the lift of each module is proportional to its planform area, the $x$-direction of the mean aerodynamic center of the three module model is given by,

$$
\overline{\mathrm{x}}=\frac{\mathrm{x}_{1} \mathrm{~S}_{1} \mathrm{C}_{\mathrm{L} \alpha_{1}}+\mathrm{x}_{2} \mathrm{~S}_{2} \mathrm{C}_{\mathrm{L} \alpha_{2}}+\mathrm{x}_{3} \mathrm{~S}_{3} \mathrm{C}_{\mathrm{L} \alpha_{3}}}{\mathrm{~S}_{1} \mathrm{C}_{\mathrm{L} \alpha_{1}}+\mathrm{S}_{2} \mathrm{C}_{\mathrm{L} \alpha_{2}}+\mathrm{S}_{3} \mathrm{C}_{\mathrm{L} \alpha_{3}}}
$$

\subsection{Center of Gravity}

When determining the center of gravity for the morphing wing, we seek the center of gravity of each module. Afterwards, a weighted average can be applied to determine the average location of the center of gravity for all the modules. Given a tapered wing, taking the assumption that the mass axis of each module is at $40 \%$ chord from the leading edge, and that the mass distribution along the span is proportional to the airfoil size, for each module, we have the figure as shown in Figure 28. 


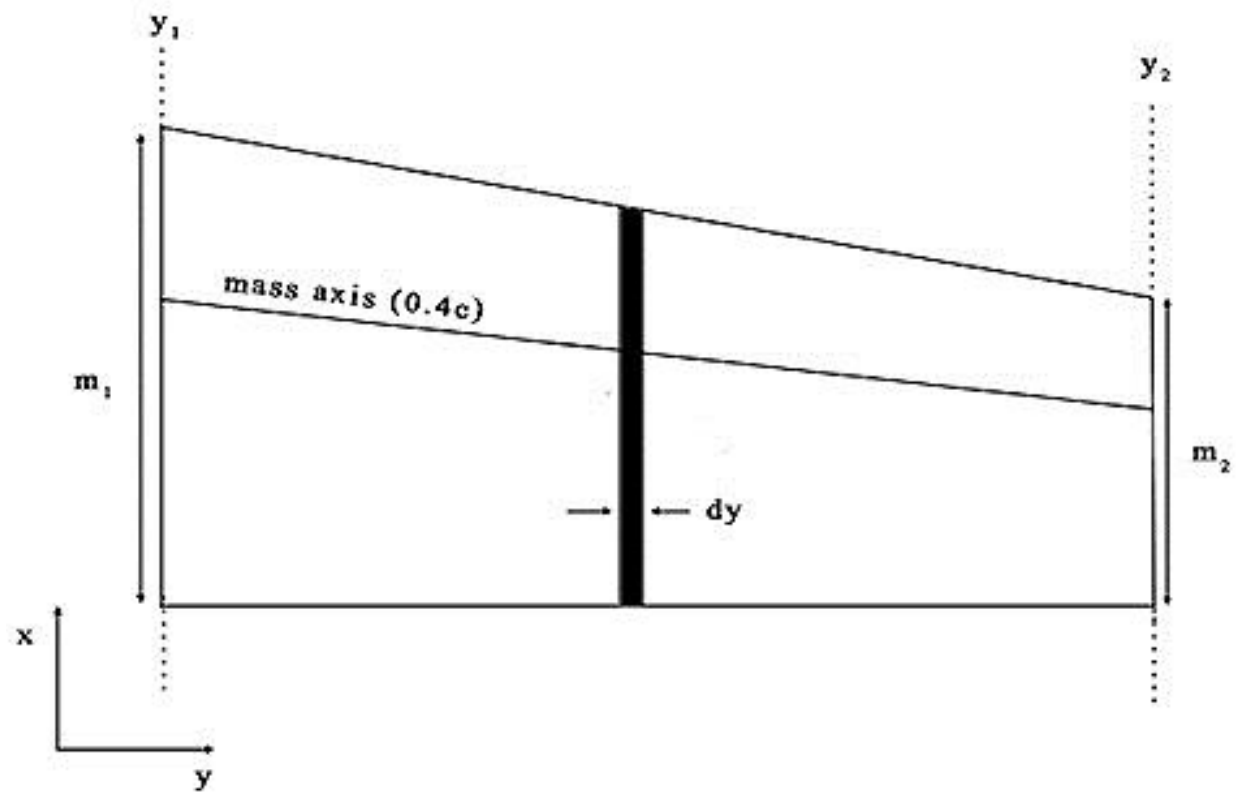

Figure 28: Geometric measurements of one module

It is assumed that the mass distribution in the $y$-direction is proportional to the airfoil size. The equation to solve for the chord length at any location along a tapered wing is given by,

$$
c(y)=\frac{2 S_{w}}{(1+\lambda) b}\left(1-\frac{(1-\lambda) y}{b}\right)
$$

Where $S_{w}$ is the planform area, $b$ is the span distance and $\lambda$ is the taper ratio. The center of mass along the $y$-axis can be obtained by adding the mass of every element $d y$ and dividing it by the mass of the entire module.

$$
\mathrm{cm}_{\mathrm{y}}=\int_{\mathrm{y}_{1}}^{\mathrm{y}_{2}} \frac{\mathrm{ydm}}{\mathrm{M}}=\frac{1}{\mathrm{M}} \int_{\mathrm{y}_{1}}^{\mathrm{y}_{2}} \mathrm{y} \cdot \mathrm{c}(\mathrm{y}) \cdot \rho \mathrm{dy}
$$

Added in the $\rho$ for material density and substituting chord lengths into the center of mass equation, 


$$
\mathrm{cm}_{\mathrm{y}}=\frac{1}{\mathrm{M}} \frac{2 \rho S_{\mathrm{w}}}{(1+\lambda) \mathrm{b}} \int_{\mathrm{y}_{1}}^{\mathrm{y}_{2}}\left(\mathrm{y}-\frac{(1-\lambda) \mathrm{y}^{2}}{\mathrm{~b}}\right) \mathrm{dy}
$$

After performing integration and simplifying, we obtain,

$$
\mathrm{cm}_{\mathrm{y}}=\frac{1}{\mathrm{M}} \frac{2 \rho \mathrm{S}_{\mathrm{w}}}{(1+\lambda) \mathrm{b}}\left[\frac{\left(\mathrm{y}_{2}^{3}-\mathrm{y}_{1}^{3}\right)(\lambda-1)}{3 \mathrm{~b}}+\frac{\left(\mathrm{y}_{2}^{2}-\mathrm{y}_{1}^{2}\right)}{2}\right]
$$

The equation requires the value of total mass of the module, which can be found by,

$$
\mathrm{M}=\int_{\mathrm{y}_{1}}^{\mathrm{y}_{2}} \mathrm{dm}=\int_{\mathrm{y}_{1}}^{\mathrm{y}_{2}} \mathrm{c}(\mathrm{y}) \cdot \rho \mathrm{dy}
$$

Substituting the variation $\mathrm{c}(\mathrm{y})$,

$$
M=\frac{2 \rho S_{w}}{(1+\lambda) b} \int_{y_{1}}^{y_{2}}\left(1-\frac{(1-\lambda) y}{b}\right) d y
$$

And after simplification we have,

$$
M=\frac{2 \rho S_{w}}{(1+\lambda) b}\left[\frac{\left(y_{2}^{2}-y_{1}^{2}\right)(\lambda-1)}{2 b}+\left(y_{2}-y_{1}\right)\right]
$$

Finally, substituting equation (5.16) into equation (5.13) and simplifying, the center of mass can be expressed as,

$$
\mathrm{cm}_{\mathrm{y}}=\frac{2(\lambda-1)\left(\mathrm{y}_{1}^{2}+\mathrm{y}_{1} \mathrm{y}_{2}+\mathrm{y}_{2}^{2}\right)+3 \mathrm{~b}\left(\mathrm{y}_{1}+\mathrm{y}_{2}\right)}{3(\lambda-1)\left(\mathrm{y}_{1}+\mathrm{y}_{2}\right)+6 b}
$$

Since we are only concerned with where the center of gravity is per module, $\mathrm{y}_{1}$ can always be set zero, and $\mathrm{y}_{2}$ is the span of the module. Once the center of gravity along the $y$-axis is determined, we have to find its location in the $x$-axis. Since the mass axis is located at $40 \%$ of the chord length from the leading edge, we locate the $x$ directional value of the center of gravity with respect to a fixed reference point. 
Similar to the aerodynamic center, we use the leading edge wing apex as the reference point, as such, applying basic geometry, we have,

$$
\mathrm{cm}_{\mathrm{x}}=(0.4) \frac{2 \mathrm{~S}_{\mathrm{w}}}{(1+\lambda) \mathrm{b}}\left(1-\frac{(1-\lambda) \mathrm{cm}_{\mathrm{y}}}{\mathrm{b}}\right)+\mathrm{cm}_{\mathrm{y}}\left(\frac{\mathrm{m}_{1}-\mathrm{m}_{2}}{2 \mathrm{~b}}\right)+\mathrm{cm}_{\mathrm{y}} \tan \theta
$$

The first term is the distance between the center of gravity and the leading edge, along the same chord. The second term is the $x$-directional distance between the wing apex and the leading edge of the chord of which the center of gravity lies on. The third term is when the module has a sweep angle of $\theta$. It should be mentioned that equation (5.19) only applies for one module. From geometry, additional terms would have to be considered for the second and third module, so forth. Finally, to determine the center of gravity in the $\mathrm{x}$-direction, weighted averages can be applied,

$$
\mathrm{CG}_{\mathrm{x}_{\text {total }}}=\frac{\left(\mathrm{cm}_{\mathrm{x}_{1}} \mathrm{M}_{1}\right)+\left(\mathrm{cm}_{\mathrm{x}_{2}} \mathrm{M}_{2}\right)+\cdots+\left(\mathrm{cm}_{\mathrm{x}_{\mathrm{n}}} \mathrm{M}_{\mathrm{n}}\right)}{\mathrm{M}_{1}+\mathrm{M}_{2}+\cdots+\mathrm{M}_{\mathrm{n}}}
$$

Where $\mathrm{n}$ is the total number of modules in the morphing wing system. 


\section{Chapter 6}

\section{Theory Application: A Case Study}

\subsection{The Case}

For the case, the contributions of the horizontal stabilizer are considered, but are considered as constant, fixed in location, and lie on a common chordline along with the aerodynamic center and center of gravity of the main wing. Given that the wing has an arbitrarily cambered airfoil that maintains constant in shape from wing root to wing tip, the only change in the airfoil will be its size. For the airfoil, other assumptions include the aerodynamic center being located at quarter-chord point and the center of gravity located at $40 \%$ chord distance from the leading edge. With the wing center of gravity aft of the aerodynamic center and contributions from the horizontal stabilizer, the aircraft at its initial position is considered to be statically stable. 


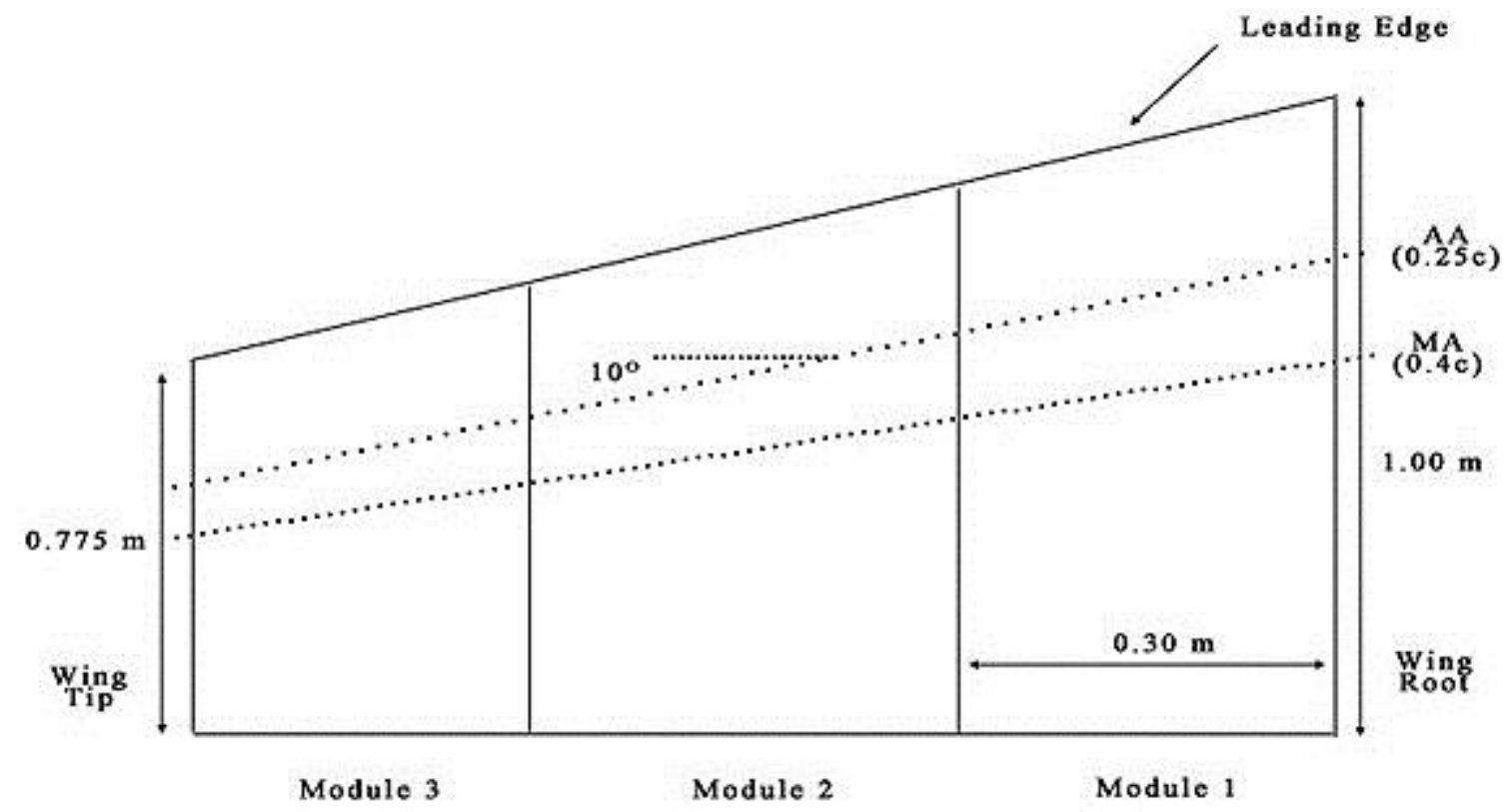

Figure 29: Top view for the dimensions of the three module wing in initial position used in the case study

In Figure 29, AA represents aerodynamic axis while MA is the mass axis. The taper ratio is 0.25 and there is a sweep angle of $10^{\circ}$. The nomenclature for axes will be kept consistent with the rest of the thesis. To further simplify the problem, the elastic axis will be coincident with the mass axis.

From the initial position, the goal is morph into a configuration of an overall addition of $30^{\circ}$ sweep, $15^{\circ}$ twist, $60^{\circ}$ dihedral and increase of $0.1 \mathrm{~m}$ in span. For sweep and dihedral angles, the transformations will add to the default dimensions of the modules. For the examination of longitudinal stability, the most important parameters are twist and sweep. The large dihedral has little effect on longitudinal stability and is emphasized for visual verification, shown in Section 6.4. 


\subsection{Solution Methodology}

In the model, there are three modules, with each module having a total of 16 different actuation paths resulting in a total of 4096 unique paths from initial configuration to the final configuration. Discussed earlier in Chapter 4.3, the strategy is to determine the best actuation path through a set series of criterion. Depending on the desired parameters of performance, different sets of criterion can be applied. However, the entire criterion will be based on the theory of static margin.

For this case, the desired performance is greatest longitudinal stability for the aircraft. Therefore, the maximization of the static margin with the minimization of standard deviation is desired. This set of criterion sets the wing morph to select the morphing path with the least change in static margin while minimizing overall displacement. The maximization of static margin is the actuation path that allows for greatest longitudinal stability from the initial configuration to the final configuration while the minimization of standard deviation represents the least overall displacement during the wing morph maneuver. Without the minimization of standard deviation, due to the quantity of possible actuation paths, there may be several permutations of actuation paths that offer similar maximized longitudinal stability performance. 


\subsection{Interpretation of Results}

The result of this case study is generated by an implemented code within the MATLAB software. Tables 4 and 5 below summarize the results of the three most longitudinally stable as well as the results of the three least.

Each table on the left defines the module path. The module paths are numbered one through sixteen to represent the sixteen possible motions. As each module can perform these motions, each module's path is labeled. For a given module path, Pose 1 and Pose 2 parameters change, but the initial and final poses do not change. For Pose 1 and Pose 2 for each module path, the aerodynamic center, center of gravity, and the static margin are shown.

Table 4: Pose performance parameters of the three least movement module paths (more stable)

\begin{tabular}{|c|c|c|c|c|c|c|}
\hline \multicolumn{3}{|c|}{ Least Movement Module Paths } & \multicolumn{4}{|c|}{ Pose Performance Parameters } \\
\hline Mod 1 & Mod 2 & Mod 3 & \multirow{4}{*}{ 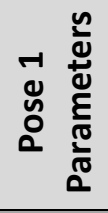 } & AC 1 & CG 1 & Margin 1 \\
\hline 13 & 7 & 11 & & 29.089 & 42.633 & -13.544 \\
\hline 13 & 11 & 7 & & 29.874 & 43.434 & -13.561 \\
\hline 13 & 7 & 7 & & 28.747 & 42.236 & -13.489 \\
\hline Mod 1 & Mod 2 & Mod 3 & \multirow{4}{*}{ 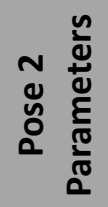 } & AC 2 & CG 2 & Margin 2 \\
\hline 13 & 7 & 11 & & 28.974 & 42.556 & -13.582 \\
\hline 13 & 11 & 7 & & 29.742 & 43.342 & -13.6 \\
\hline 13 & 7 & 7 & & 28.641 & 42.167 & -13.526 \\
\hline
\end{tabular}

Table 5: Pose performance parameters of the three most movement module paths (less stable)

\begin{tabular}{|c|c|c|c|c|c|c|}
\hline \multicolumn{3}{|c|}{ Most Movement Module Paths } & \multicolumn{4}{|c|}{ Pose Performance Parameters } \\
\hline Mod 1 & Mod 2 & Mod 3 & \multirow{4}{*}{ 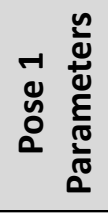 } & AC 1 & CG 1 & Margin 1 \\
\hline 3 & 3 & 3 & & 39.238 & 54.185 & -14.947 \\
\hline 3 & 3 & 5 & & 37.437 & 52.326 & -14.889 \\
\hline 4 & 3 & 4 & & 39.238 & 54.185 & -14.947 \\
\hline Mod 1 & Mod 2 & Mod 3 & \multirow{4}{*}{ 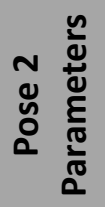 } & AC 2 & CG 2 & Margin 2 \\
\hline 3 & 3 & 3 & & 39.218 & 54.187 & -14.969 \\
\hline 3 & 3 & 5 & & 39.172 & 54.069 & -14.897 \\
\hline 4 & 3 & 4 & & 37.134 & 51.941 & -14.807 \\
\hline
\end{tabular}


Of course, with only the locations of aerodynamic center and center of gravity, one can only conclude that certain morphing paths have less change in static margin from pose to pose. It is also possible to determine if the aircraft will be stable or unstable at a certain pose. Since the initial and final configurations are given, along with the data in the table above, we can compare the difference in static margins and their standard deviations as well. Doing so will offer a more definitive perspective on how some actuation paths have less movement than others. The data is culminated in Table 6 below,

Table 6: Table of module path results and static margin comparisons

\begin{tabular}{|c|c|c|c|c|c|c|c|}
\hline \multicolumn{3}{|c|}{ Least Movement Module Paths } & \multicolumn{5}{|c|}{ Static Margins Comparison } \\
\hline Mod 1 & Mod 2 & Mod 3 & Difference 1 & Difference 2 & Difference 3 & Avg. Difference & Standard Dev. \\
\hline 13 & 7 & 11 & -0.1097 & -0.0378 & -0.1022 & -0.083267 & 0.027962 \\
\hline 13 & 11 & 7 & -0.1266 & -0.0389 & -0.0842 & -0.083267 & 0.031015 \\
\hline 13 & 7 & 7 & -0.0546 & -0.0376 & -0.1574 & -0.083267 & 0.045827 \\
\hline \multicolumn{4}{|c|}{ Most Movement Module Paths } & \multicolumn{4}{|c|}{ Static Margin Comparison } \\
\hline Mod 1 & Mod 2 & Mod 3 & Difference 1 & Difference 2 & Difference 3 & Avg. Difference & Standard Dev. \\
\hline 3 & 3 & 3 & -1.513 & -0.0220 & 1.2857 & -0.083267 & 0.99035 \\
\hline 3 & 3 & 5 & -1.455 & -0.0081 & 1.2134 & -0.083267 & 0.94459 \\
\hline 4 & 3 & 4 & -1.513 & 0.1401 & 1.1236 & -0.083267 & 0.9423 \\
\hline
\end{tabular}

From Table 6, more data are available for how some morphing paths can have less change in their static margins from pose to pose. Recalling from Chapter 5.2: the lower the differences between the static margins from pose to pose, likely suggests less modular movement per actuation, which results in greater the longitudinal stability. As a result, with that criterion, a morphing path having a large static margin difference likely means a large change in wing geometry. Upon examining the columns of "Difference 1" and "Difference 3" between the least movement and most movement module paths, by intuition, morphing path $13-7-11$ 
is significantly more stable than morphing path $3-3-3$. In an illustrative sense, a graph to compare static margins and respective poses is shown below.

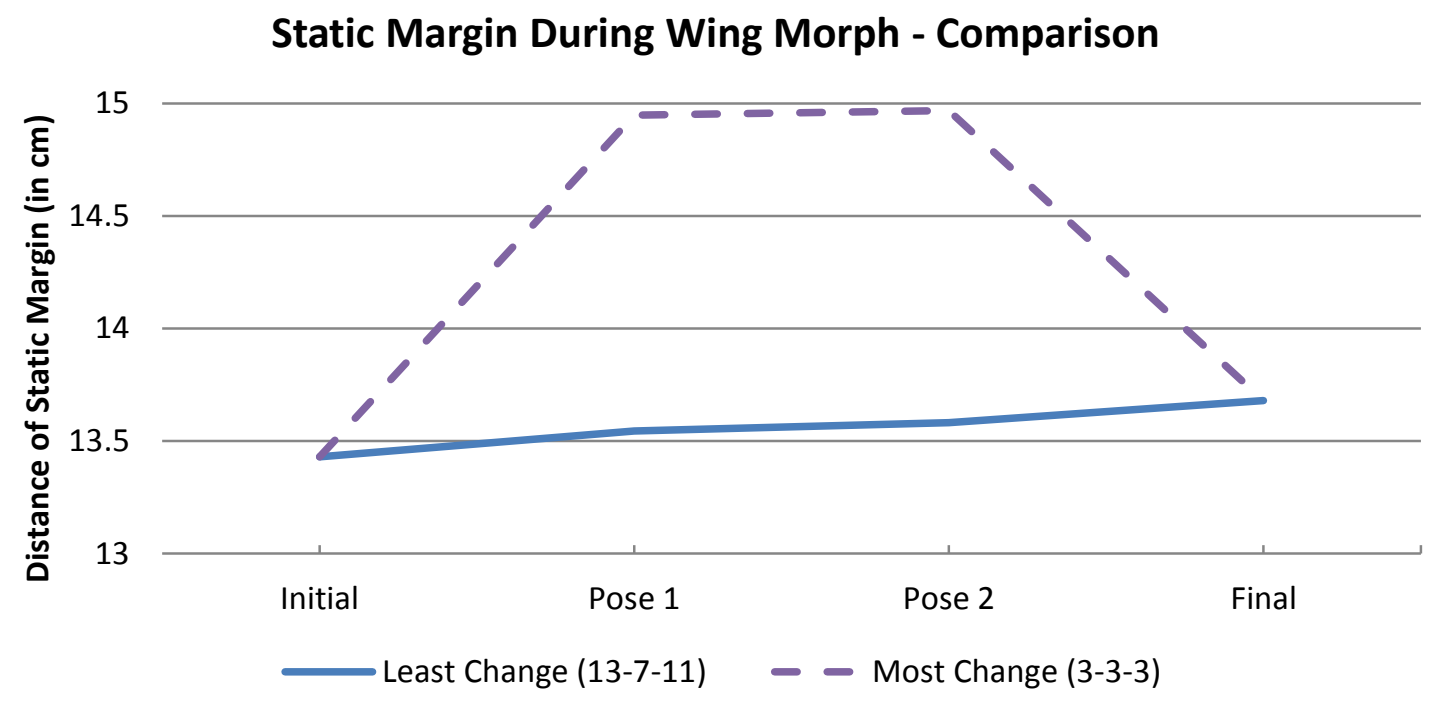

Figure 30: A comparison of static margin and respective morphing paths

From the figure above, the morphing path with least modular movement illustrates a smooth and gradual transition between the initial pose and the final pose. The least change graph (solid line) indicates that there is little change in static margin from pose to pose, which likely indicate a small amount of motion. Overall, for this actuation path, there are no static margin changes that are larger than 0.11 $\mathrm{cm}$. The small amount of motion is likely attributed to small changes in the modules designated by the actuation path. With less motion required by the modules, it is unlikely that there drastic changes in the planform shape. Without large changes in the actuation path, a smooth transition from pose to pose can be performed, resulting in greater longitudinal static stability compared to the other actuation path. 
In contrast, the most modular movement morphing path (dotted line) has vigorous changes in the figure. There is a significant increase from initial pose to first pose as well as a steep decline from the second pose to the final pose. From the initial pose to the first interim pose is a change in static margin of $1.49 \mathrm{~cm}$. By contrast, at the initial configuration, the static margin is $13.43 \mathrm{~cm}$, so this change in static margin is greater than $10 \%$ of the initial static margin. The substantial change in static margin also implicate that the aerodynamic center and center of gravity is shifting further from each other. This is because the morphing wing is performing a larger maneuver, and through application of theory, this morphing path has lesser longitudinal static stability.

One important result is that regardless of morphing path, the average difference remains constant. The average difference in static margin from configuration to configuration dictates the movement between the aerodynamic center and the center of gravity. Because the initial and final configurations are constant, regardless of morphing path, they must start and end at those respective configurations - meaning that the morphing path is independent to the average difference in static margin.

One other condition that must be applied is that the actuation process for all three modules and for each pose begins and ends simultaneously. If each module were to actuate out of sync, there would be additional complications in the determination of the aerodynamic center and center of gravity. Thus, out-of-sync actuation paths would likely lead to a plethora of interim poses and time-based 
results would have to be considered to determine whether the aircraft is longitudinally stable during wing morph. In addition, depending on the severity of change in any morphing dimension, these longitudinal static analyses may not be fully applicable. For instance, if sweep was to reach a rather high level, other stability analyses in the lateral or yaw direction will have to be utilized.

It is possible that at any time during a wing morphing procedure that the aircraft is in an unstable state. The analysis takes into account the entire wing morph procedure, and analyzes the effectiveness of the actuation path based on the stability of the full wing morph.

\subsection{Verification of Results}

To visually verify results, CATIA was used to take four snapshots for each pose in a morphing path. Each snapshot is taken at the initial pose, first interim pose, second interim pose, and the final pose. These snapshots are populated into Tables 7 and 8 below. The two morphing paths depicted are the same morphing paths in Figure 33, which are the least static margin change and the most static margin change to offer the greatest comparison.

There are four views provided per pose. They are: isometric view, front view, top view, and side view. Each view is able to provide greater clarity for a different morphing dimension. The front view is to emphasize dihedral changes, where the 
top view highlights sweep, while side view better shows twist. The isometric view is the generic view that best shows the combination of morphing.

Table 7: Visual morphing path for least static margin change (more stable path)

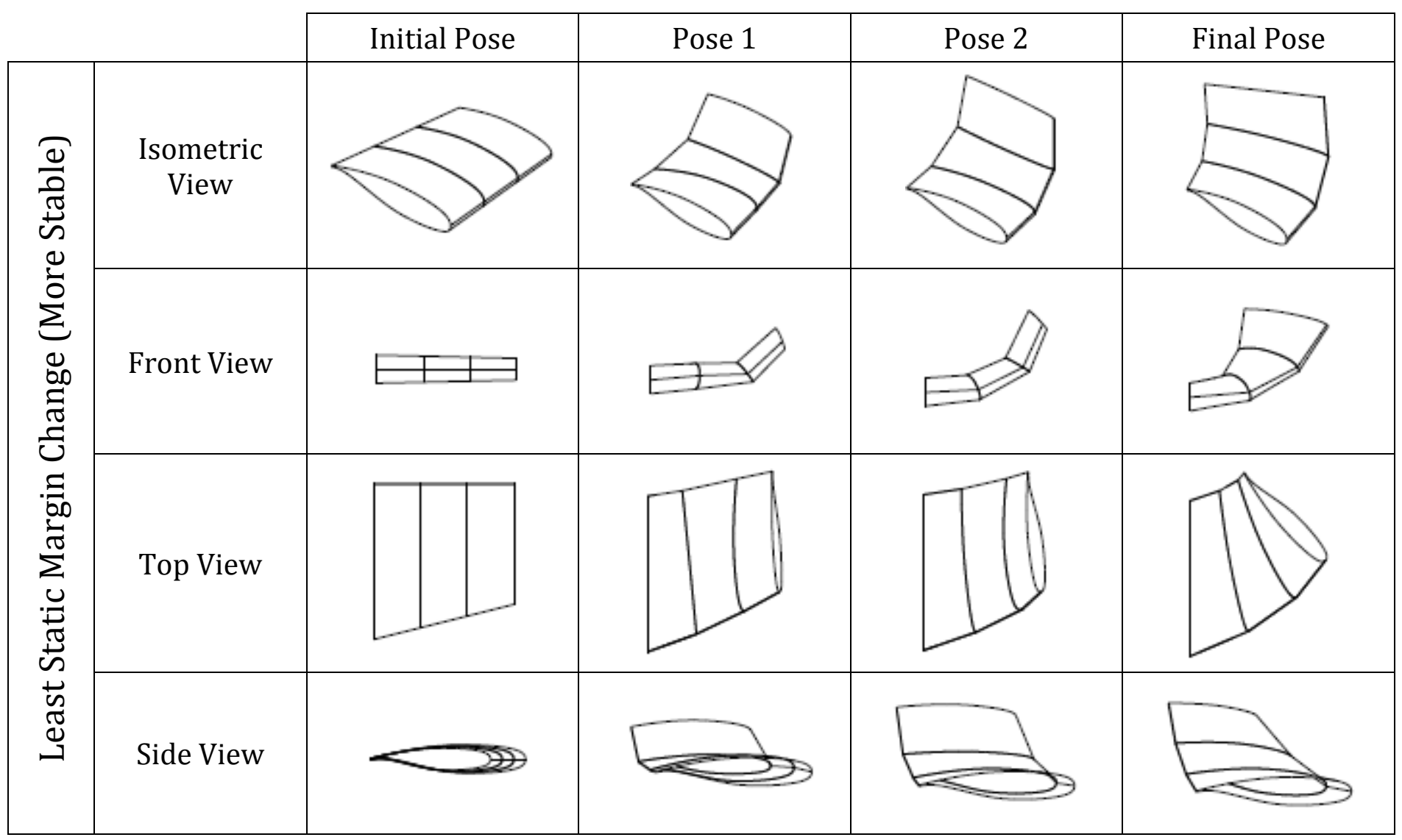

From the figures within Table 7, intuitively, this shows a natural transition between the initial pose to the final pose. There appears to be very little excessive movement by the modules such that between every pose, and it can be seen that there is a natural progression from the initial pose towards the final pose. This natural progression can be applied to every dimension of morphing, but is most notable in sweep and dihedral. 


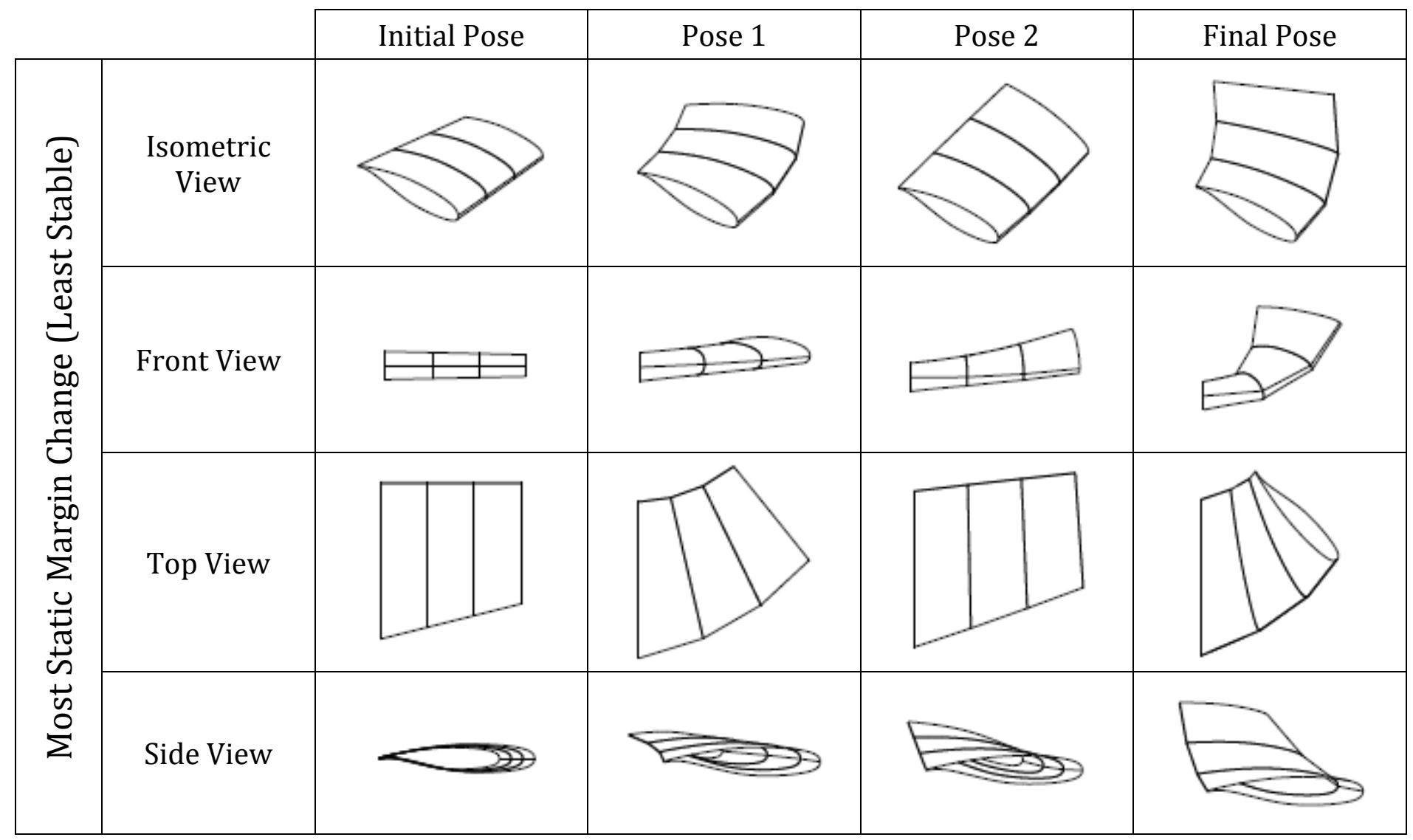

From Table 8 above, without comparisons to Table 7, one could understand that there are some confusing movements between different poses. The most notable confusion could be seen along the top view row. At initial configuration, sweep in increased substantially in all three modules to reach interim pose one, and then returns to a very similar configuration to the initial configuration in pose two. Visually, this movement appears to be of excess of a step to reach the final pose.

These images provide visual verification to the theory discussed in the thesis, notably for Chapter 4 and 5 . With four snapshots per pose, the visuals are able to provide a comprehensive understanding of what the modular wing appears as in 
every pose. As such, with the figures provided, there would be more depth to the theory as intuition can be applied to verify the theory.

As prior stated, the dimension of morph that most impacts the determination of static margin is sweep. As such, arguably the most important set of images would be from the top view. From Table 7, the sweep applied to the morphing wing in Pose 1 and Pose 2 is mild, while progressing towards the final pose. It is between Pose 2 and the final pose where a more aggressive increase in span and sweep occurs. Comparing those images with the ones in Table 8, there is an aggressive change in various dimensions from pose to pose, especially from Pose 2 to the final pose where both dihedral and sweep increase substantially. Therefore, aligned with the theory of longitudinal static stability, this aggressive change in sweep is a strong cause which results in the actuation path having more variation in the static margin.

Upon examining the figures, in addition to considerations of aircraft stability, these figures could show additional concern for structural considerations for morphing paths. For a short example, should the morphing path in Table 8 be chosen, the critically large difference in both sweep and dihedral could place large strains within the joints in the modular system. For future work on structural concerns of the modular morphing wing, these figures may be an effective starting point. 


\section{Chapter 7}

\section{Conclusion and Future Work}

This thesis has provided a geometric-based method to determine the static longitudinal stability of a morphing wing consisting of variable geometry truss modules. To start, within the literature review, topics reviewed included some current aircraft stability theory, but only applicable to fixed non-morphing winged aircraft. It also covered challenges of developing a feasible morphing wing system, including the difficulty of actuation, structural concerns, and difficulty in designing a skin structure. Afterwards, the design of the VGTM was explained as well as the motion control. For motion control, robotic mechanism and kinematic actuation was briefly explained in the chapter.

For the development of morphing wings, the methods and analyses presented in this thesis could be used to determine, for each phase of the wing morph, the aerodynamic center, the center of gravity, and the change in static margin. As there are very few feasible morphing wing system ideas, the amount of aircraft stability analyses on morphing wings are extremely scarce. Therefore, this thesis is meant to be a stepping stone to more sophisticated conceptual design and geometric feasibility. To justify the theory presented in the thesis, the methods and 
results are verified with a case study, complete with data and visual figures, with several justified aerodynamic assumptions applied.

The process of selecting the ideal morphing path based on longitudinal static stability can be briefly summarized below, based on a three module morphing wing:

1) Understand the parameters of the initial pose, such as the aerodynamic center, center of gravity and measurements of each module.

2) Based on desired performance of the aircraft, understand the parameters of the final pose.

3) From the motion control theory, apply the theory and obtain the 4096 possible morphing path solutions. In addition to the measurements, calculate the aerodynamic center and center of gravity for each possible morphing path. For the case in Chapter 6, this was completed in MATLAB.

4) From the 4096 solutions, obtain the difference in static margin for each pose. Since the initial and final poses will remain constant, arrange the morphing paths based on standard deviation. The lowest standard deviation means the least change in static margin, and holds true for vice-versa.

Building on this thesis, several directions of study could be led. One is to elaborate the stability analysis to time-based, resulting in dynamic analyses or the consideration of out-of-sync morphing paths. Time-based dynamic analyses will allow for more realistic assumptions and will be able to take into account various other factors such as different maneuvers and external aerodynamic forces (i.e. wind gusts). Similarly, time-based analyses allow for out-of-sync morphing paths, 
which open the possibilities of roll and yaw control without the use of control surfaces. It is also possible to introduce new criterion into the iterative process to check for any configurations that would risk damaging the structure of the morphing wing.

Another direction of study could be to eliminate the iteration process to find mathematical relationships in the morphing algorithm. This could result in a great reduction in time required to determine the desired morphing path. Furthermore, studies to improve feasibility of the morphing wing system include the consideration of parts and systems that occur within a conventional aircraft wing and how they would interact with a modular environment. Some parts within a conventional aircraft wing that would pose a great challenge include the line of thrust (should the engine be mounted on the wing), fuel tank, bleed air pipes and de-icing systems, to name a few.

During the writing of this thesis, the author is aware of other on-going theses related to the VGTM modular morphing wing idea. One of which is the development of a functional skin system, and the other is the computational fluid dynamic analysis of the morphing wing during a wing morph. In the near future, a functional wind tunnel model could potentially be achieved. 


\section{Appendix A}

\section{Module Pose Vectors for Case Study}

The following are the set of dimensions used to create Table 8 and Table 9 in CATIA. They contain the physical dimensions of each module in every pose for both morphing paths. Recalling Figure 24, the dimensions used to draw the figures, and used exclusively in this section, are:

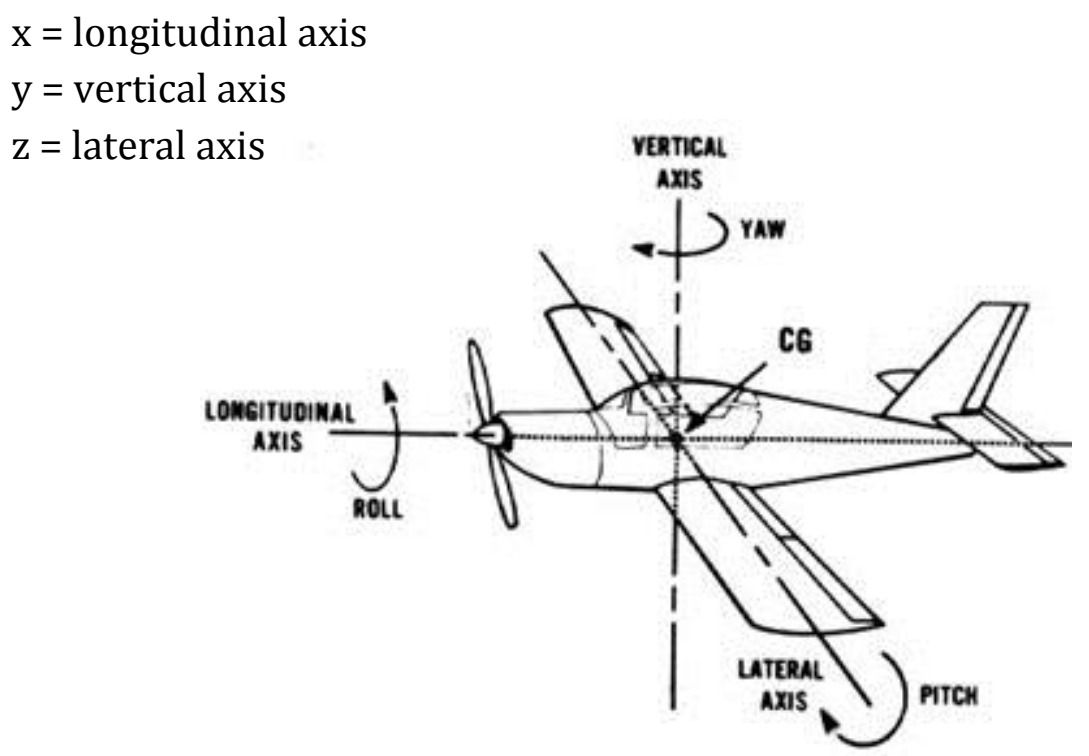

Figure 31: Aircraft axes and rotation; to demonstrate pose vector dimensions

Table 9: Pose Vectors of least change in static margin: module 1

\begin{tabular}{|c|c|c|c|c|c|}
\hline \multirow{7}{*}{ 恶 } & MODULE 1 & Initial Pose & Pose 1 & Pose 2 & Final Pose \\
\hline & $\mathrm{Rx}$ (in) & 0.00 & 1.50 & 1.59 & 3.20 \\
\hline & Ry (in) & 0.00 & 0.92 & 0.99 & 2.00 \\
\hline & $\mathrm{Rz}$ (in) & 11.81 & 11.49 & 12.30 & 13.00 \\
\hline & Rotation X (deg) & 0.00 & 0.62 & -20.64 & -20.00 \\
\hline & Rotation Y (deg) & 0.00 & 5.59 & 5.12 & 10.00 \\
\hline & Rotation Z (deg) & 0.00 & -1.08 & 2.12 & 5.00 \\
\hline
\end{tabular}


Table 10: Pose Vectors of least change in static margin: module 2

\begin{tabular}{|c|c|c|c|c|c|}
\hline \multirow{7}{*}{ 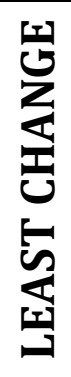 } & MODULE 2 & Initial Pose & Pose 1 & Pose 2 & Final Pose \\
\hline & $\mathrm{Rx}$ (in) & 0.00 & 1.67 & 1.67 & 3.20 \\
\hline & Ry (in) & 0.00 & 1.06 & 1.06 & 2.00 \\
\hline & $\mathrm{Rz}$ (in) & 11.81 & 13.02 & 13.02 & 13.00 \\
\hline & Rotation X (deg) & 0.00 & -38.34 & -38.34 & -20.00 \\
\hline & Rotation Y (deg) & 0.00 & -3.55 & -3.55 & 10.00 \\
\hline & Rotation Z (deg) & 0.00 & 3.23 & 3.23 & 5.00 \\
\hline
\end{tabular}

Table 11: Pose Vectors of least change in static margin: module 3

\begin{tabular}{|c|c|c|c|c|c|}
\hline \multirow{7}{*}{$\underset{5}{3}$} & MODULE 3 & Initial Pose & Pose 1 & Pose 2 & Final Pose \\
\hline & Rx (in) & 0.00 & 1.58 & 1.58 & 3.20 \\
\hline & Ry (in) & 0.00 & 0.98 & 0.98 & 2.00 \\
\hline & $\mathrm{Rz}$ (in) & 11.81 & 12.24 & 12.24 & 13.00 \\
\hline & Rotation X (deg) & 0.00 & 17.48 & 17.48 & -20.00 \\
\hline & Rotation Y (deg) & 0.00 & 0.30 & 0.30 & 10.00 \\
\hline & Rotation Z (deg) & 0.00 & 0.93 & 0.93 & 5.00 \\
\hline
\end{tabular}

Table 12: Pose Vectors of most change in static margin: module 1

\begin{tabular}{|c|c|c|c|c|c|}
\hline \multirow{7}{*}{ 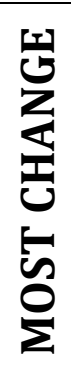 } & MODULE 1 & Initial Pose & Pose 1 & Pose 2 & Final Pose \\
\hline & $\mathrm{Rx}$ (in) & 0.00 & 1.79 & 1.80 & 3.20 \\
\hline & Ry (in) & 0.00 & 1.14 & 1.13 & 2.00 \\
\hline & $\mathrm{Rz}$ (in) & 11.81 & 14.14 & 14.14 & 13.00 \\
\hline & Rotation X (deg) & 0.00 & 0.40 & -0.06 & -20.00 \\
\hline & Rotation Y (deg) & 0.00 & 12.98 & 1.30 & 10.00 \\
\hline & Rotation Z (deg) & 0.00 & 2.54 & 6.26 & 5.00 \\
\hline
\end{tabular}

Table 13: Pose Vectors of most change in static margin: module 2

\begin{tabular}{|c|c|c|c|c|c|}
\hline \multirow{7}{*}{ 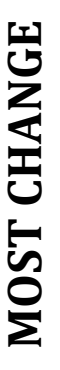 } & MODULE 2 & Initial Pose & Pose 1 & Pose 2 & Final Pose \\
\hline & $\mathrm{Rx}$ (in) & 0.00 & 1.79 & 1.80 & 3.20 \\
\hline & Ry (in) & 0.00 & 1.14 & 1.13 & 2.00 \\
\hline & Rz (in) & 11.81 & 14.14 & 14.14 & 13.00 \\
\hline & Rotation X (deg) & 0.00 & 0.40 & -0.06 & -20.00 \\
\hline & Rotation Y (deg) & 0.00 & 12.98 & 1.30 & 10.00 \\
\hline & Rotation Z (deg) & 0.00 & 2.54 & 6.26 & 5.00 \\
\hline
\end{tabular}


Table 14: Pose Vectors of most change in static margin: module 3

\begin{tabular}{|c|c|c|c|c|c|}
\hline \multirow{7}{*}{ 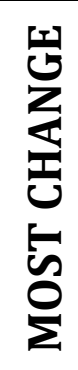 } & MODULE 3 & Initial Pose & Pose 1 & Pose 2 & Final Pose \\
\hline & $\mathrm{Rx}$ (in) & 0.00 & 1.79 & 1.80 & 3.20 \\
\hline & Ry (in) & 0.00 & 1.14 & 1.13 & 2.00 \\
\hline & Rz (in) & 11.81 & 14.14 & 14.14 & 13.00 \\
\hline & Rotation X (deg) & 0.00 & 0.40 & -0.06 & -20.00 \\
\hline & Rotation Y (deg) & 0.00 & 12.98 & 1.30 & 10.00 \\
\hline & Rotation Z (deg) & 0.00 & 2.54 & 6.26 & 5.00 \\
\hline
\end{tabular}




\section{Appendix B}

\section{MATLAB Program Code}

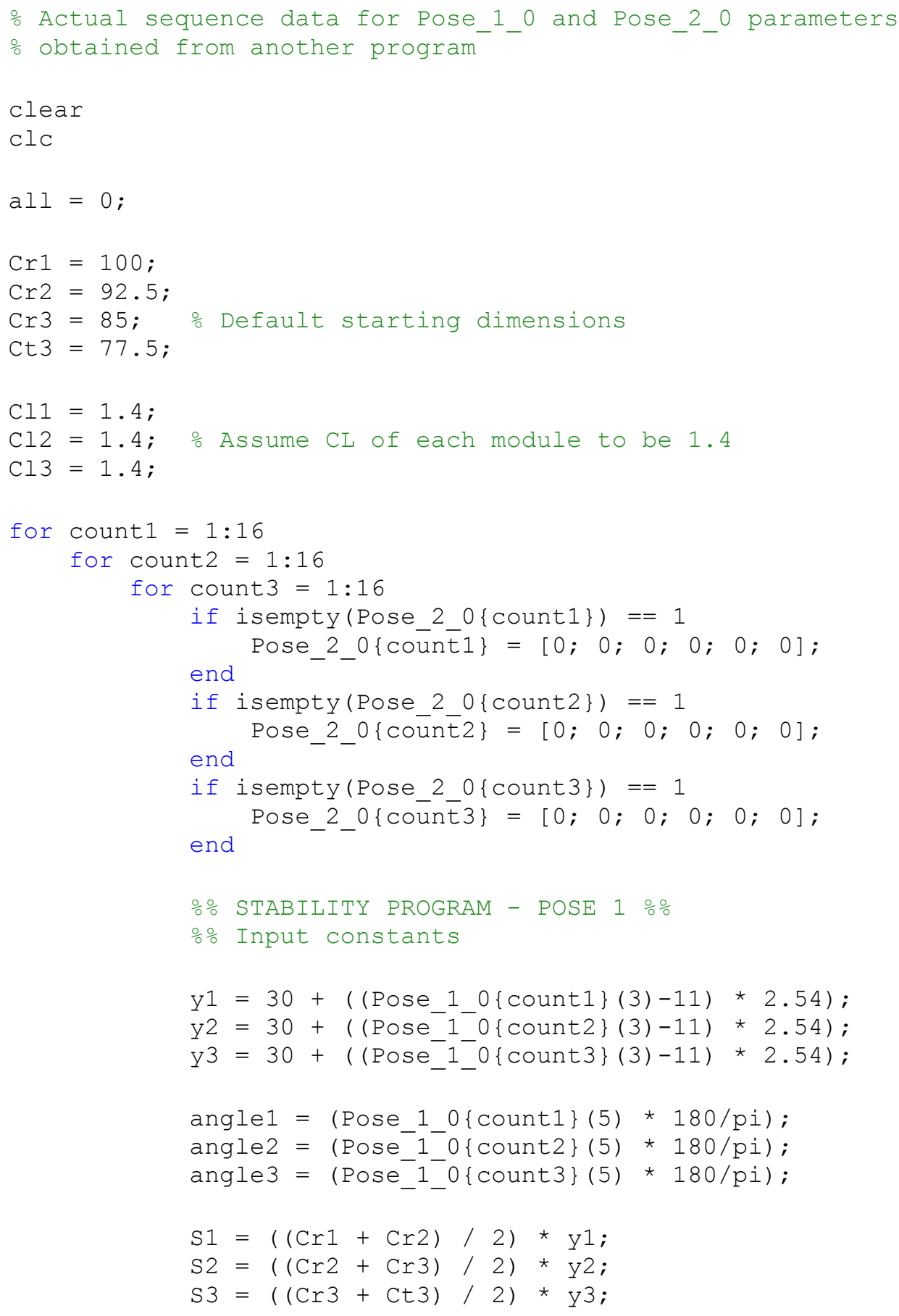




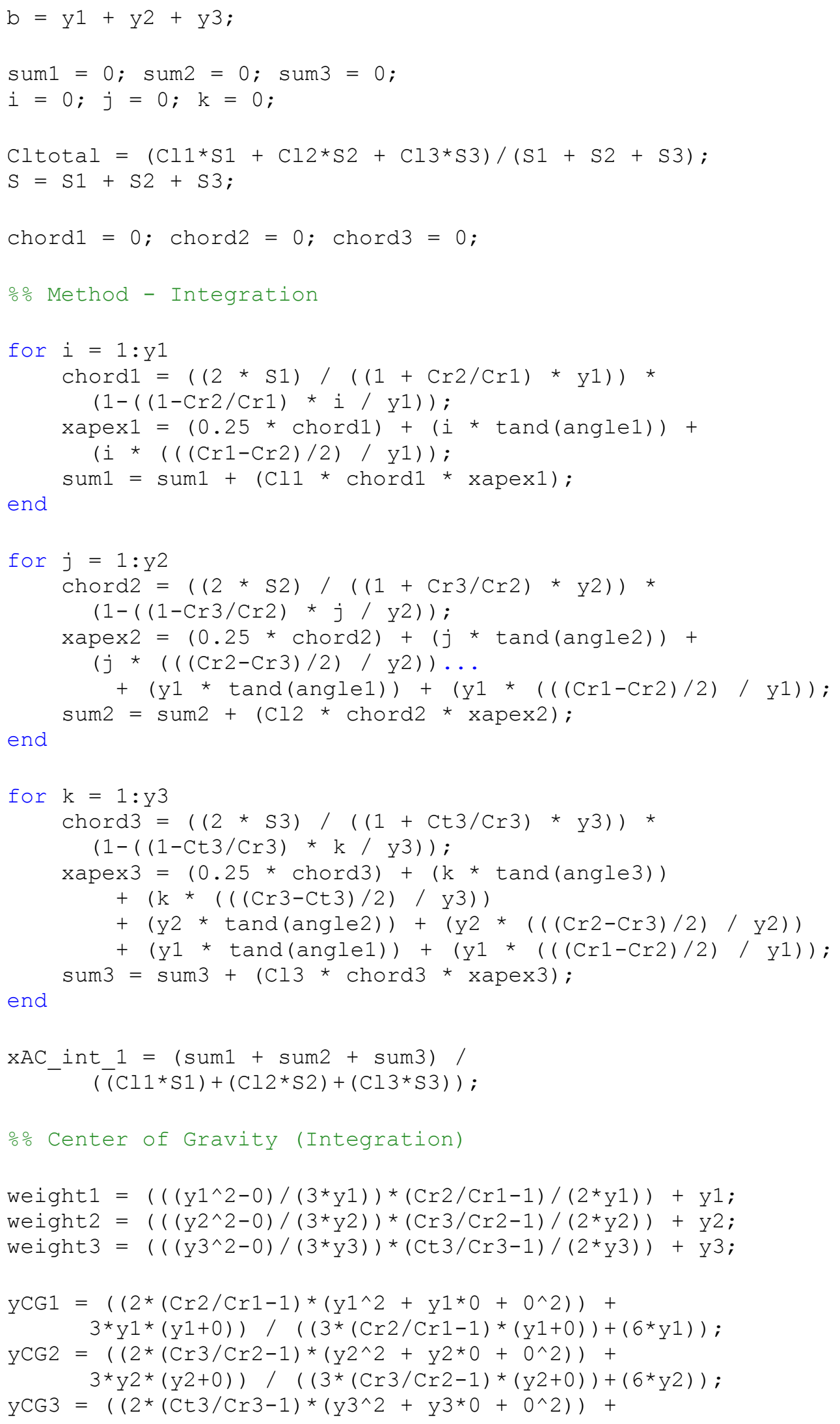




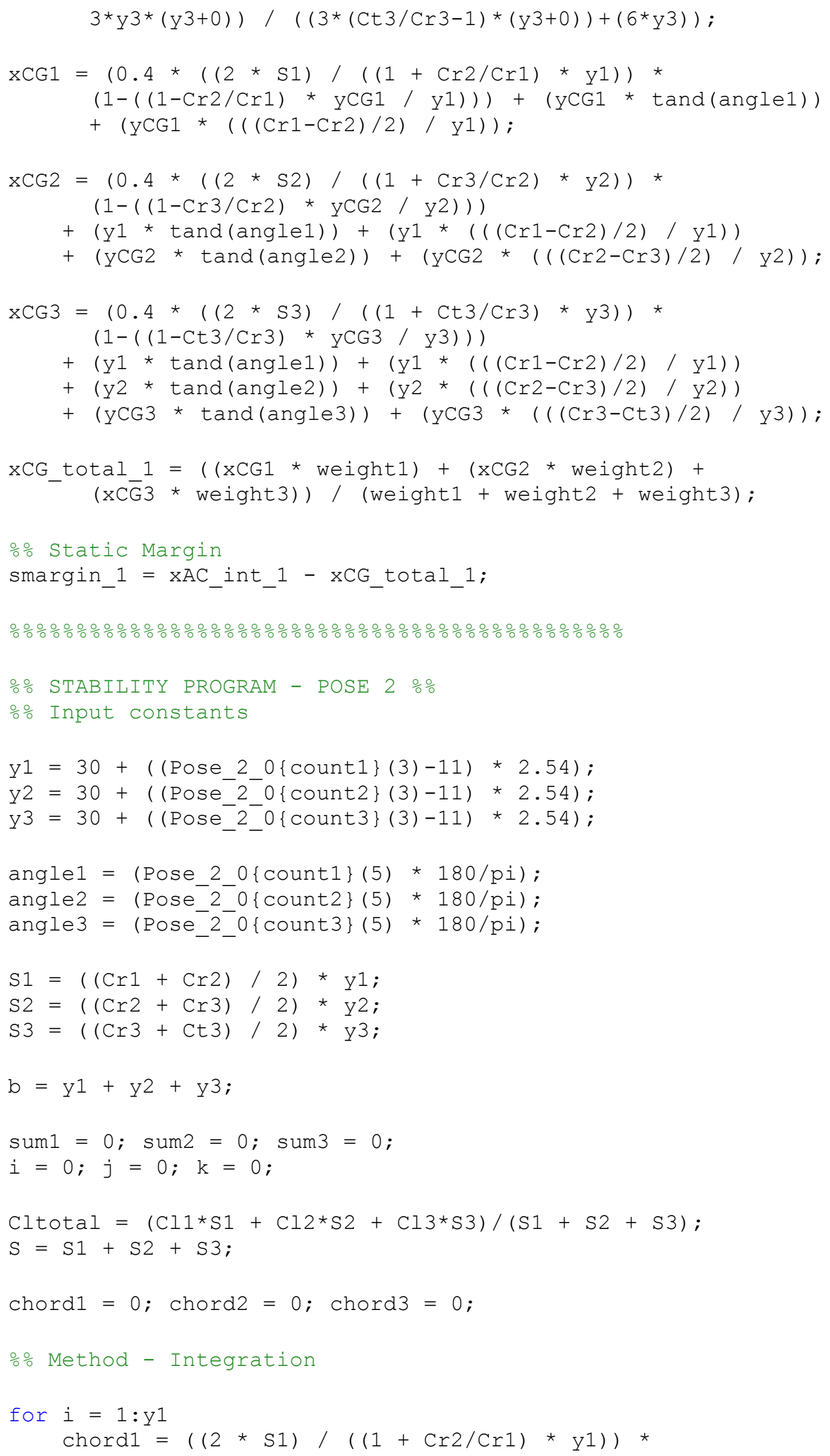




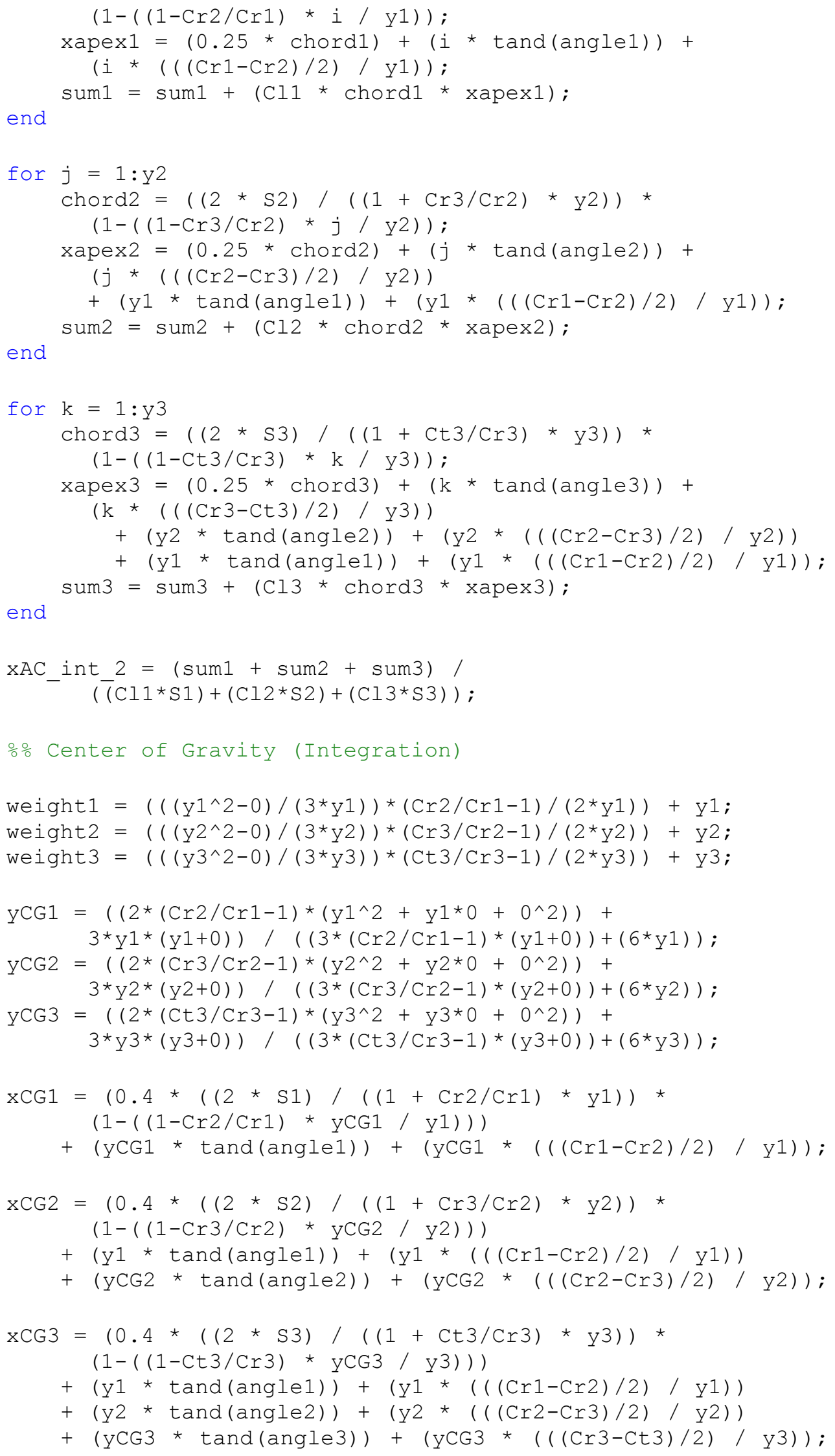




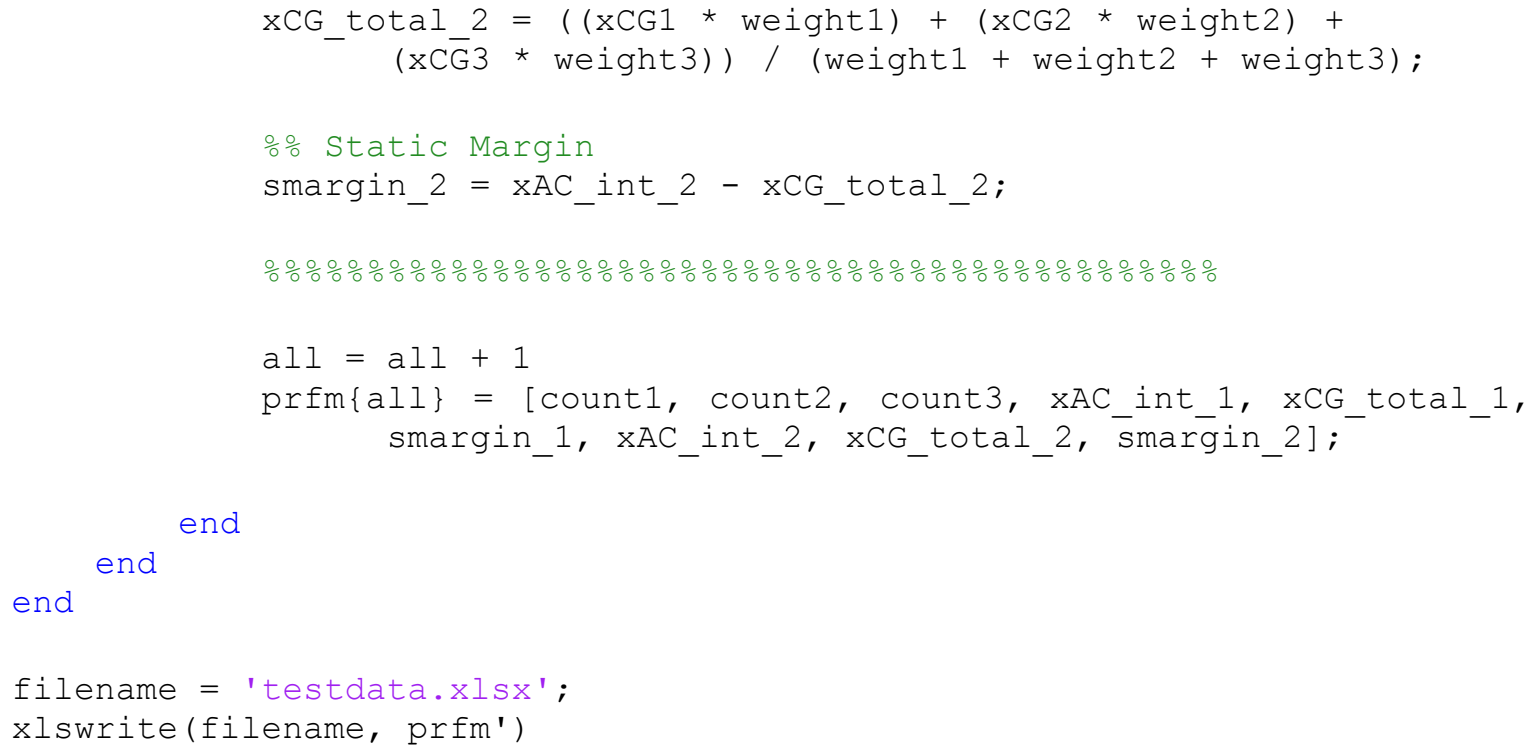




\section{References}

[1] D. T. Grant, M. Abdulrahim, and R. Lind. Flight dynamics of a morphing aircraft utilizing independent multiple-joint wing sweep. AIAA-2006-6505.

[2] C. O. Johnston, D. A. Neal, L. D. Wiggins, H. H. Robertshaw, W. H. Mason, and D. J. Inman. A model to compare the flight control energy requirements of morphing and conventionally actuated wings. AIAA/ASME/ASCE/AHS/ASC Structures, Structural Dynamics and Materials Conference, Norfolk, 2003, pp. 2862-2870.

[3] F J. Bowman, B. Sanders, B. Cannon, J. Kudva, S. Joshi, and T. Weisshaar. Development of next generation morphing aircraft structures. 48th AIAA/ASME/ASCE/AHS/ASC Structures, Structural Dynamics and Materials Conference, 23-26 April, Honolulu, pp. 1-10, 2007.

[4] J. Blondeau, J. Richeson, and D. J. Pines. Design, development and testing of a morphing aspect ratio wing using an inflatable telescopic spar. AIAA/ASME/ASCE/AHS/ASC Structures, Structural Dynamics and Materials Conference, Norfolk, 2003, pp. 2883-2893.

[5] R. M. Botez, P. Molaret, E. Laurendeau. Laminar flow control on a research wing project presentation covering a three year period. Canadian Aeronautics and Space Institute Annual General Meeting, April 25-26, 2007.

[6] A. Seifert, S. Eliahu, D. Greenblatt, and I. Wygnanshi. Use of piezoelectric actuators for airfoil separation control. AIAA Journal, Vol. 36, No. 8, Aug. 1998, pp. 1535-1536. 
[7] C. Bauer, W. Martin, and H. F. Siegling. An Adaptive Composite Structure to Control the Sonic Shock of Transport Aircraft Wings. Proceedings of the 4th European Conference on Smart Structures and Materials and 2nd MIMR Conference, edited by G. R. Tomlinson and W. A. Bullough, Inst. of Physics Publishing, Philadelphia, 1998, pp. 25-32.

[8] M. Secanell, A. Suleman, and P. Gamboa. Design of a morphing airfoil using aerodynamic shape optimization. AIAA Journal, Vol. 44, No. 7, July 2006, pp.1550-1562.

[9] S. P. Joshi, Z. Tidwell, W. A. Crossley, and S. Ramakrishnan. Comparison of morphing wing strategies based upon aircraft performance impacts. $4^{\text {th }}$ AIAA/ASME/ASCE/AHS/ASC Structures, Structural Dynamics \& Materials Conference, 2004.

[10] J. D. Anderson. Fundamentals of Aerodynamics - $4^{\text {th }}$ Ed. McGraw-Hill Press: New York, 2007. Print.

[11] Y. Heryawan, H. C. Park, N. S. Goo, K. J. Yoon, Y. H. Byun. Design and demonstration of a small expandable morphing wing. Smart Structures and Materials 2005: Smart Structures and Integrated Systems, Proc. Of SPIE Vol. 5764, pp. 224-231, 2005.

[12] I. Ostrovsky, Y. Henn. Present State and Future of Magnesium Application in Aerospace Industry. International Conference "New Challenges in Aeronautics”, ASTEC '07, Moscow, August 19-22, 2007.

[13] A. Moosavian, F. Xi, S. M. Hashemi. Design and Motion Control of Fully Variable Morphing Wings. AIAA, Journal of Aircraft, in press. 
[14] H. M. Garcia, M. Abdulrahim, and R. Lind. Roll Control for a Micro Air Vehicle Using Active Wing Morphing. Proceedings of the AIAA Guidance, Navigation, and Control Conference and Exhibit, AIAA 2003-5347, 2003.

[15] D. T. Grant, M. Abdulrahim, and R. Lind. Flight Dynamics of a Morphing Aircraft Utilizing Independent Multiple-JointWing Sweep. Proceedings of the AIAA Atmospheric Flight Mechanics Conference and Exhibit, AIAA 2006$6505,2006$.

[16] P. Bourdin, A. Gatto, and M. I. Friswell. The Application of Variable Cant Angle Winglets for Morphing Aircraft Control. Proceedings of the Twenty-Fourth Applied Aerodynamics Conference, AIAA 2006-3660, 2006.

[17] D. A. Neal, M. G. Good, C. O. Johnston, H. H. Robertshaw, et al. Design and wind-tunnel analysis of a fully adaptive aircraft configuration. $45^{\text {th }}$ AIAA/ASME/ASCE/AHS/ASC Structures, Structural Dynamics \& Materials Conference, 2004.

[18] D. Inoyama, B. P. Sanders, J. J. Joo. Computational design of morphing wing structures through multiple-stage optimization process. $48^{\text {th }}$ AIAA/ASME/ASCE/AHS/ASC Structures, Structural Dynamics \& Materials Conference, 2007.

[19] D. S. Ramrakhyani, G. A. Lesieutre, M. Frecker, and S. Bharti. Aircraft structural morphing using tendon-actuated compliant cellular trusses. Journal of Aircraft: Vol. 42, No. 6, Nov-Dec 2005. pp 1615-1621.

[20] S. Bharti, M. Frecker, G. Lesieutre, and J. Browne. Tendon actuated cellular mechanisms for morphing aircraft wing. Modeling, Signal Processing, and Control for Smart Structures, edited by D. K. Lindner. Proc. of SPIE Vol. 6523, 2007. 
[21] G. R. Andersen, D. L. Cowan, and D. J. Piatak. Aeroelastic modeling, analysis and testing of a morphing wing structure. $48^{\text {th }}$ AIAA/ASME/ASCE/AHS/ASC Structures, Structural Dynamics \& Materials Conference, 2007.

[22] J. J. Joo, B. Sanders, T. Johnson, and M. Frecker. Optimal actuator location within a morphing wing scissor mechanism configuration. Smart Structures and Materials 2006: Modeling, Signal Processing, and Control, edited by D. K. Lindner, Proc. of SPIE Vol. 6166, 2006.

[23] J. Blondeau, J. Richeson, and D. J. Pines. Design, development and testing of a morphing aspect ratio wing using an inflatable telescopic spar. $44^{\text {th }}$ AIAA/ASME/ASCE/AHS Structures, Structural Dynamics, and Materials Conference, 7-10 April 2003.

[24] W. J. Buehler, J. V. Gilfrich, and R. C. Wiley. Effect of low-temperature phase changes on the mechanical properties of alloys near composition. TiNi, J Appl. Phys., 1963, pp. 1475.

[25] J. D. Jacob, A. D. Simpson, and S. W. Smith. Design and flight testing of inflatable wings with wing warping. SAE Trans J Aerospace, 2005.

[26] S. Barbarino, R. Pecora, L. Lecce, A. Concilio, S. Ameduri, and E. Calvi. A Novel SMA-based concept for airfoil structural morphing. Journal of Materials Engineering and Performance, Vol. 18 (5-6), Aug. 2009, pp. 696-705.

[27] A. Y. N. Sofla, S. A. Meguid, K. T. Tan, and W. K. Yeo. Shape morphing of aircraft wings: status and challenges. Materials and Design 31, 2010, pp. 1284-1292.

[28] J. H. Mabe, F. T. Calkins, G. W. Butler. Boeing's variable geometry chevron, Morphing Aerostructure for Jet Noise Reduction. AIAA 2006-2142. 
[29] D. J. Harti, D. C. Lagoudas, F. T. Calkins, J. H. Mabe. Use of a Ni60Ti shape memory alloy for active jet engine chevron application: I. thermomechanical characterization. 2010 Smart Mater. Struct. 19-015020.

[30] J. H. Mabe, F. T. Calkins, R. T. Ruggeri. Full-scale flight tests of aircraft morphing structures using SMA actuators. Proc. SPIE 6525. Active and Passive Smart Structures and Integrated Systems 2007, 65251C (3 April, 2007).

[31] G. Murray, F. Ghanhi, and C. Bakis. Flexible matrix composite skins for onedimensional wing morphing. $48^{\text {th }}$ AIAA/ASME/ASCE/AHS/ASC Structures, Structural Dynamics \& Materials Conference, 2007.

[32] F. Ghanhi and P. Anusonti-Inthra. Skin design studies for variable camber morphing airfoils. Smart Materials and Structures, Vol. 17, 2008.

[33] J. Vale, F. Lau, A. Suleman, and P. Gamboa. Optimization of a morphing wing based on coupled aerodynamic and structural constraints. $3^{\text {rd }}$ AIAA Multidisciplinary Design Optimization Specialists Conference, April 2007.

[34] B. Stanford, M. Abdulrahim, R. Lind, P. Ifju. Design and optimization of morphing mechanisms for highly flexible micro air vehicles. $4^{\text {th }}$ AIAA/ASME/ASCE/AHS/ASC Structures, Structural Dynamics \& Materials Conference, 2006.

[35] E. A. Bubert. Highly extensible skin for a variable wing-span morphing aircraft utilizing pneumatic artificial muscle actuation. ProQuest: 2009. University of Maryland, College Park, Aerospace Engineering. Print.

[36] T. P. Ratvasky and R. J. Ranaudo. Icing effects on aircraft stability and control determined from flight data - preliminary results. AIAA1993-0398. 
[37] W. J. Baars, R. O. Stearman, C. E. Tinney. A review on the impact of icing on aircraft stability and control. Journal of aeroelasticity and structural dynamics, Vol. 2, No. 1, 2010.

[38] M. W. Brenner, J-Y. Trepanier, C. Tribes, E. Petro. Conceptual design framework for blended wing body aircraft. AIAA2012-5649.

[39] C. M. Moua, S. C. McWherter, T. H. Cox, J. Gera. Flight test results on the stability and control of the F-15 Quiet Spike aircraft. NASA/TM-2012-215978.

[40] J. D. Anderson. Introduction to Flight $-6^{\text {th }}$ Ed. McGraw-Hill Companies Inc.: New York, U.S.A., 2008. Print.

[41] A. D. Finistauri, F. Xi, P. Walsh. Discretization method for the development of a modular morphing wing. Journal of Aircraft, Vol. 49, No. 1 (2012), pp. 116125.

[42] A. D. Finistauri, and F. Xi. Type Synthesis and Kinematics of a Modular Variable Geometry Truss Mechanism for Aircraft Wing Morphing. Proceedings of the ASME/IFToMM International Conference on Reconfigurable Mechanisms and Robots, American Society of Mechanical Engineers, Fairfield, NJ, 2009.

[43] J. Xi. AE/ME 8138 Computational Dynamics - Lecture Notes. Ryerson University: Toronto, 2009. Print.

[44] R. C. Nelson. Flight Stability and Automatic Control $-2^{\text {nd }}$ Ed. WCB/McGrawHill: U.S.A., 1998. Print.

[45] Etkin, B., and Reid, L.D. Dynamics of Flight, Stability and Control - $3^{\text {rd }}$ Ed. John Wiley and Sons, Inc: U.S.A., 1996. Print. 
[46] K. R. Olympio, F. Gandhi, L. Asheghian, J. Kudva. Design of a flexible skin for a shear morphing wing. Journal of Intelligent Material Systems and Structures, Nov. 2010, Vol. 21, No. 17. pp. 1755-1770.

[47] Phillips, W. F. Mechanics of Flight. John Wiley and Sons, Inc: U.S.A., 2004. Print.

[48] J. Bae, T. M. Seigler, D. J. Inman, and I. Lee. Aerodynamic and aeroelastic considerations of a variable-span morphing wing. AIAA 2004-1726.

[49] F. Sabri and S. A. Meguid. Flutter boundary prediction of an adaptive morphing wing for unmanned aerial vehicle. Int J Mech Mater Des, Vol. 7, 2011, pp. 307-312. 